\title{
Do Novel Antipsychotics Have Similar Pharmacological Characteristics? A Review of the Evidence
}

\author{
J. Arnt, D. Sci., Ph.D., and T. Skarsfeldt, M. Sci.
}

The pharmacological properties of the novel antipsychotic drugs (APDs) risperidone, sertindole, olanzapine, quetiapine, ziprasidone, remoxipride, and amperozide are reviewed and compared with haloperidol and clozapine. Focus is made on their receptor profiles, their effects in animal models used for evaluation of antipsychotic activity, and extrapyramidal side effects (EPS). In addition, the contrasting actions of these compounds on animal models of cognition, anxiety, and depression are briefly reviewed. The available evidence indicates that novel APDs and clozapine can be differentiated from haloperidol, particularly in models of EPS and cognitive side effects. However, among the group of novel APDs there are many individual differences in models reflecting limbic versus striatal inhibition of dopamine function: clozapine and sertindole show the largest limbic selectivity, followed by quetiapine, ziprasidone, olanzapine and remoxipride, whereas risperidone in many respects has a profile that resembles haloperidol. To date, the results of clinical studies have confirmed the predictions of lower incidence or absence of EPS after administration of novel APDs in doses which demonstrate antipsychotic efficacy.

[Neuropsychopharmacology 18:63-101, 1998] (C) 1998 American College of Neuropsychopharmacology. Published by Elsevier Science Inc.
KEY WORDS: Novel antipsychotic drugs; Clozapine; Haloperidol; Extrapyramidal side effects; Receptor profiles; Cognition; Anxiety; Depression; Animal models

During the last decade there has been a dramatic increase in the efforts to develop novel antipsychotic drugs (APDs) with improved clinical efficacy and fewer or no extrapyramidal side effects (EPS) than the classical APDs such as haloperidol and fluphenazine. These efforts were undoubtedly inspired by the previous development of clozapine, which fulfilled these criteria to a large extent, although having other troublesome side

From the Pharmacological Research, H. Lundbeck A/S, Ohiliavej 9, DK-2500, Copenhagen-Valby, Denmark.

Address correspondence to: Jørn Arnt, Pharmacological Research, H. Lundbeck A/S, Ottiliavej 9, DK-2500 Copenhagen-Valby, Denmark. Received January 6, 1997; revised June 26, 1997; accepted July 7, 1997. effects (Baldessarini and Frankenburg 1991; Coward 1992; Wagstaff and Bryson 1995; Buchanan 1995; Ashby and Wang 1996).

The novel APDs were assigned the popular term "atypical antipsychotic" drugs to differentiate them from the classic or "typical" APDs or neuroleptics. The most widely accepted definition of a neuroleptic is a compound that has antipsychotic activity and induces EPS with high frequency. The definition of "atypicality" was equivocal, however, because the term was often used for drugs before any clinical results were available. For example, the term was applied to a compound that induced little or no catalepsy in rats, and that was effective in another model believed to reflect antipsychotic activity, e.g., inhibition of D-amphetamine (AMPH)-induced hypermotility. A more precise definition is to base it solely on clinical evidence as a wide differentiation between the dosages used to control psychosis and those inducing EPS-or on other aspects of clinical superior- 
ity over classic APDs, e.g., efficacy on negative symptoms of schizophrenia or in drug-resistant patients (for recent review, see Kinon and Lieberman 1996). However, because these very different characteristics are difficult to incorporate in a common definition, we suggest that the terminology "atypical" is best avoided. Indeed, as will be discussed, novel APDs show many individual differences.

The suggested alternative terminology "novel APD" is also not precise, but it can be defined as a compound that has been shown to inhibit positive symptoms of schizophrenia and has either been recently launched or is in phase II/III clinical development. Their specific profiles can be described more precisely, e.g., EPS-free APD, etc. It is not anticipated that novel APDs will be marketed in the future, unless having certain advantages over classic APDs.

Most of the novel APDs that have reached an advanced developmental stage (i.e., demonstrated antipsychotic efficacy in a placebo-controlled phase II study) have mixed effects on the dopamine (DA) $D_{2}$ receptor subfamily, $5-\mathrm{HT}_{2}$ receptors, and on $\alpha_{1}$-adrenoceptors as part of their broad receptor activity profiles. The objective of this review is to describe and discuss available evidence for similarities and differences between this group of APDs in preclinical models for psychosis, EPS, cognition, anxiety, and depression, and to relate these to available information on their clinical effects. Animal data can be used to predict clinical differences between some of the compounds, and these may be studied prospectively in patients. In turn, clinical information gives important feedback for the evaluation of the validity of presently used animal models.

The novel APDs in this review comprise the marketed drugs clozapine, risperidone, sertindole, and olanzapine, and the close-to-launch drugs, quetiapine (Seroquel ${ }^{\mathrm{TM}}$ ) and ziprasidone. Finally, remoxipride (which has been withdrawn from market due to serious adverse events) and amperozide (which no longer appears to be in active development) are included in the discussion. It is not the intention to review animal models of schizophrenia or the involved receptor types in depth (for review, see Ellenbroek and Cools 1990; Ellenbroek 1993; Jackson and Westlind-Danielsson 1994).

\section{EFFECTS ON NEUROTRANSMITTER RECEPTORS}

The receptor profile of an APD is usually presented by tabulating the affinity constants or $\mathrm{IC}_{\overline{5} 0}$ values obtained for different neurotransmitter receptors in vitro, using homogenates of brain tissue or of cells specifically expressing cloned receptors. Although this strategy is straightforward it does not always give results that can be transferred to studies in vivo, where receptors are present in their natural environment. Some discrepancies between in vitro and in vivo findings can be explained solely on methodological grounds, e.g., in vivo effects include metabolite activities and may be influenced by uneven distribution of the study drug in the animal, but this cannot explain discrepant findings in all cases. To provide a framework for the later discussion of functional studies, the receptor profiles of novel APDs based on in vitro, ex vivo, and in vivo studies will be summarized briefly.

\section{In Vitro Profiles}

The results obtained for novel antipsychotics and haloperidol at the Research Laboratories of $\mathrm{H}$. Lundbeck A/S are summarized in Table 1 as $K_{i}$ values for selected receptor types. Furthermore, pie charts (indicating relative affinities in vitro as well as relative potencies ex vivo and in vivo) are shown for some of the important receptors where in vivo models are available (Figure 1 ). The objective of using the pie chart is to illustrate preferential receptor effects irrespective of the numeric affinity in vitro or potency in vivo and to show the degree of correspondence between the two experimental conditions.

Furthermore, results obtained at cloned dopamine $\mathrm{D}_{2}$-like receptors are shown in Table $2 \mathrm{~A}$, together with literature data.

The Lundbeck data are generally consistent with those obtained by others (Schotte et al. 1996a; Bymaster et al. 1996a; Saller and Salama 1993; Seeger et al. 1995), with the exception that risperidone in our screening assay has lower histamine $\mathrm{H}_{1}$ affinity than shown by Janssen researchers (Schotte et al. 1996a). No explanation for this discrepancy can be given.

Our results (Tables 1 and 2A; Figure 1) and the cited studies indicate that a common feature of novel APDs are mixed affinities for the $\mathrm{DA} \mathrm{D}_{2}$ receptor subfamily, $5-\mathrm{HT}_{2 \mathrm{~A}}$ receptors and $\alpha_{1}$-adrenoceptors. Remoxipride (a DA $D_{2} / D_{3}$ selective antagonist; Malmberg et al. 1993) is the only exception to this rule.

The mixed receptor profiles are consistent with current theories that balanced affinities for these receptors are responsible for the improvement of the ratio between doses inducing antipsychotic activity and EPS for novel APDs compared with classical APDs (Baldessarini et al. 1992; Meltzer and Nash 1991; Coward 1991; Stockmeier et al. 1993; Ashby and Wang 1996). Given this commonality, it should be emphasized that the relative affinities for these sites differ markedly between the compounds as illustrated in Figure 1. Likely, these differences have important consequences for the subtle differences in the in vivo profiles of the novel APDs.

In addition to common features, most novel APDs have high relative affinities for additional receptors: DA $\mathrm{D}_{1}$ receptors (clozapine and olanzapine), $5-\mathrm{HT}_{2 \mathrm{C}}$ recep- 


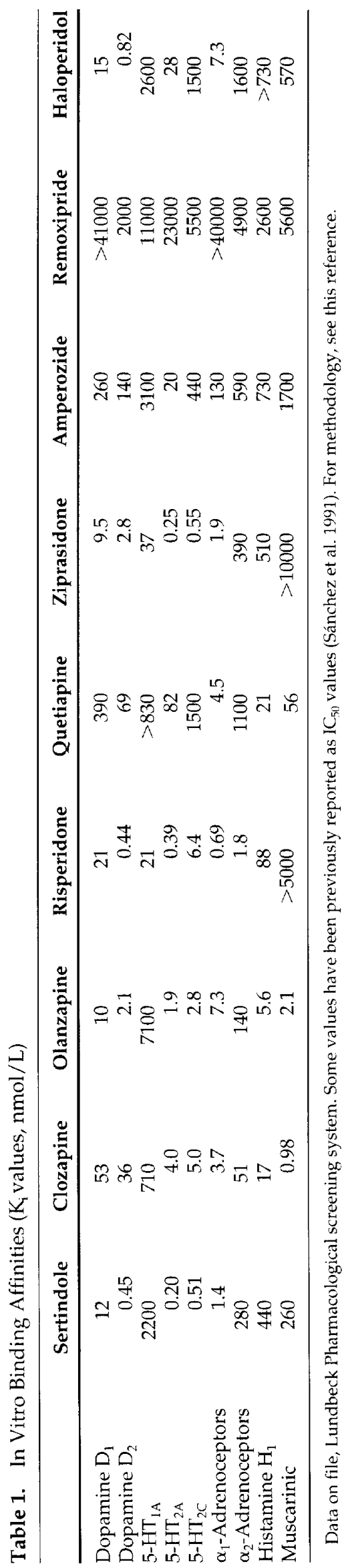

tors (sertindole, clozapine, olanzapine, ziprasidone), $\alpha_{2^{-}}$ adrenoceptors (risperidone), histamine $\mathrm{H}_{1}$ receptors (clozapine, olanzapine, risperidone, quetiapine) or muscarinic receptors (clozapine, olanzapine). Thus, there is not a uniform affinity pattern for all compounds (Schotte et al. 1996a; Bymaster et al. 1996a; Saller and Salama 1993; Seeger et al. 1995; Newman-Tancredi et al. 1996). These additional effects of APDs are probably important for their individual pharmacological (and clinical) properties, including the side effect spectrum. The effect of clozapine on $D^{2} D_{1}$ receptors has been considered to be of importance for its pharmacological profile in animals and man (Arnt 1987; Nordström et al. 1995). However, clinical studies of selective DA $\mathrm{D}_{1}$ antagonists have been disappointing (Karlsson et al. 1995).

When the in vitro affinities for $D_{2}$ subfamily receptors are considered, particular interest is currently focused on the $\mathrm{D}_{4}$ receptor for which clozapine has shown preferential affinity in early studies (Van Tol et al. 1991; Seeman and Van Tol 1994). Later studies indicate little or no selectivity of clozapine for $D_{4}$ versus $D_{2}$ and $D_{3}$ receptors (Lahti et al. 1993; Schotte et al. 1996a; Roth et al. 1995) (Table 2A). Some novel APDs have moderate to high $\mathrm{D}_{4}$ affinities, but do not demonstrate $\mathrm{D}_{4}$ selectivity (Table 2A; loc. cit.). Exceptions are remoxipride $\left(\mathrm{K}_{\mathrm{i}}\right.$ value $3700 \mathrm{nmol} / \mathrm{L}$ ); (Van Tol et al. 1991; Seeman and Van Tol 1994) and quetiapine (Table 2), which lack $D_{4}$ receptor affinity. This indicates that $\mathrm{D}_{4}$ receptor occupancy is not required for antipsychotic activity (unless mediated by active metabolite(s)). However, the lack of $\mathrm{D}_{4}$ activity with remoxipride and quetiapine does not exclude that $\mathrm{D}_{4}$ receptor blockade can contribute to clinical efficacy of an APD, and it has been suggested that a high ratio between affinities for $D_{4}$ and $D_{2}$ receptors is a factor contributing to low EPS potential (Seeman et al. 1997). However, this is a controversial issue. The functional and clinical relevance of $\mathrm{D}_{4}$ receptors can not be addressed until data on selective $\mathrm{DA}_{4}$ receptor antagonists become available.

A few studies suggest that APDs may have affinities for the recently cloned $5-\mathrm{HT}_{6}$ and/or $5-\mathrm{HT}_{7}$ receptors. However, only a few results have been published for the compounds discussed here, and these results do not indicate a consistent relation between pharmacological profiles and affinities of APDs for $5-\mathrm{HT}_{6}$ or $5-\mathrm{HT}_{7}$ receptors (Schotte et al. 1996a; Roth et al. 1994). Clozapine has high affinity for both receptors, olanzapine and sertindole have high affinities for $5-\mathrm{HT}_{6}$ receptors, whereas risperidone has high affinity only for $5-\mathrm{HT}_{7}$ receptors, (Table 2B). Again, selective ligands are needed to evaluate the function of these new receptors.

Whereas APDs are generally thought to be antagonists at the sites for which they show high affinities, more recent studies indicate deviations from this view: clozapine and, less potently, olanzapine have agonist activity at muscarinic $\mathrm{m} 4$ receptors (Zorn et al. 1994; Zeng et al. 1997). 

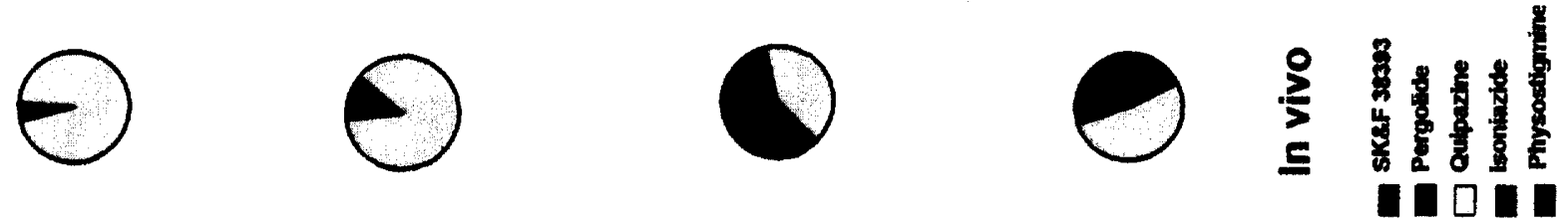

$\frac{5}{6}$

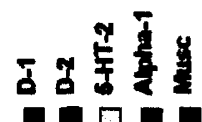
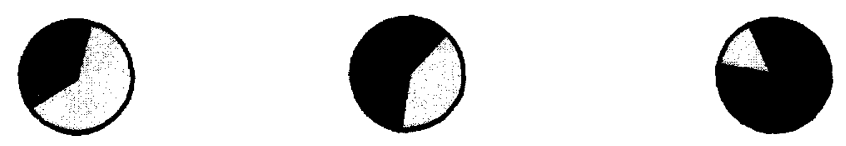

- $1 \frac{0}{\underline{\underline{n}}}$
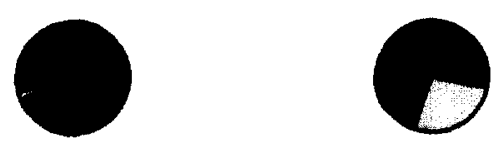

O 旁
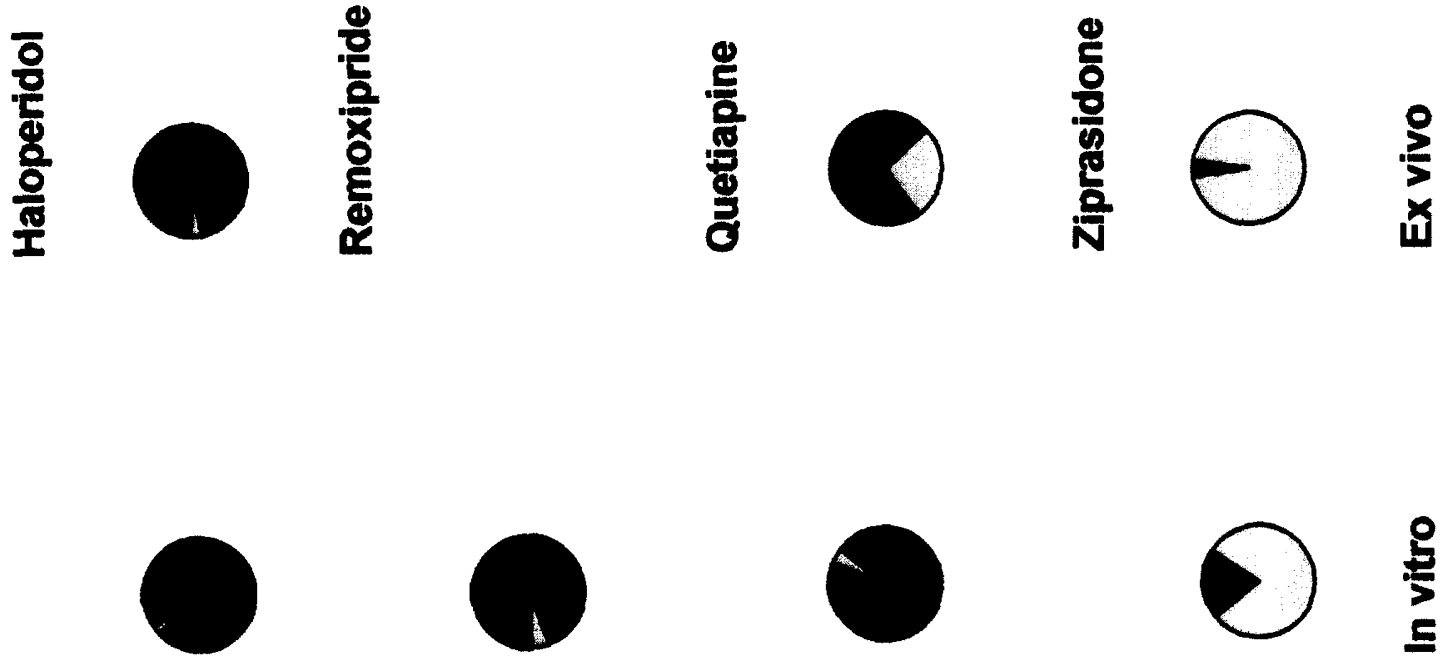

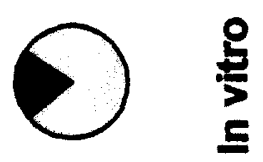


Table 2A. Affinities for $\mathrm{D}_{2}, \mathrm{D}_{3}$, and $\mathrm{D}_{4}$ Receptor Subtypes

\begin{tabular}{|c|c|c|c|c|c|c|c|c|}
\hline & \multicolumn{8}{|c|}{$\mathrm{K}_{\mathrm{i}}$ Values (nmol/L) } \\
\hline & \multicolumn{3}{|c|}{ Lundbeck ${ }^{a}$} & \multicolumn{3}{|c|}{ Janssen $^{b}$} & \multicolumn{2}{|c|}{ Astra $^{c}$} \\
\hline & $\begin{array}{c}\mathrm{D}_{2} \text { Rat } \\
\text { Striatum }\end{array}$ & $\begin{array}{c}\mathbf{D}_{3} \mathbf{r} \\
\text { Cloned }\end{array}$ & $\begin{array}{c}\mathbf{D}_{4 \cdot 2} \mathbf{h} \\
\text { Cloned }\end{array}$ & $\begin{array}{c}\mathrm{D}_{2 \mathrm{~L}} \mathrm{~h} \\
\text { Cloned }\end{array}$ & $\begin{array}{c}\mathrm{D}_{3} \mathrm{~h} \\
\text { Cloned }\end{array}$ & $\begin{array}{c}\mathbf{D}_{4 \cdot 2} \mathrm{~h} \\
\text { Cloned }\end{array}$ & $\begin{array}{c}\mathrm{D}_{2 \mathrm{~A}} \mathrm{~h} \\
\text { Cloned }\end{array}$ & $\begin{array}{c}\mathrm{D}_{3} \mathrm{~h} \\
\text { Cloned }\end{array}$ \\
\hline Sertindole & 0.45 & 2.6 & 11 & 7.0 & 10 & 21 & 0.62 & 1.6 \\
\hline Clozapine & 36 & 160 & 22 & 190 & 280 & 40 & 60 & 83 \\
\hline Olanzapine & 2.1 & 2.0 & 17 & 31 & 49 & 28 & nt & nt \\
\hline Risperidone & 0.44 & 2.8 & 13 & 5.9 & 14 & 16 & 1.7 & 6.7 \\
\hline Quetiapine & 69 & $>180$ & $>500$ & 700 & 340 & 1600 & nt & nt \\
\hline Ziprasidone & 2.8 & 7.9 & 28 & 4.6 & 10 & 39 & nt & nt \\
\hline Remoxipride & 2000 & nt & nt & nt & nt & nt & 125 & 970 \\
\hline Haloperidol & 0.82 & 7.3 & 2.5 & 2.2 & 7.8 & 11 & 0.67 & 2.7 \\
\hline
\end{tabular}

Table 2B. Affinities of Sertindole and Comparators for 5- $\mathrm{HT}_{2 \mathrm{~A}}, 5-\mathrm{HT}_{6}$, and $5-\mathrm{HT}_{7}$ Receptors

\begin{tabular}{|c|c|c|c|c|c|c|}
\hline & \multicolumn{6}{|c|}{$\mathrm{K}_{\mathrm{i}}$ Values (nmol/L) } \\
\hline & \multicolumn{3}{|c|}{ Janssen $^{a}$} & \multicolumn{3}{|c|}{ Roth, Meltzer, Kohen ${ }^{b, c, d}$} \\
\hline & $\begin{array}{c}5-\mathrm{HT}_{2 \mathrm{~A}} \text { Rat } \\
\text { Frontal Cort }\end{array}$ & $\stackrel{5-\mathrm{HT}_{6}}{\text { r Cloned }}$ & $\begin{array}{c}\text { 5-HT } \\
\text { m Cloned }\end{array}$ & $\begin{array}{l}\text { r } \text { Cloned }^{b} \\
\text { Clon }\end{array}$ & $\begin{array}{l}{ }^{5-\mathrm{HT}_{7}} \\
\text { Cloned }\end{array}$ & $\begin{array}{c}5 \cdot \mathrm{HT}_{6} \\
\text { h Cloned }\end{array}$ \\
\hline Sertindole & 0.85 & nt & 28 & $5.4^{d}$ & $28^{c}$ & nt \\
\hline Clozapine & 3.3 & 4.0 & 21 & 4 & 6.3 & 9.5 \\
\hline Olanzapine & 1.9 & 2.5 & 120 & 2.5 & 100 & 10 \\
\hline Risperidone & 0.16 & 420 & 1.6 & 430 & 1.4 & 2400 \\
\hline Quetiapine & 120 & nt & 290 & nt & nt & 33 \\
\hline Ziprasidone & 0.31 & nt & 4.9 & nt & nt & nt \\
\hline Amperozide & nt & nt & nt & 67 & 550 & 1600 \\
\hline Remoxipride & nt & $\mathrm{nt}$ & nt & $>5000$ & $>5000$ & nt \\
\hline Haloperidol & 25 & $>5000$ & 380 & $>5000$ & 260 & 6600 \\
\hline
\end{tabular}

a Schotte et al. 1996a.

${ }^{b}$ Roth et al. 1994.

${ }^{c}$ Roth and Meltzer, personal communication.

${ }^{d}$ Kohen et al. 1996.

h, $r, m=$ human, rat, or mouse receptor; $n t=$ not tested.

Figure 1. Relative affinities in vitro (left), ex vivo (middle), and antagonist potencies in vivo (right) of classic and novel APDs at $\mathrm{DA} \mathrm{D}_{1}, \mathrm{DA} \mathrm{D}_{2}, 5-\mathrm{HT}_{2 \mathrm{~A}}, \alpha_{1}$-adrenergic and muscarinic receptors. The $\mathrm{K}_{\mathrm{i}}$ values in vitro are taken from Table 1 and converted to percentage of total activities by the following formula:

$$
\left(1 / \mathrm{K}_{\mathrm{i}} \mathrm{D}_{1}\right)+\left(1 / \mathrm{K}_{\mathrm{i}} \mathrm{D}_{2}\right)+\left(1 / \mathrm{K}_{\mathrm{i}} 5-\mathrm{HT}_{2}\right)+\left(1 / \mathrm{K}_{\mathrm{i}} \alpha_{1}\right)+\left(1 / \mathrm{K}_{\mathrm{i}} \text { musc }\right)=100 \%
$$

The in vivo pie charts are constructed in the same manner, except that $\mathrm{ED}_{50}$ values are used instead of $\mathrm{K}_{\mathrm{i}}$ values. The models used for each receptor are described in the section "Methodological Considerations .... " For all compounds, subcutaneous administration is used with short-term pretreatment times. Actual $\mathrm{ED}_{50}$ values can be found for sertindole, haloperidol, and clozapine in Sánchez et al. (1991).

The ex vivo pie charts are based on $\mathrm{ED}_{50}$ values obtained by Schotte et al. (1996a). The following $\mathrm{ED}_{50}$ values are missing in that study, but based on the receptor affinities in vitro missing values will most likely not contribute significantly: $D_{A} \mathrm{D}_{2}$ effects were measured in striatum. For sertindole, quetiapine, and ziprasidone, DA D1 and muscarinic receptors were not studied. Remoxipride was not included in that study. 
Furthermore, clozapine and ziprasidone have been shown to have some $5-\mathrm{HT}_{1 \mathrm{~A}}$ agonist activity at moderate to high concentrations (Seeger et al. 1995; NewmanTancredi 1996).

Finally, a few studies suggest that some APDs are inverse agonists in vitro at some receptors, e.g., $5-\mathrm{HT}_{2 \mathrm{~A} / 2 \mathrm{C}}$ (Westphal and Sanders-Bush 1994), DA $D_{2}$ (Nilsson et al. 1996) or $D_{3}$ receptors (Griffon et al. 1996). However, until more systematic and comparative studies have been made, it is not possible to evaluate the functional importance of such findings in vivo. Nevertheless, inverse agonism for compounds regarded so far as neutral antagonists may well contribute to differentiation between pharmacological profiles. It should be noted that all studies of inverse agonism of APDs have been made in cell lines in vitro.

\section{Ex Vivo Binding Studies}

Ex vivo binding techniques are often used to give a rough estimate on the receptor profile of a compound. A certain time after systemic administration of the drug, the animal is killed, and the amount of drug bound to the receptors is determined in brain homogenates or autoradiographically. The major drawback of the technique is that the drug may dissociate from the receptors during preparation of tissue, and thus there is a risk for underestimation of occupancy. However, with careful methodology the technique gives very useful information.

Ex vivo binding to homogenates and autoradiography experiments largely confirm the in vivo profiles at the receptors for which high in vitro affinities were found (Schotte et al. 1996a; Bymaster et al. 1996b). Of particular interest is the extensive autoradiography study by Schotte et al. (1996a). Pie charts for the selected APDs on basis of data from that study are shown in Figure 1. Though mostly in agreement with in vitro results, this study also indicated some differences: ziprasidone bound only to $5-\mathrm{HT}_{2 \mathrm{~A}}$ receptors despite high in vitro affinities for $5-\mathrm{HT}_{1 \mathrm{~A}}, \mathrm{D}_{2}, \alpha_{1}$-adrenergic and $\mathrm{H}_{1}$ histamine receptors, and clozapine was the only APD which ex vivo displayed $D_{3}$ receptor occupancy at high doses, although all novel APDs and haloperidol actually have higher affinities in vitro. The lack of occupancy of $\mathrm{D}_{3}$ receptors is suggested to be limited by high endogenous DA concentrations, as shown by preincubation experiments (Schotte et al. 1996b).

For ex vivo $D_{2}$ receptor binding, no regional differences in affinities were found with any of the studied APDs in striatum, nucleus accumbens, olfactory tubercle, and substantia nigra (Schotte et al. 1996a). The DA $\mathrm{D}_{2}$ receptor in the frontal cortex was not studied. Whereas sertindole in the above-mentioned study showed an ex vivo binding profile similar to that seen in vitro, different results were observed in another study: here $\mathrm{DA} \mathrm{D}_{2}$ receptor binding was much weaker than ex- pected from the high in vitro, affinity (Hyttel et al. 1992). In contrast $5-\mathrm{HT}_{2 \mathrm{~A}}$ receptor occupancy was observed at the expected low doses (loc. cit.).

In addition to the standard approach of evaluating relative potencies, it has been suggested that slopes of dose-binding curves be used for characterization of an APD (Schotte et al. 1996a). It was found that the slope of the ex vivo dose-occupancy curve of risperidone at striatal $D A D_{2}$ receptors was more shallow than with other APDs, and it was argued that this profile would make it easier to titrate the clinical dose optimally. The argument for the advantage of shallow slope is based on the assumption that the occupancy of the $\mathrm{D}_{2}$ dose-occupancy curve is the main predictor of antipsychotic activity and EPS liability, because this differentiation between slopes was not seen with risperidone at $5-\mathrm{HT}_{2 \mathrm{~A}}$ receptors and $\alpha_{1}$-adrenoceptors. As discussed elsewhere in this article, most hypotheses favor the involvement of balanced effects at several receptor types as the main predictor of pharmacological profile of a novel APD. To our knowledge, the dose-binding slope approach has not been used by others, and the clinical significance, if any, remains unknown. Furthermore, no mechanistic explanation for the difference is known.

\section{In Vivo Binding Studies}

In vivo binding occupancy can be measured either by ligand binding methods or by studying protection against the irreversibly inactivating compound EEDQ. Most results correspond closely to findings obtained by the ex vivo methodology.

Selective protection against inactivation of $5-\mathrm{HT}_{2}$ receptors compared with $\mathrm{DA} \mathrm{D}_{1}$ or $\mathrm{D}_{2}$ receptors has been demonstrated with clozapine, quetiapine, and amperozide. Risperidone showed preferential $5-\mathrm{HT}_{2 \mathrm{~A}}$ receptor protection but also had significant effects at $\mathrm{DA}_{2}$ receptors (Matsubara et al. 1993; Saller and Salama 1993). Olanzapine was almost equipotent for $\mathrm{D}_{2}$ receptor protection compared with ex vivo ligand binding to $5-\mathrm{HT}_{2 \mathrm{~A}}$ and muscarinic receptors (Bymaster et al. 1996b), though the different methodology complicates direct comparison.

In vivo ligand binding studies confirm that risperidone, clozapine, and amperozide preferentially bind to $5-\mathrm{HT}_{2 \mathrm{~A}}$ in cortex versus $\mathrm{DA} \mathrm{D}_{2}$ receptors in striatum and the limbic system, whereas haloperidol and remoxipride show the opposite selectivity (Stockmeier et al. 1993; Sumiyoshi et al. 1995). Interestingly, remoxipride has higher potency at $\mathrm{D}_{2}$-like receptors in hippocampus, septum, and olfactory tubercle than in striatum (Ögren et al. 1984; Bischoff et al. 1988). The mechanism responsible for the difference is unknown. Similar results have been obtained with sertindole, which had very weak effects in striatum (Bischoff, personal communication). Also, risperidone has shown higher occu- 
pancy at cortical compared to striatal $\mathrm{DA}_{2}$-like receptors (Sumiyoshi et al. 1994).

In summary, though many of the receptor binding results obtained in vitro, ex vivo, and in vivo show consistency across techniques, subtle differences are observed for several of the APDs. In addition to identifying differences between the compounds, these studies also indicate that in-depth characterization is desirable for a critical evaluation of the receptor profiles of novel and classical APDs. It should also be mentioned that to date all ex vivo and in vivo binding studies have been made after acute drug administration, and thus the occupancies after repeated treatment at steady-state conditions are unknown.

\section{A Human Correlation to In Vivo Receptor Binding- PET/SPECT Studies}

To evaluate the mechanism of action of APDs in humans, it is crucial to demonstrate which CNS receptors are occupied at clinically relevant doses. Only limited information is available for novel APDs, and only for striatal DA $\mathrm{D}_{2}$ and cortical $5-\mathrm{HT}_{2}$ receptors.

$\mathrm{DA} \mathrm{D}_{2}$-Like Receptors. For classic APDs it has been demonstrated that antipsychotic treatment leads to striatal $\mathrm{D}_{2}$ occupancies between 60 and $80 \%$, and that occupancies above $80 \%$ in most cases are associated with EPS. As an exception clozapine shows lower $\mathrm{D}_{2}$ occupancy, in the range 20 to $60 \%$ (for review, see Farde et al. 1992; Goyer et al. 1996). However, the threshold of $\mathrm{D}_{2}$ occupancy necessary for maintenance of antipsychotic activity of classic APDs is not known. Recent studies have, however, indicated that relatively low $D_{2}$ occupancies (minimum $20 \%$, median about $50 \%$ ) do not lead to relapse during treatment with depot preparations of classic APDs (Nyberg et al. 1995).

Despite these limitations, it is of crucial importance to evaluate whether any of the novel APDs can maintain sufficient antipsychotic efficacy at low (or even without) $D_{2}$ receptor occupancy. Such results would point to different mechanisms of action of novel compared with classic APDs. Alternatively, if normal $D_{2}$ occupancies are found for novel APDs, then the lower EPS propensity may be explained by additional effects on other targets that hinder the expression of EPS. Another point of great scientific interest is to gain knowledge on the association between antipsychotic activity and occupancies of $\mathrm{D}_{2}$-like receptors at extrastriatal sites that may be more important for antipsychotic activity, including areas where $\mathrm{D}_{3}$ and $\mathrm{D}_{4}$ receptors are expressed at higher levels (Lahti et al. 1995a). A new ligand with high affinities for $D_{2}$ and $D_{3}$, but not $D_{4}$ receptors, FLB 457 (Halldin et al. 1995), has made PET studies of extrastriatal $D_{2}$ receptors feasible, but no comparative striatal/extrastriatal measurements of occupancies for APDs are yet available. A recent prelimi- nary SPECT study demonstrated labeling of ${ }^{123}$ I-epideride to both striatal and extrastriatal $D_{2}$ receptors and showed selectivity of clozapine but not classic APDs for $\mathrm{D}_{2}$ receptors in temporal cortex (Pilowsky et al. 1997a).

PET and/or SPECT studies of risperidone, remoxipride, and ziprasidone in striatum indicate high $\mathrm{D}_{2}$ occupancies after administration of doses comparable to those used clinically (Farde et al. 1995; Bench et al. 1996; Busatto et al. 1995; Kufferle et al. 1996). The first PET study of olanzapine in healthy volunteers indicates moderately high $\mathrm{D}_{2}$ occupancies (59 to $63 \%$ ) (Nyberg et al. 1997) after a single dose of $10 \mathrm{mg}$. Olanzapine has also been studied in two SPECT studies that revealed high (Kasper et al. 1995) or moderate (clozapine-like) occupancies (Pilowsky et al. 1996), respectively, after administration of $10-20 \mathrm{mg}$, whereas risperidone in the same study produced occupancies similar to classic APDs (Pilowsky et al. 1996). Quetiapine had lower (i.e., clozapine-like) $\mathrm{D}_{2}$ occupancy after administration of $150 \mathrm{mg}$ t.i.d. as measured by PET using ${ }^{11} \mathrm{C}$-raclopride (Gefvert et al. 1995). However, this dose level may be in the lower range of clinically effective doses. No full articles are published yet with sertindole, but studies are ongoing. Preliminary SPECT results show conflicting results: either low (Kasper et al. 1995) or high $D_{2}$ occupancies (Pilowsky et al. 1997b) are obtained at antipsychotic doses.

These results suggest that high $D_{2}$ receptor occupancies can be tolerated for olanzapine, sertindole, and possibly risperidone in the absence of EPS. Whether this is due to concomitant $5-\mathrm{HT}_{2}$ receptor occupancy or (an)other mechanism(s) masking EPS is presently unknown. Further, the results indicate that SPECT studies apparently can lead to contradictory results between laboratories, emphasizing a critical evaluation of such data. It should be noted that most of the imaging studies have been made with small numbers of volunteers or patients. Thus, variability in patients due to carryover occupancy from previous treatment with classic APDs, including depot preparations, may explain some discrepancies. Larger samples of patients treated for longer periods with the study compound are needed to finally answer the question about relation between $D_{2}$ occupancy and clinical efficacy as well as EPS.

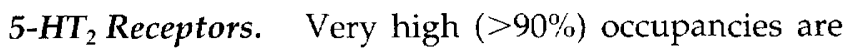
demonstrated with clozapine, risperidone, and ziprasidone at subclinical dose levels (Farde et al. 1995; Nordström et al. 1995; Kapur et al. 1995; Nyberg et al. 1993; Fischman et al. 1996), using ${ }^{11} \mathrm{C}-\mathrm{N}$-methyl-spiperone as the ligand. Quetiapine showed high occupancy after $150 \mathrm{mg}$ t.i.d. (maximum 72\%; Gefvert et al. 1995) as did olanzapine (74 to $92 \%$ ) after a single dose of $10 \mathrm{mg}$ ( $\mathrm{Ny}-$ berg et al. 1997). For sertindole, complete blockade of $5-\mathrm{HT}_{2}$ receptors labeled by ${ }^{18} \mathrm{~F}$-setoperone has been achieved in volunteers treated with $12 \mathrm{mg} /$ day for 2 weeks (unpublished observations). This is the lowest 
dose to show significant antipsychotic activity in shortterm phase II/III studies (van Kammen et al. 1996; Kerwin and Taylor 1996; Tamminga and Lahti 1996).

The above-mentioned ligands are unable to differentiate between $\mathrm{DA} \mathrm{D}_{2}$-like, $5-\mathrm{HT}_{2 \mathrm{~A}}$, and $5-\mathrm{HT}_{2 \mathrm{C}}$ receptors and can as such not be used for evaluation of $5-\mathrm{HT}_{2}$ receptors in DA-rich areas. However, very recently a selective $5-\mathrm{HT}_{2 \mathrm{~A}}$ ligand, ${ }^{11} \mathrm{C}-\mathrm{MDL} 100.907$, has been introduced for PET studies (Lundkvist et al. 1996). This compound will be of great interest in evaluating the importance of $5-\mathrm{HT}_{2 \mathrm{~A}}$ receptor blockade in the clinical pharmacology of novel APDs. This compound is in phase II development as an APD (Kehne et al. 1996).

In summary, these results suggest that the occupancy of $5-\mathrm{HT}_{2}$ receptors in human brain induced by novel APDs is high even when administered below the clinically effective dosage. Thus, $5-\mathrm{HT}_{2}$ receptor blockade is most probably insufficient for antipsychotic activity but may well contribute to the overall efficacy and side effect profile, e.g., effects on negative symptoms or to a lower EPS potential, (e.g., Meltzer and Nash 1991; Busatto and Kerwin 1997).

$\alpha_{1}$-Adrenoceptors. Unfortunately, no ligand is available for the study of $\alpha_{1}$-adrenoceptor occupancy by APDs. Development of a PET ligand that enables imaging of $\alpha_{1}$-adrenoceptors would be of high interest given hypotheses regarding the contribution of this site to antipsychotic activity of clozapine (Baldessarini et al. 1992).

\section{Behavioral Assays of In Vivo Effects}

Traditionally, the functional effects of APDs on central nervous system (CNS) neurotransmitter receptors have been determined by monitoring a behavioral change that is as specific as possible for a given neurotransmitter receptor, often using a selective agonist as a tool. Because the balance between inhibitory effects on DA, $5-\mathrm{HT}_{2}$, and muscarinic receptors as well as $\alpha_{1}$-adrenoceptors is considered to be of primary importance for the pharmacological profiles of APDs in models related to antipsychotic activity and EPS, these receptors were chosen for the pie charts in Figure 1.

\section{Methodological Considerations by Using In Vivo} Assays for Evaluation of Relative Receptor Effects. Often several test models can be chosen for a given receptor effect, and the specificity of the given response for each receptor type is validated by correlation to the relative binding potencies in vitro or in vivo for a range of compounds with high and low affinities for the site in question. However, no behavioral test model is completely specific for one receptor, because pharmacodynamic interactions between different neuronal systems often lead to indirect effects of compounds without direct affinity for the target receptor. Given these limita- tions, it is useful to illustrate the relative dominance of acute receptor effects in vivo by pie charts as previously described for in vitro binding assays (Figure 1). The lower the $\mathrm{ED}_{50}$ value, the larger the slice of the pie chart will be. The models for each receptor should preferably reflect CNS effects to avoid bias from uneven distribution of some drugs or active metabolite(s) in the animal. The following models were selected:

- $\mathrm{DA} \mathrm{D}_{1}$ and $\mathrm{D}_{2}$ receptor antagonism was measured by inhibition of circling behavior induced by SK\&F 38393 and pergolide in 6-hydroxy-DA-lesioned rats, respectively. These models have shown high sensitivity for DA antagonism and relatively high selectivity for $D_{1}$ and $D_{2}$, receptors, respectively, with minor effects of $\alpha_{1}$-adrenoceptor antagonists (Arnt and Hyttel 1986).

- Antagonism of $5-\mathrm{HT}_{2}$ receptors was evaluated by measuring inhibition of quipazine-induced head twitches in rats (Arnt et al. 1989; Sánchez et al. 1991). The effect is blocked by a selective $5-\mathrm{HT}_{2 \mathrm{~A}}$ antagonist (Kehne et al. 1996; Arnt, unpublished observations), while the contribution of $5-\mathrm{HT}_{2 \mathrm{C}}$ receptors is unknown due to lack of results with selective antagonists. Antagonism of $\alpha_{1}$-adrenoceptors can also contribute slightly to inhibition of the quipazine-induced response (Arnt et al. 1989).

- Inhibition of $\alpha_{1}$-adrenoceptors was measured either by antagonism of the discriminative stimulus properties of the $\alpha_{1}$-adrenoceptor agonist St 587 in rats (Arnt 1992) or by inhibition of isoniazide-induced convulsions in mice. Isoniazide is an inhibitor of glutamic acid decarboxylase (GAD), the enzyme responsible for synthesis of GABA, and is as such a test for anticonvulsive effects of GABA stimulants and benzodiazepines. No direct evidence supports that $\alpha_{1}$ adrenoceptors are involved, but results from our laboratories (Sánchez, unpublished observations) have indicated a good correlation between affinities for $\alpha_{1}$-adrenoceptors in vitro and anticonvulsant potencies against isoniazide, as long as affinity for GABA or benzodiazepine receptors can be excluded. Such compounds would be false positives. Because all APDs, except remoxipride, were studied in the isoniazide model, and because the remaining compounds gave compatible results to the more specific drug discrimination model, the isoniazide test was used for the pie charts, except for remoxipride.

- Finally muscarinic cholinergic antagonism was measured as protection against the lethal effects of physostigmine in mice (Sánchez et al. 1991).

The methods used for pie charts were validated using selective antagonists of each receptor subtype: $\mathrm{SCH}$ 23390 (DA $D_{1}$ receptors), nemonapride (DA $D_{2}$ receptors), ritanserin (5- $\mathrm{HT}_{2}$ receptors), prazosin ( $\alpha_{1}$-adrenoceptors), and scopolamine (muscarinic receptors). In all 
instances, except for prazosin, the target receptor for each selective antagonist showed at least $90 \%$ preference for the appropriate in vivo model. For prazosin the $\alpha_{1}$-adrenoceptor slice of the in vivo pie chart accounts for about two-thirds of the total pie area. The reason for the lower selectivity compared with other receptors is not due to lack of receptor selectivity of prazosin as such, but to pharmacological interaction between $\alpha_{1^{-}}$ adrenoceptors and other receptor systems.

The pie charts in Figure 1 show large differences for $\mathrm{APDs}$ in their relative effects on these receptors in vitro and in vivo: Haloperidol had the expected $\mathrm{DA} \mathrm{D}_{2}$ preference both in vitro and in vivo. Clozapine and olanzapine had the most complex in vitro profiles. However, their in vivo effects were different: olanzapine but not clozapine had significant DA antagonism, whereas clozapine had preferential inhibitory effects on 5- $\mathrm{HT}_{2}$ receptors and $\alpha_{1}$-adrenoceptors. The muscarinic antagonism was much less evident in vivo than in vitro for both compounds. Risperidone and sertindole had very similar in vitro pie charts, showing similar affinities for DA $\mathrm{D}_{2}$ and 5- $\mathrm{HT}_{2}$ receptors as well as for $\alpha_{1}$-adrenoceptors. However, in vivo both compounds had predominant 5- $\mathrm{HT}_{2}$ antagonism, with additional $\mathrm{D}_{2}$ antagonism for risperidone and additional $\alpha_{1}$-adrenoceptor antagonism for sertindole. The DA $\mathrm{D}_{2}$ antagonism for sertindole is unexpectedly weak. No ready explanations can be given for the discrepancy from the in vitro profile. Ziprasidone shows similarities to sertindole in vitro, whereas the in vivo pie chart is almost identical to that of risperidone. Quetiapine differs from the other APDs by having large preference for $\alpha_{1}$-adrenoceptors in vitro, whereas almost equipotent effects on all receptors, except the muscarinic, in vivo. Part of this varied profile may be explained by the efficacy of $\alpha_{1}$-adrenoceptor antagonism in several of the models. However, the ex vivo binding results previously discussed (Schotte et al. 1996a) confirm a nonselective profile of quetiapine. Remoxipride has very weak in vitro affinities for most receptors in our assays but is a selective $D_{2}$ antagonist in vivo. It should be noted that remoxipride shows the expected $D_{2}$ selectivity in vitro when using a ${ }^{3} \mathrm{H}$-benzamide ligand (Malmberg et al. 1993).

In summary, the various experimental approaches, in vitro as well as in vivo, indicate common features and differences between novel APDs. This is further substantiated in the next sections describing activity profiles in animal models for antipsychotic activity and EPS.

\section{EFFECTS IN MODELS FOR ANTIPSYCHOTIC AND EPS ACTIVITY}

\section{Limbic versus Nigrostriatal DA Selectivity}

The most widely accepted hypothesis is that antipsychotic activity is related to inhibition of DA function in limbic and/or cortical brain regions (though not necessarily by blocking the receptors), whereas EPS are mediated by inhibition of nigrostriatal DA function (for a review, see Deutch et al. 1991). The hypothesis has stimulated studies of the neurobiology of the separate DA systems, as well as the development of animal models reflecting regional DA activity. Further, it has most importantly led to development of novel APDs.

Though we generally discuss inhibition of limbic DA function as the most important determinant for antipsychotic activity, it should be emphasized that the hypothesis includes limbic as well as cortical DA systems. Limbic and cortical structures are closely interconnected, and there are several lines of evidence for neuropathological and neurophysiological changes of prefrontal-temporolimbic cortices in schizophrenia (Ross and Pearlson 1996; Weinberger and Lipska 1995; Deutch et al. 1991; Gray et al. 1991). Studies using lesions or microinjection approaches have demonstrated that the functional consequences of DA manipulations are often opposite in frontal cortex and nucleus accumbens (Deutch 1992). Differential involvement of cortical versus limbic structures in the mechanism of action of novel APDs will be further discussed in the sections covering microdialysis and immediate early gene (i.e., c-fos) expression.

Selective inhibition of limbic versus striatal DA activity can be achieved in different ways: it is possible, but unlikely, that an APD accumulates selectively in the relevant brain area(s). There is limited evidence for regional differences in $\mathrm{D}_{2}$ receptor occupancies after acute administration of a few compounds, e.g., remoxipride (Köhler et al. 1992), but no studies have shown this to be the case after repeated administrations leading to a steady state level of drug in brain. Further, receptor inactivation studies in vivo using EEDQ have suggested that remoxipride (acute treatment) binds to a subpopulation (unspecified) of $\mathrm{D}_{2}$ receptors (Ögren et al. 1994).

Another possible strategy to obtain limbic selectivity is to develop compounds with preferential or selective affinity for subtypes of the $D_{2}$ receptor family mainly expressed in the limbic system (Lahti et al. 1995a,b). This strategy is under active investigation, for example, by development of specific $\mathrm{D}_{3}$ (Millan et al. 1995; Pugsley et al. 1995) and $D_{4}$ ligands (Merchant et al. 1996a; Rowley et al. 1996). However, there is no evidence for selective binding to $D_{2}$ receptor subtypes for the present generation of novel APDs (see previous discussion in the section on in vitro effects).

The most widely accepted hypothesis for obtaining limbic and/or cortical selectivity is that a correctly balanced inhibition of several neurotransmitter receptors, particularly DA $\mathrm{D}_{2}$ and 5-HT2 receptors as well as $\alpha_{1}{ }^{-}$ adrenoceptors and muscarinic receptors, leads to a selective inhibition of limbic/cortical DA function (Chiodo and Bunney 1985; Kinon and Lieberman 1996; Grace et al. 1997). This explanation is probably an oversimplifi- 
cation, because it is difficult to incorporate this hypothesis into profiles of all available compounds and to reproduce limbic selectivity by combination of classic APDs with other selective antagonists, (e.g., Gardner et al. 1993). Thus, presently unknown mechanisms may be operative as well.

In the next sections, the evidence for selective inhibition of limbic and/or cortical versus striatal DA function by APDs studied with electrophysiological, biochemical, and behavioral techniques is discussed.

\section{Effects of Novel APDs on Electrophysiological Activity of DA Neurons}

Acute Drug Treatment. Studies initiated by Bunney and colleagues show that acute intravenous (IV) administration of AMPH, which releases DA and blocks the DA reuptake (Carlsson et al. 1966), inhibits spontaneously active DA neurons in the substantia nigra pars compacta (SNC) and the ventral tegmental area (VTA) (Bunney et al. 1973; Bunney and Aghajanian 1975; Aghajanian 1978). The inhibition can be reversed by injection of APDs (i.e., DA antagonists) such as chlorpromazine, haloperidol, and fluphenazine, whereas administration of a DA antagonist in the absence of AMPH significantly elevates firing rates (Bunney and Grace 1978). An identical electrophysiological profile is observed with other APDs, whereas the structurally related drug, promethazine, is ineffective. Promethazine is an antihistaminic compound with a phenothiazine structure and possesses no antipsychotic or EPS potential.

Several attempts have been made to classify standard as well as novel compounds as classic or limbic selective based on their profile in VTA and SNC after IV administration. As mentioned, haloperidol and clozapine reverse the AMPH-induced inhibition. In contrast, risperidone has never been reported to reverse the AMPH effect in VTA and shows variable effects in SNC (Blum and Robisch 1989). Stockton and Rasmussen
(1993) reported that olanzapine selectively increases DA firing frequency in VTA while leaving the activity in SNC unaffected. In this study, AMPH was not used to decrease DA activity. Further, quetiapine is able to reverse the AMPH effect in both areas (Goldstein et al. 1993), whereas sertindole does not influence DA neuron activity even after very high doses (Skarsfeldt 1992) (Table 3). The reason for these differences is unknown, but a lack of effect is considered as evidence against direct DA receptor blockade.

Svensson and colleagues have focused on the basal activity (firing rate) of the DA neurons and have also examined changes in firing pattern, i.e., regularity of firing and the degree of firing in bursts (Grenhoff et al. 1988b). Substantial evidence suggests that the PFC regulates DA release and bursts firing in VTA (Murase et al. 1993; Svensson and Tung 1989). Interestingly, spontaneous burst firing is associated with a marked increase in DA release from the terminals (Bean and Roth 1991). Consequently, unchanged basal firing rate after pharmacological intervention does not explicitly indicate that the function of the DA system is unaltered, as the degree of burst firing could change without changes in the overall firing rate.

To our knowledge, amperozide is the only novel APD that has been tested in this paradigm (Grenhoff et al. 1990) and it was without effect on the DA activity in $\mathrm{SNC}$, whereas it either increased firing rate and burst firing (i.e., an excitation) or regularized the firing activity in VTA (i.e., activity level down-regulated). These data illustrate that amperozide selectively affects the mesocorticolimbic DA system, which is predictive of a low liability for EPS.

Repeated Treatment. The discrepancies between effects in the acute electrophysiological test model and the clinical experiences were long regarded as a problem, because instant release of DA induced by administration of AMPH does not cause schizophrenia-like symptoms in humans. In addition, patients having severe psychotic

Table 3. Reversal of amphetamine (AMPH)-Induced Inhibition of DA Neuron Firing in VTA and SNC by Acute APD Treatment

\begin{tabular}{lccll}
\hline & \multicolumn{2}{c}{$\begin{array}{c}\text { Reversal of AMPH-Induced Inhibition } \\
\text { of DA Firing Activity }\end{array}$} & \\
\cline { 2 - 3 } Compound & \multicolumn{2}{c}{ Reversal in VTA } & Reversal in SNC & Reference \\
\hline Sertindole & no & no & & Skarsfeldt 1992 \\
Clozapine & yes & yes/no & & Skarsfeldt 1992; Chiodo and Bunney 1983; White and Wang 1993 \\
Risperidone & n.t. & no/yes & & Blum and Robisch 1989 \\
Olanzapine & yes & no & & Stockton and Rasmussen 1996b; Marsha et al. 1996 \\
Quetiapine & yes & yes & & Goldstein et al. 1993 \\
Ziprasidone & n.t. & n.t. & \\
Amperozide & n.t. & n.t. & \\
Remoxipride & n.t. & n.t. & \\
Haloperidol & yes & yes & Skarsfeldt 1992; Chiodo and Bunney 1983; White and Wang 1993 \\
\hline
\end{tabular}

"Administration of olanzapine increased firing frequencies without the initial treatment with AMPH.

n.t. $=$ not reported. 
symptoms are typically repeatedly treated (several weeks) before obtaining a substantial therapeutic response.

This dilemma was addressed by Bunney and Grace (1978) who instead of measuring DA firing rate counted the number of spontaneously active DA neurons in SNC after repeated (22 days) treatment with haloperidol. In a predefined area of SNC they encountered 0.83 neurons per track in control rats, whereas only 0.08 cells per track was found in the haloperidol-treated $(0.5 \mathrm{mg} /$ $\mathrm{kg} /$ day) group. Chiodo and Bunney (1983) subsequently found that haloperidol inhibited the number of active DA neurons in VTA as well.

Additionally, White and Wang (1993) reported that haloperidol had a gradual onset of action in both areas, as no effect was observed after 1 week treatment. After 3 to 4 weeks of daily treatment, the effect was at its maximum and the effect of haloperidol did not further change up to 8 weeks of treatment. Intracellular studies have proven that the firing of the DA neurons is blocked due to a depolarization inactivation of the neurons (Grace and Bunney 1986).

The exact mechanism of the depolarization blockade of the DA neurons is at present unknown, but a recent review focused on the differences between the acute DA receptor blockade and the delayed inactivation of the DA neurons after repeated APD treatment (Grace et al. 1997). It is evident that antipsychotic-induced acute blockade of the DA receptors is unable to generate the depolarization blockade, as even lethal doses of haloperidol fail to decrease the number of spontaneously active DA neurons (Hollerman and Grace 1989).

Presumably, the mechanism of depolarization blockade is not caused by the direct effect on the DA-containing neurons projecting from the VTA and the SNC to the terminal areas, but instead it is speculated that DAcell depolarization block in at least SNC is mediated via a concert of both excitatory and inhibitory neuronal pathways between the striatum, globus pallidus, subthalamic nucleus, and the substantia nigra. As it is beyond the scope of the present review to go into further details, see Grace et al. (1997) for a current review.

The finding of antipsychotic-induced depolarization blockade stimulated considerable research and supporting studies showed that classic neuroleptics, i.e., with high propensity for inducing EPS, inhibited the number of active DA neurons in both SNC and VTA (White and Wang 1993). In general, compounds having an antipsychotic potential decrease the number of spontaneously active DA neurons in VTA. An overview of results obtained in our laboratories is shown in Table 4. Haloperidol and sertindole are very potent compounds, whereas much higher doses are needed for clozapine, olanzapine, and quetiapine to decrease the number of active DA neurons in VTA. The same compounds demonstrate a more variable response in SNC after repeated administration: haloperidol potently inhibited the ac- tivity in SNC, whereas clozapine, olanzapine, and remoxipride were unable to influence the activity in SNC.

Most important is the ratio between the effects in VTA versus the SNC as an estimate of the expected therapeutic index (i.e., antipsychotic efficacy versus liability to cause EPS) of the compounds. In this regard sertindole showed extreme selectivity (ratio 110), followed by remoxipride (ratio $>6$ ), clozapine and olanzapine (Table 4). Due to toxicological problems (i.e., necrosis) using high subcutaneous doses of olanzapine (doses above $32 \mu \mathrm{mol} / \mathrm{kg} /$ day corresponding to 20 $\mathrm{mg} / \mathrm{kg}$ ), only a single dose showed selectivity for the VTA area. This effect of olanzapine is in accordance with the results of Stockton and Rasmussen (1996a). The selectivity ratio of clozapine is also unknown, again because toxicity precluded testing of higher doses, whereas quetiapine was equipotent in both areas (ratio between VTA and SNC approximately one) indicating a classic-like profile. In contrast, Goldstein et al. (1993) reported that quetiapine (treatment for 28 days with 20 $\mathrm{mg} / \mathrm{kg}, \mathrm{PO}$, corresponding to $45 \mu \mathrm{mol} / \mathrm{kg}$ ) selectively inhibited the activity in VTA compared to the SNC. Unfortunately, they only tested a single dose of quetiapine, which does not indicate the selectivity ratio between the two areas. In accordance with the clinical results, both haloperidol and risperidone had a ratio near to or below one, indicating a more classic antipsychotic profile of these two compounds.

In conclusion, the present data indicate that acute treatment with several of the compounds is able to reverse the inhibitory effect in VTA of acutely administered AMPH and apparently, this effect is correlated with the affinity for DA $D_{2}$ receptors. However, the DA neuron population studies using repeated drug administration exhibited marked differences in the VTA/SNC index of the tested drugs and the observed mesolimbic selectivity of several compounds is in accordance with the reported clinical observations, as these compounds show less EPS liability compared to classic APDs. One caveat to this conclusion must be mentioned. In our hands, quetiapine possesses a classic profile in the VTA/SNC model, but the available clinical data (Casey 1996a; Hirsch et al. 1996) indicate that quetiapine induces less EPS in schizophrenic patients than does haloperidol. The reason for the discrepancy is at present unknown.

Comparison between effects after acute and repeated treatment further indicates that an acute effect on DA neuron firing is not a prerequisite for producing depolarization blockade after repeated treatment, as observed for sertindole.

\section{Biochemical Measures of Limbic versus Nigrostriatal Selectivity}

Microdialysis. Acute administration of APDs blocks DA receptors and produces a compensatory increase in 
Table 4. Inactivation of DA Neurons after Daily Treatment for 3 Weeks

\begin{tabular}{|c|c|c|c|}
\hline \multirow[b]{2}{*}{ Compound } & \multicolumn{2}{|c|}{$\mathrm{ED}_{50}(\mu \mathrm{mol} / \mathrm{kg} / \mathrm{day}, \mathrm{PO})$} & \multirow[b]{2}{*}{ Ratio } \\
\hline & Inhibition in VTA & Inhibition in SNC & \\
\hline Sertindole & 0.015 & 1.6 & 110 \\
\hline Clozapine & $56^{a}$ & $>120$ & $>2.1$ \\
\hline Risperidone $^{a}$ & $\sim 0.2$ & $\sim 0.3$ & 1.5 \\
\hline Olanzapine $^{b}$ & $\sim 35$ & $>32$ & $>1.0$ \\
\hline Quetiapine & 38 & 29 & 0.76 \\
\hline Ziprasidone & $\sim 0.2$ & $\sim 0.2$ & 1.0 \\
\hline Amperozide & $\sim 10$ & 19 & $\sim 2$ \\
\hline Remoxipride $^{b}$ & $1.9^{a}$ & $>12$ & $>6$ \\
\hline Haloperidol & 0.043 & 0.033 & 0.77 \\
\hline
\end{tabular}

DA cell firing that causes an elevation in the DA release and metabolism (Imperato and Di Chiara 1987; Westerink and Kikkert 1986). Presumably, the mechanism behind the favorable clinical profile of the novel APDs might be due to regional differences in the effect on the DA system, and both electrophysiological techniques (single cell recordings) and measurement of the Fos immunoreactivity have supported this hypothesis (this review).

Studies using microdialysis techniques have demonstrated that DA release (or, more precisely, measurement of extracellular DA-hereafter termed release) is elevated in nucleus accumbens (NAc) and striatum (STR) after acute administration of the classic neuroleptics (haloperidol, chlorpromazine, thioproperazine, spiperone or (-)-sulpiride) (Osborne et al. 1994; Moghaddam and Bunney 1990; Rayevsky et al. 1995). In contrast to the results obtained with electrophysiological techniques and Fos immunoreactivity, acute administration of the limbic-selective APDs, i.e., clozapine, thioridazine, and fluperlapine also surprisingly increase DA release in both NAc and STR (Imperato and Angelucci 1989; Rayevsky et al. 1995; Invernizzi et al. 1990; Meltzer et al. 1994).

Although the limbic selective compounds do not induce catalepsy in animals, they are able to stimulate the release of DA in the striatum like the classic APDs. The release of DA after the classic APDs is relatively shortlasting compared to the behavioral effects observed (catalepsy), and consequently the DA release should experience an acute tolerance (Di Chiara and Imperato 1985). The time course after clozapine and fluperlapine is longer, and additional administration of test compound renewed the release of DA (Imperato and Angelucci 1989). Nevertheless, measurement of DA release in NAc and STR after acute administration of an APD does not appear to distinguish between limbic selective and nonselective neuroleptic compounds.

In Table 5, data on DA release or measurement of the DA metabolite using microdialysis after acute drug administration have been collected. In one of the reports

Table 5. Effect of Acute Drug Administration on the Release of DA or DOPAC in Different Brain Areas Using Microdialysis

\begin{tabular}{lcccll}
\hline Compound & Dose $(\mathbf{m g} / \mathbf{k g})$ & NAc & DLSTR & PFC & \multicolumn{1}{c}{ References } \\
\hline Sertindole & $3-6^{a}$ & + & ++ & +++ & Fink-Jensen et al. 1996 \\
Clozapine & $2-5$ & & + & + & Imperato and Angelucci 1989 \\
& 10 & + & + & ++ & Hertel et al. 1996 \\
& $5-10^{a}$ & + & + & ++ & Fink-Jensen et al. 1996 \\
Risperidone & $0.2-2.0$ & ++ & ++ & ++ & Hertel et al. 1996 \\
& $0.2-0.4^{a}$ & + & ++ & ++ & Fink-Jensen et al. 1996 \\
Amperozide & 10 & 0 & 0 & ++ & Hertel et al. 1996 \\
& $5.0-10$ & ++ & ++ & ++ & Nomikos et al. 1994 \\
Haloperidol & 0.25 & ++ & ++ & & Osborne et al. 1994 \\
& $0.1-0.2$ & + & ++ & ++ & Fink-Jensen et al. 1996 \\
\hline
\end{tabular}

$0=$ No significant increase in the DA content, $+=0-99 \%$ increase in DA content, $++=100-249 \%$ increase of DA content,$+++=>500 \%$ increase in content of DA.

"The DA metabolite, DOPAC, was measured in this experiment.

$\mathrm{NAC}=$ nucleus accumbens; DLSTR $=$ dorsolateral striatum; PFC $=$ prefrontal cortex 
on sertindole, clozapine, and risperidone (Fink-Jensen et al. 1996) microdialysis was used to measure the release of the DA metabolite, DOPAC, rather than DA. Amperozide has shown variable effects on the DA levels in STR, as Hertel et al. (1996) reported that amperozide produced only minor increases in DA levels, whereas Nomikos et al. (1994) observed a marked increase. However, based on numerous reports, the general view is that the majority of the tested compounds increases DA release in STR, though with marked differences in potencies. Additionally, all the compounds increase DA release in the NAc, and this is in accordance with the view that acute administration of APDs stimulates the DA neuron activity in the VTA.

Interestingly, several of the compounds (sertindole, clozapine, risperidone) show a marked difference in their effect on extracellular DOPAC in STR/NAc versus PFC. Imbalance in the function of the PFC is currently regarded as a potentially important element in the pathophysiology of schizophrenia, and hypofunctionality of PFC has been hypothesized to correspond with negative symptomatology (Weinberger 1988). Hence, compounds with preferential effect in PFC may have clinical efficacy on the negative symptoms.

As described previously, repeated administration of APDs induces depolarization blockade of the DA neurons in VTA area, whereas classic, but not limbic selective, APDs are effective in SNC. Based on the electrophysiological data, it should be predicted that DA turnover would decrease due to the depolarization inactivation. However, microdialysis studies using repeated administration of APDs have shown variable responses. Ichikawa and Meltzer (1992) observed no effect of repeated treatment with clozapine on basal release of DA, and the amount of DOPAC and HVA in NAc compared to control levels, whereas clozapine increased the extracellular level of DA in STR. This could not be confirmed by others (Youngren et al. 1994) who found that clozapine was without effect on the DA level in STR. Additionally, repeated treatment with haloperidol failed to change the basal outflow of DA and its response to administration of a challenge dose of haloperidol (Moghaddam and Bunney 1993). However, the characteristics of the DA terminals seem to be altered, as response to $\mathrm{K}+$ stimulated $(30 \mathrm{mmol} / \mathrm{L})$ release of DA was significantly decreased in the haloperidol-treated rats compared with vehicle-treated rats. The lack of effect on basal DA outflow is inconsistent with the electrophysiological results, as haloperidol induces depolarization inactivation of the DA neurons projecting to STR. Results inconsistent with depolarization blockade were also obtained by Klitenick et al. (1996) who observed that chronic haloperidol treatment failed to attenuate stress- and PFCstimulation-induced DA release in NAc.

It might be speculated that, in spite of the observed depolarization blockade of the majority of DA neurons found after repeated APD treatment, the remaining active DA neurons might increase their burst activity, which accordingly should enhance DA release (Grenhoff et al. 1988a). A recent study has suggested that implantation of the microdialysis probe $24 \mathrm{~h}$ before the test reversed depolarization inactivation induced by haloperidol (Todd et al. 1996), and this suggests that the discrepancy between electrophysiology and microdialysis results may be due to methodological problems.

It would be interesting to evaluate the effect of some novel APDs on the release of DA and the levels of DOPAC and HVA, but to our knowledge no novel APDs have been studied after repeated administration.

Expression of c-fos and Related Genes. Substantial efforts have been made to understand the phenomena of electrical activity, transmitter release, and receptor coupling, as well as the second messenger systems involved in the function of the nervous system. These phenomena are all rapidly occurring events that are coupled with subsequent changes in gene transcription in the cell nucleus. Within the last decade, methods have been developed that enable the detection of intracellular molecular events induced by quickly occurring extracellular signals.

Table 6. Effect of Acute APD Treatment on Expression of Fos Protein in Different Brain Regions

\begin{tabular}{llllllll}
\hline Compound & Dose $(\mathbf{m g} / \mathbf{k g})$ & NAc & MSTR & LSTR & PFC & LS & References \\
\hline Clozapine & $10,20,30$ & ++ & ++ & +++ & + & ++ & Robertson and Fibiger 1992 \\
Haloperidol & $0.5,1.0$ & ++ & +++ & +++ & 0 & + & Robertson and Fibiger 1992 \\
Risperidone & 10 & +++ & $\mathrm{nt}$ & +++ & ++ & $\mathrm{nt}$ & Fink-Jensen and Kristensen 1994 \\
Sertindole & 10 & +++ & $\mathrm{nt}$ & 0 & + & $\mathrm{nt}$ & Fink-Jensen and Kristensen 1994 \\
Olanzapine & 5,10 & +++ & +++ & +++ & ++ & +++ & Robertson and Fibiger 1996 \\
Quetiapine & $10,20,40$ & + & ++ & 0 & + & ++ & Robertson et al. 1994 \\
Remoxipride & 2.25 & ++ & + & 0 & $\mathrm{nt}$ & $\mathrm{nt}$ & Deutch et al. 1992 \\
& $1.5,3.0$ & ++ & +++ & ++ & + & ++ & Robertson et al. 1994 \\
\hline
\end{tabular}

nt $=$ Not tested, $0=0-99 \%$ increase compared to vehicle treatment.

$+=100-249 \%$ increase compared to vehicle.

$++=250-499 \%$ increase compared to vehicle treatment.

$+++=>500 \%$ increase.

NAc = nucleus accumbens; MSTR = medial striatum; LSTR = lateral striatum; PFC = prefrontal cortex; LS = lateral septum. 
Stimulation or blockade of membrane receptors influences intracellular second messenger systems, which may lead to an induction of the immediate early gene, $c$-fos. It has been reported that haloperidol and nemonapride but not SCH 23390 significantly increase the c-fos expression in the STR (Dragunow et al. 1990). The $\mathrm{DA}_{2}$ receptor agonist quinpirole attenuates the haloperidol-induced effect (Miller 1990), and these results suggest that $c$-fos induction in STR correlates to blockade of striatal $\mathrm{DA} \mathrm{D}_{2}$ receptors. The involvement of $\mathrm{DA}$ is further substantiated by the fact that unilateral 6-OHDAinduced lesions of the DA projection abolished the increase in Fos immunoreactivity induced by haloperidol and clozapine in DA innervated areas (e.g., lateral striatum and NAc), whereas 6-OHDA lesion did not inhibit the effect of clozapine in the lateral septum (LS) and PFC (Robertson and Fibiger 1992), areas densely innervated by various serotonergic receptor subtypes as well as other neurotransmitters (O'Dell et al. 1990; Pazos et al. 1985).

Clozapine and haloperidol have shown regional differences on $c$-fos expression in the rat brain. Acute administration of haloperidol dramatically increased the number of Fos-positive cells in the dorsolateral region of STR, whereas clozapine was ineffective (Robertson and Fibiger 1992; Deutch et al. 1992). Additionally, haloperidol but not clozapine increased the expression in both the striatal patch and matrix compartment. The NAc shows greater variability, as the NAc has been divided into subregions, i.e., the shell, core, and cone region (Robertson and Fibiger 1992). The shell region is related to the limbic part of the brain, whereas the core relates to the striatal part, while the relationship of the cone region is at present uncertain. In the NAc, haloperidol increased $c$-fos expression in various parts, concentrated in patches throughout extent of NAc (Robertson and Fibiger 1992) or in the cone, shell, and core divisions of NAc (Deutch et al. 1992). Clozapine increased the Fos immunoreactivity in the cone and shell but not in the core division of NAc.

Attempts have been made to mimic the pharmacological receptor profile of clozapine (Fink-Jensen et al. 1995). Ritanserin, a $5-\mathrm{HT}_{2}$ receptor antagonist, and the $\alpha_{1}$-adrenoceptor antagonist, prazosin, do not increase Fos protein immunoreactivity by themselves. Co-administration of haloperidol and ritanserin or haloperidol and prazosin does not mimic the clozapine response, indicating that neither $\alpha_{1^{-}}, 5-\mathrm{HT}_{2}$, nor $\alpha_{1}-/ \mathrm{DA} \mathrm{D}_{2}$ or $5-\mathrm{HT}_{2} /$ $\mathrm{DA} \mathrm{D}_{2}$-receptor blockade is sufficient to explain the fos expression profile of clozapine.

As mentioned previously, dysfunction of the PFC has been hypothesized to be related to the negative and/or cognitive symptoms of schizophrenia. It is believed that clozapine is effective against negative symptoms (Deutch et al. 1991), and this suggests that clozapine could act selectively or preferentially on the function of the PFC. Clozapine-but not haloperidol, raclopride, sulpiride, risperidone, SCH 23390, ritanserin, or scopolamine--induced Fos protein in the infralimbic and prelimbic part of the PFC, whereas all compounds were ineffective in the medial part of PFC. DA $\mathrm{D}_{2}$ receptor agonists (apomorphine and quinpirole) increased Fos levels in PFC. Pretreatment with apomorphine or sulpiride was not able to modify the clozapine-induced increase in PFC (Deutch and Duman 1996). The latter study clearly suggests that the effect of clozapine is not attributed to any known dopaminergic, serotonergic, $\alpha_{1}$-adrenergic, or muscarinic receptor and that the unique clinical profile of clozapine might be due to a preferential action in the PFC areas.

Special interest has been put on the novel APDs (see Table 6). Sertindole and quetiapine showed regional selectivity for PFC and NAc while leaving the Fos expression in dorsolateral STR unaffected (Fink-Jensen and Kristensen 1994; Robertson et al. 1994), and remoxipride showed regional selectivity for NAc compared to STR (Deutch et al. 1992; Robertson et al. 1994). Olanzapine, however, increased Fos immunoreactivity in PFC, NAc, and the dorsolateral STR, an effect that correlates with the ability to produce EPS (Robertson and Fibiger 1996). It is recently suggested that $D A D_{3}$ and $D_{4}$ antagonism is involved in $c$-fos expression in PFC (Merchant et al. 1996a,b), though the response to clozapine in NAc but not in PFC was attenuated by the preferential DA $\mathrm{D}_{3}$ agonist 7-OH-DPAT (Guo et al. 1995).

It appears that expression of the Fos protein in NAc shell region is a relatively consistent marker of neurons activated by acute administration of APDs. Furthermore, it is hypothesized that the effect in PFC may be related to efficacy on negative symptoms (c.f., active compounds in Table 6).

The discrepancy between the rapid induction of Fos and the delayed clinical effects of APDs is again emphasized, as repeated administration of clozapine or haloperidol for 3 weeks results in a reduced increase in Fos-like immunoreactivity after a challenge dose in several brain areas (haloperidol: dorsolateral STR, NAc and central amygdala; clozapine: LS, paraventricular hypothalamus and central amygdala). Induction of Fos persisted in NAc after repeated treatment with clozapine, and in LS after treatment with haloperidol (Sebens et al. 1995). Tolerance to clozapine has also been shown in PFC (Merchant et al. 1996b).

These results indicate that tolerance develops to the stimulation of Fos immunoreactivity in several brain areas. The importance of this tolerance is at present unknown, but a simplistic view is that these brain areas are of minor importance in the maintenance of antipsychotic action or for inducing EPS. More likely, it indicates that the Fos immunoreactivity is just the first step in a cascade of, yet unknown, more permanent processes.

This hypothesis is emphasized by the fact that recent studies have indicated that other members of the fos family are persistently elevated after chronic alteration 
of dopaminergic neurotransmission. Doucet et al. (1996) demonstrated that destruction of the nigrostriatal pathway by 6-OHDA injection in rats produced a prolonged elevation of a truncated form of FosB known as $\Delta$ FosB (43-45 $\mathrm{kDa}$ polypeptide). Acute administration of haloperidol produced peak values in Fos expression at $1-2 \mathrm{~h}$ after administration, whereas expression of $\Delta$ FosB reached peak levels at $4 \mathrm{~h}$ and even after $24 \mathrm{~h}$ the $\Delta$ FosB expression was still detectable. Repeated haloperidol for 14 days selectively elevated expression of $\Delta$ FosB. In support of this (Vahid-Ansari et al. 1996) reported that repeated administration (19 days) of haloperidol increased the number of $\Delta$ FosB immunoreactive cells in striatum (both ventral, medial, and dorsolateral parts), whereas haloperidol did not increase the immunoreactivity in PFC and LS. In contrast, clozapine and quetiapine elevated $\Delta$ FosB immunoreactivity in the ventral part of STR, LS, and PFC. These data suggest similarities between quetiapine and clozapine, as demonstrated previously by the acute fos experiments.

In conclusion, the results suggest that $\Delta F o s B$ immunoreactivity can be used to detect neurons activated by chronic administration of APDs, and it will be interesting to observe the possible regional differences of $\Delta \mathrm{FosB}$ immunoreactivity induced by repeated treatment with novel APDs.

Neurotensin. Even though DA is thought to play a dominant role in the pathophysiology of schizophrenia, other transmitter systems might be of importance and the involvement of neuropeptides (e.g., neurotensin, NT) has been suggested (Nemeroff 1980). NT is a tridecapeptide, which is distributed widely in the peripheral as well as in the central nervous system (Uhl et al. 1977; DiPaola and Richelson 1990). Extensive studies have shown that NT is predominantly present in regions associated with dopaminergic neurons, as NT coexists with DA in some midbrain cell bodies and their terminals (Hökfelt et al. 1984). The highest levels of NT are observed in the ventral tegmentum, substantia nigra (SN), NAc, STR, septum, amygdala, brain stem, and the spinal cord, whereas lower levels of NT are found in cortical areas. NT does not readily pass the blood-brain barrier, but NT exerts pronounced behavioral effects after intracranial administration. NT injected in VTA produces motor stimulation, whereas injection into NAc inhibits locomotor activity induced by dopaminergic stimulants (e.g., Gully et al. 1995).

Electrophysiological experiments have revealed that NT produces a significant increase in the firing rate of neurons in SN, VTA, medial PFC, and hypothalamus (Liégeois et al. 1995). Uhl et al. (1977) found low doses of NT to be selective for the VTA area in acute experiments, a clozapine-like activity. In general, the available electrophysiological data suggest that centrally administered NT demonstrates a profile similar to APDs ad- ministered systemically (for extensive review, see Stowe and Nemeroff 1991), and it has been proposed that NT could be an endogenous neuroleptic-like compound (Nemeroff 1980).

Acute administration of remoxipride and sulpiride failed to change NT levels in NAc (Levant et al. 1991). In contrast, repeated administration of either haloperidol or clozapine increased the NT concentration in NAC and decreased the concentration of NT in medial PFC and cingulate cortex. Haloperidol, but not clozapine, increased the NT concentration in STR (Kilts et al. 1988). These data further suggest that NT is a neuroanatomically selective substrate that might be involved in the responses mediating the therapeutic and motor disturbances observed after treatment with APDs. Unpublished studies indicate that sertindole has a profile similar to clozapine in NAc and STR (Nemeroff, personal communication). The effects of repeated treatment with other APDs on NT levels are not known, but the observations suggest that antipsychotic activity could involve regional changes in NT function. This might be used for development of novel APDs with low incidence of EPS.

Merchant et al. (1992) reported an increase in NT/ neuromedin N (NT/N) gene expression in the dorsolateral STR after acute administration of haloperidol, whereas clozapine was without this effect. Additionally, haloperidol and clozapine increased NT/N mRNA expression in the shell structure of NAc. These results suggest that APD-induced increase in NT/N gene expression in dorsolateral STR is related to a potential for developing EPS, whereas the observed effect in the shell of NAc should indicate the antipsychotic potential of the drugs. Subsequently, Merchant and Dorsa (1993) found a significant increase in NT/N gene expression in STR after acute haloperidol and fluphenazine, whereas clozapine, remoxipride, and thioridazine were ineffective. After repeated administration, haloperidol but not clozapine elevated striatal NT/N mRNA (Merchant et al. 1994; Mijnster et al. 1995). The novel APDs have not been studied. Thus, the studies of NT/N gene expression after repeated drug treatment are incomplete and as such can not presently be used as a tool to distinguish between the classic and the novel APDs.

\section{Behavioral Effects in Animal Models Related to Antipsychotic Activity and EPS}

A large variety of test models is used to evaluate the acute effects of putative APDs on DA function in animals despite the commonly noted slow onset (weeks) of the therapeutic effects of available APDs compared with the onset of DA receptor occupancy (minutes to hours). The objective of using acute experiments is usually to measure preferential effects believed to depend on limbic or cortical function compared with effects on nigrostriatal DA activity. It is beyond the scope of the 
present review to consider the evidence for pharmacological specificity and the anatomical selectivity of the different models in detail-refer to the literature references and to more detailed reviews (Ellenbroek 1993; Jackson and Westlind-Danielsson 1994) cited in the following sections.

Inhibition of hypermotility induced by DAergic drugs such as DA agonists/DA releasers (e.g., apomorphine or AMPH), as well as by the noncompetitive NMDA antagonists phencyclidine (PCP) or dizocilpine (MK 801 ), is widely used for initial screening for limbic activity of new drugs. The activity profiles in these models are compared with the inhibitory potencies against stereotyped behaviors induced by high doses of dopaminergic drugs, effects used for evaluation of effects on striatal DA function. Accordingly, the latter models are assumed to reflect potential for inducing neurological side effects of putative APDs and are used in parallel with studies of cataleptogenic activity, the classic test of EPS in rats.

Other classic animal models still in use include the inhibition of conditioned avoidance responses in the rat or monkey and inhibition of circling behavior induced by $\mathrm{D}_{1}$ or $\mathrm{D}_{2}$ agonists in unilaterally 6 -hydroxy-DAlesioned rats. Effects in these models are probably dependent on both limbic DA and striatal function (Kelly and Moore 1978; Arnt 1987).

More recently, new models have gained in popularity. These include effects on the deficits in prepulse inhibition (PPI) of acoustic startle response induced by dopaminergic drugs or NMDA antagonists as well as effects in drug discrimination assays, on latent inhibition and on drug-induced disruption of social interaction. These models give possibilities to evaluate new aspects of the pharmacology of APDs, as some of them model certain features of deficits observed in schizophrenic patients.

Stimulant-Induced Hypermotility and Stereotypy and Cataleptogenic Effect. These models are often used in the first in vivo screening of putative APDs. The rationale is the above-mentioned evidence that hypermotility is mediated by the limbic system (particularly nucleus accumbens and tuberculum olfactorium), whereas stereotyped behavior and catalepsy are associated with increased and decreased striatal DA function, respectively. Obviously the goal of a basic screening program is to obtain inhibitory effect on dopaminergic hypermotility, while minimizing antistereotypic as well as cataleptogenic activity. However, there are also several problems caused by using hypermotility models: first it is important to demonstrate that a test compound is effective in a dose that does not block spontaneous locomotor activity - this would mean possible nonspecific effects (e.g., Arnt 1995). Second, inhibition of hypermotility is not a sufficient criterion, because some drugs without antipsychotic effects show positive effects on the model, e.g., GABA agonists (Scheel-Krüger et al. 1978). Third, the effects can be demonstrated acutely within minutes.

Despite these limitations, useful information on the activity profiles of APDs has been gained from these models: classic APDs inhibit hypermotility and stereotypies induced by dopaminergic drugs and induce catalepsy at similar dose levels in rats, as exemplified by the results with haloperidol in Table 7 in which AMPH is used as a DA stimulant. Other classic APDs like fluphenazine and cis(Z)-flupentixol have similar properties (Sánchez et al. 1991; Arnt 1995).

In contrast to classic neuroleptics, novel APDs have very different activity profiles (Table 7): sertindole, clozapine, and ziprasidone selectively inhibit hypermotility induced by AMPH without effects on stereotyped behavior and catalepsy. It is noted that the stereotypy and catalepsy results correlate closely, in agreement with their presumed similar neuronal substrates.

Inhibition of AMPH-induced hypermotility has been studied using two doses of AMPH $(0.5$ and $2.0 \mathrm{mg} / \mathrm{kg})$, further adding to the complexity. Whereas the classic APDs inhibit hypermotility induced by both doses of AMPH with similar potencies (Arnt 1995), the effects of most of the novel APDs are much more potent against the low AMPH dose. Quetiapine and amperozide lack effects on catalepsy, stereotypy, and on hypermotility induced by AMPH $2 \mathrm{mg} / \mathrm{kg}$ but inhibit selectively the hypermotility induced by the low AMPH dose, thus differentiating these compounds from sertindole, clozapine, and ziprasidone.

A number of APDs can be placed in an intermediate group between the above-mentioned novel APDs and classic APDs: remoxipride fails to produce catalepsy in our experimental conditions but inhibits only with marginal selectivity the AMPH-induced hypermotility versus stereotypy. Others have similar results, including additional observation of catalepsy after high doses of remoxipride (Ögren et al. 1984). Finally, risperidone and olanzapine are effective in all models, but in contrast to classic APDs, they show some preference in blocking the hypermotility response to AMPH, particularly when the low AMPH dose is used. Similar results indicating slight selectivity of olanzapine (Moore et al. 1993; Hoffman and Donovan 1995b) and risperidone (Janssen et al. 1988; Megens et al. 1994; Hoffman and Donovan $1995 b)$ in these models have been published by others.

Comparisons between inhibitory potencies on spontaneous locomotor activity and on AMPH-induced hypermotility indicate that the effects on the AMPH 2 $\mathrm{mg} / \mathrm{kg}$ dose are of questionable specificity. Only remoxipride and to some extent sertindole and ziprasidone have preferential effects on AMPH versus spontaneous locomotor activity (Table 7). Much larger separation to the inhibition of spontaneous motility was obtained using the low AMPH dose, except for haloperidol. 
It is difficult to offer strict explanations for all differences in drug profiles, as numerous mechanisms appear to be involved. The nonselective effects of classic APDs can be explained by predominant $D A D_{2}$ receptor antagonism. This is the only receptor blockade that both leads to catalepsy and inhibition of AMPH stereotyped behavior in the experimental conditions shown in Table 7 (Arnt et al. 1986; Arnt et al. unpublished). In contrast, the inhibition of AMPH-induced hypermotility can be achieved by different mechanisms: the effect of both doses of AMPH is also inhibited by a selective $\alpha_{1}$-adrenoceptor antagonist, e.g., prazosin, with marginal selectivity for inhibition of the lower AMPH dose (Arnt 1995). Finally, selective 5- $\mathrm{HT}_{2}$ antagonists, e.g., ritanserin $\left(5-\mathrm{HT}_{2 \mathrm{~A} / 2 \mathrm{C}}\right)$ and MDL $100.151\left(5-\mathrm{HT}_{2 \mathrm{~A}}\right)$ inhibit the effect of the low AMPH dose only (Arnt 1995). In addition to the direct effects of selective receptor blockers, a variety of receptor interactions influences the actual potencies of individual compounds in these models. Unpublished observations in the authors' laboratory suggest that either $\alpha_{1}$-adrenoceptor or 5 - $\mathrm{HT}_{2}$ blockade can enhance the inhibitory activity of a classic APD (haloperidol) in the AMPH hypermotility models, whereas the cataleptogenic and antistereotypic effects of DA antagonists are unchanged (Arnt et al. 1986) or only weakly influenced (Svendsen et al. 1986; Kapur 1996). Thus, weak inhibitory effects on DA receptors, combined with marked $\boldsymbol{\alpha}_{1}$-adrenoceptor and/or 5 - $\mathrm{HT}_{2}$ antagonism could theoretically lead to limbic selectivity in these acute models.

Furthermore, it is well known that additional antimuscarinic effects reverse or weaken the functional consequences particularly of nigrostriatal DA receptor blockade (catalepsy, inhibition of stereotyped behavior), while having less influence on behaviors mediated by DA receptors in the limbic system (e.g., druginduced motor stimulation) (Arnt et al. 1981; Arnt and Christensen 1981; Ellenbroek 1993). The net effect of DA antagonism plus muscarinic antagonism is thus a separation of the potencies to block responses mediated by the limbic and nigrostriatal DA system. A similar result is obtained by combining a DA antagonist with a $5-\mathrm{HT}_{1 \mathrm{~A}}$ agonist, as demonstrated by interaction studies with 8-OH-DPAT, showing reversal of catalepsy induced by the classic APD raclopride while enhancing other effects of this APD (Wadenberg and Ahlenius 1995).

The activity profiles of sertindole, clozapine, and ziprasidone may thus be explained by their weak DA $\mathrm{D}_{2}$ antagonism combined with potent $\alpha_{1}$-adrenoceptor and $5-\mathrm{HT}_{2}$ receptor blockade (all three compounds) with additional contribution of antimuscarinic activity (clozapine) and /or 5- $\mathrm{HT}_{1 \mathrm{~A}}$ agonism (ziprasidone, clozapine). Ziprasidone and clozapine have shown significant 5- $\mathrm{HT}_{1 \mathrm{~A}}$ agonist activity in vitro (Seeger et al. 1995; Newman-Tancredi et al. 1996). The 5- $\mathrm{HT}_{1 \mathrm{~A}}$ agonism remains to be shown in vivo, however (loc. cit.; Kleven et al. 1996). It should be mentioned that it is controversial whether an antimuscarinic activity of a $\mathrm{D}_{2}$ antagonist leads to limbic selectivity, based on combination studies of haloperidol with an antimuscarinic drug. The combination effect was shown not to be clozapine-like (Gardner et al. 1993). In this respect, it was mentioned previously that clozapine has agonist activity at $\mathrm{m} 4$ muscarinic receptors, which are abundant in basal ganglia (see in vitro section).

The profile of amperozide is identical to that observed with the selective $5-\mathrm{HT}_{2}$ antagonist ritanserin as could be expected from their receptor profiles. For the $5-\mathrm{HT}_{2 \mathrm{~A}}$ antagonist MDL 100.907, specific inhibition of drug-induced hypermotility versus stereotyped behavior is also one of the main findings (Sorensen et al. 1993; Kehne et al. 1996). The results with amperozide are in agreement with other literature data as well (Gustafsson and Christensson 1990b; Kimura et al. 1993). Surprisingly, quetiapine has also a profile simi-

Table 7. Effect on Amphetamine-Induced Behaviors and on Catalepsy in Rats

\begin{tabular}{|c|c|c|c|c|c|c|c|}
\hline \multirow[b]{2}{*}{ Compound } & \multicolumn{7}{|c|}{$\mathrm{ED}_{50}(\mu \mathrm{mol} / \mathrm{kg}$, s.c. $)$} \\
\hline & $\begin{array}{c}\text { АМРН Нyp } \\
0.5 \mathrm{mg} / \mathrm{kg}\end{array}$ & $\begin{array}{l}\text { ermotility } \\
2.0 \mathrm{mg} / \mathrm{kg} \\
\end{array}$ & $\begin{array}{c}\text { AMPH }^{b} \\
13 \text { mg/kg } \\
\text { Stereotypy }\end{array}$ & $\begin{array}{c}\text { Ratio } \mathrm{ED}_{50} \\
\text { AMPH Stereo/ } \\
\text { Motility } \\
(2.0 \mathrm{mg} / \mathrm{kg}) \\
\end{array}$ & $\begin{array}{c}\text { Ratio ED } \\
\text { AMPH Motil } \\
0.5 / 2.0 \mathrm{mg} / \mathrm{kg}\end{array}$ & Catalepsy $^{b}$ & $\begin{array}{c}\text { Inhib } \\
\text { Spontaneous } \\
\text { Locomotor } \\
\text { Activity }^{a} \\
\end{array}$ \\
\hline Sertindole & 0.25 & 4.6 & $>45$ & $>10$ & 18 & $>91$ & 12 \\
\hline Clozapine & 1.2 & 12 & $>120$ & $>10$ & 10 & $>120$ & 7.8 \\
\hline Risperidone & 0.35 & 3.5 & 11 & 3.1 & 10 & 17 & 2.6 \\
\hline Olanzapine & 1.4 & 9.1 & 36 & 4.0 & 6.5 & 37 & 8.7 \\
\hline Quetiapine & 4.6 & $>40$ & $>80$ & - & $>8.7$ & $>80$ & 72 \\
\hline Ziprasidone & 0.47 & 5.7 & $>190$ & $>33$ & 12 & $>48$ & 12 \\
\hline Amperozide & 2.6 & $>46$ & $>180$ & - & $>18$ & $>46$ & 34 \\
\hline Remoxipride & 2.9 & 4.8 & 15 & 3.1 & 1.7 & $>47$ & $>47$ \\
\hline Haloperidol & 0.099 & 0.24 & 0.15 & 1.2 & 2.4 & 0.34 & 0.41 \\
\hline
\end{tabular}

"From Arnt (1995).

${ }^{b}$ Sertindole, clozapine, and haloperidol data from Sánchez et al. (1991).

For methods, please refer to Arnt (1995) and Sánchez et al. (1991). 
lar to a selective $5-\mathrm{HT}_{2}$ antagonist that does not correspond to its broad receptor profile in vivo including high $\alpha_{1}$-adrenoceptor affinity (see Figure 1 and Migler et al. 1993).

The marginal selectivity (hypermotility versus stereotypy) of risperidone and olanzapine is most likely caused by their more predominating DA antagonism compared with clozapine and sertindole (Figure 1). The slight selectivity is likely obtained by additional $\alpha_{1^{-}}$ adrenoceptor and $5-\mathrm{HT}_{2}$ receptor blockade. It could be expected that the high in vitro and ex vivo muscarinic affinity of olanzapine would further enhance selectivity (Bymaster et al. 1996a,b), but the in vivo antimuscarinic activity is rather weak in our hands (Figure 1).

As mentioned in the ex vivo binding section, it has been shown that risperidone has a more shallow doseresponse curve at $\mathrm{DA} \mathrm{D}_{2}$ receptors than do other APDs (Megens et al. 1992; Schotte et al. 1996a). This has been followed up in behavioral experiments showing that the AMPH interaction with risperidone occurs over a wider dose range than observed with classic APDs (Megens et al. 1992). The impact of this result for evaluation of limbic selectivity is not clear.

Finally, the profile of remoxipride is different from all other APDs. The failure to differentiate between the two doses of AMPH can be explained by its lack of marked affinities for $\alpha_{1}$-adrenergic and $5-\mathrm{HT}_{2}$ receptors, but the preferential inhibition of AMPH hypermotility compared with stereotypy and catalepsy is unexplained. However, as mentioned earlier, there is some evidence for limbic selectivity demonstrated by in vivo binding studies at $D_{2}$ receptors.

Differential effects of novel APDs and the 5- $\mathrm{HT}_{2}$ antagonist ritanserin have also been demonstrated after DA-stimulant-induced hyperactivity elicited by intracerebral injections into nucleus accumbens and tuberculum olfactorium, two regions belonging to the limbic system. The olfactory tubercle is particularly sensitive to $5-\mathrm{HT}_{2}$ antagonism (including the novel APDs sertindole, risperidone, and olanzapine), whereas haloperidol is more potent in nucleus accumbens (Cools et al. 1994, 1995). Although it is not clear how these results are related to the clinical profiles of the compounds, they indicate that the hyperactivity models are more complex than generally assumed. These results, together with the previously discussed results with different AMPH doses, point to a heterogeneous regulation of dopaminergic hypermotility, shown both pharmacologically and anatomically. Even $\alpha_{1}$-adrenoceptors in frontal cortex influence AMPH-induced hypermotility (Blanc et al. 1994). In this context, a discrepant finding indicates that 6-OHDA lesions of nucleus accumbens, but not of olfactory tubercle, inhibit hypermotility induced by systemically administered AMPH $(0.5 \mathrm{mg} / \mathrm{kg}$; Clarke et al. 1988). This result is essentially opposite to that expected, as the response elicited by AMPH 0.5 $\mathrm{mg} / \mathrm{kg}$ or by dopaminergic stimulation of the olfactory tubercle is sensitive to $5-\mathrm{HT}_{2}$ antagonism.

Noncompetitive NMDA antagonists also induce hypermotility and stereotyped behavior (though of different behavioral characteristics than that of AMPH), and this model has been used in a few studies for evaluation of novel APDs. No marked differences between the potencies for inhibition of AMPH- or PCP-induced hypermotility in rats were found with remoxipride, sertindole, risperidone, clozapine, and haloperidol. The only difference was that remoxipride and sertindole were the only APDs showing PCP inhibition in the absence of suppression of spontaneous motor behavior (Jackson et al. 1994). In a study with mice, haloperidol and risperidone showed similar potencies for inhibition of apomorphine-induced climbing behavior and of dizocilpine-induced locomotion and falling, whereas clozapine and olanzapine were 10-fold more potent against dizocilpine (Corbett et al. 1995). The 5- $\mathrm{HT}_{2}$ antagonist ritanserin was ineffective in both studies.

The lack of effect of ritanserin is in contrast to results of two other studies in mice in which $5-\mathrm{HT}_{2}$ antagonists (ritanserin, ketanserin, and MDL 100.907) potently blocked the effect of PCP (Gleason and Shannon 1997). In this study, olanzapine and clozapine had PCP-antagonistic effects at doses below those affecting spontaneous locomotor activity. These results are consistent with those of Carlsson (1995) who showed that MDL 100.907 inhibited hypermotility induced by either dizocilpine, atropine, or the DA-uptake inhibitor GBR 12909 in mice.

Finally, Maurel-Remy et al. (1995) have reported that the $5-\mathrm{HT}_{2 \mathrm{~A}}$ antagonist MDL 100.907 as well as risperidone and clozapine are much more potent antagonists of PCP- than AMPH-induced hyperactivity in rats, whereas haloperidol is equipotent. However, the PCP dosage in this study was extremely high $(20 \mathrm{mg} / \mathrm{kg})$ compared with other studies. This high dose induces behavioral toxicity with no coordinated locomotor activity, questioning the specificity of inhibitory effect mediated by $5-\mathrm{HT}_{2}$ receptor antagonism. Furthermore, neurotoxicity, including formation of vacuoles, is produced by high doses of PCP and dizocilpine (Olney and Farber 1995; Farber et al. 1996), although the relation of this effect to behavioral changes is unknown.

Taken together, the acute hypermotility results are somewhat confusing and suggest that the efficacies of classic and novel APDs as well as $\alpha_{1}$-adrenoceptor and $5-\mathrm{HT}_{2}$ antagonists depend critically on the experimental conditions and on endogenous DA tone (challenge dose of behavioral stimulant, animal species, and possibly even strain). In particular, a critical analysis of the motor effect of the APD (when given alone) and the possible involvement of nonspecific behavioral toxicity that occurs with NMDA antagonists is warranted when interpreting results obtained with APDs. Certainly, the results illustrate the complex interaction between DA, 
noradrenaline, glutamate, and 5-HT systems for regulation of motor activity. Despite these limitations, we believe that characterization of novel APDs in the models discussed gives a wealth of useful information. However, direct comparison between compounds requires that the comparative studies be conducted under identical experimental conditions.

Another approach to the hypermotility models is the use of 2 weeks continuous intracerebral infusion of DA into the nucleus accumbens of rats in order to create a subchronic limbic DA hyperfunction. DA infusion leads to a complex hyperactivity pattern that is reversed by APDs. Limbic selectivity of the APD (given daily during the infusion period) is defined as an ability to prevent or normalize the hyperactivity to control levels, whereas suppression of motor activity below the level of vehicle controls is taken as evidence of nonselective depression of behavior. Furthermore, classic APDs generally induce a rebound hyperactivity after simultaneous withdrawal of DA and APD, which is not seen in control DA groups or after treatment with novel APDs. Sertindole has shown a high selectivity and potency in this model, whereas haloperidol and fluphenazine are nonselective. Clozapine inhibits the effect of DA, suppresses motor activity below baseline level, and fails to induce rebound hyperactivity, thus having an intermediate profile between sertindole and haloperidol (Costall et al. 1987; Domeney et al. 1994). No data are available for other novel APDs. Although this model is of potential interest due to its subchronic nature, it is poorly validated in terms of pharmacological characterization. Furthermore, the mechanism behind the rebound hyperactivity is not understood. Finally, there are only published results from a single laboratory, with a consequent need for confirmatory data from other sources.
Still another approach to differentiate between classic and novel APDs is that chosen by Cools, Ellenbroek, and colleagues (references, see below). These investigators measure cataleptic responses in rats separately in the fore- and hindpaws and have suggested each response to be an indicator of EPS and antipsychotic activity, respectively. Consistent with the previous discussion, haloperidol is equally effective in both measures, whereas the novel APDs (sertindole, risperidone, olanzapine, quetiapine) have 4- to 20 -fold selectivity on hindlimb retraction times (Cools et al. 1995; Ellenbroek et al. 1996a). There is evidence for complex interactions between DA, 5- $\mathrm{HT}_{1 \mathrm{~A}}, 5-\mathrm{HT}_{2}$ and $\alpha_{1}$-adrenergic receptors in the regulation of these effects (Prinssen et al. 1994). Thus, the paw model appears to give qualitatively similar differentiation between APDs as the previously discussed hypermotility/stereotypy models.

Acute EPS in Primates. The ability of APDs to induce acute dystonia and other neurological side effects in non-human primates is considered to be the most predictive model of EPS in humans. The expression of symptoms is varied and is closely analogous to those seen in humans. Furthermore, this model has a very high sensitivity when using monkeys sensitized to the dystonic effect of classical APDs by long-term treatment, as is illustrated by the high potency of haloperidol (Casey 1993)-see Table 8. Casey $(1993,1996 b)$ used the potency of haloperidol to develop a criterion for predicting the dose level producing EPS in schizophrenic patients by deriving a correlation between results in monkeys and the accepted dose-response of haloperidol for EPS (threshold and maximum effect) in the clinic. Multiplication of the minimal effective dystonic dose in the monkeys by this factor (200 and 800 to

Table 8. Acute Dystonic Reactions in Cebus Monkeys

\begin{tabular}{lccc}
\hline & $\begin{array}{c}\text { Dystonia Threshold } \\
\text { in Monkeys } \\
\text { MED }(\mu \mathbf{m o l} / \mathbf{k g}(\mathbf{m g} / \mathbf{k g}), \\
\text { i.m. or s.c. })^{f}\end{array}$ & $\begin{array}{c}\text { Clinical Dose Range } \\
\mathbf{m g} / \text { day PO }\end{array}$ & $\begin{array}{c}\text { Estimated EPS } \\
\text { Threshold in Humans } \\
\text { mg/day }\end{array}$ \\
\hline Sertindole & $1.1-2.3(0.5-1.0)^{b, d}$ & $12-24$ & $100-800$ \\
Clozapine & $>76(25)^{a}$ & $250-500$ & $>5000$ \\
Risperidone & $0.061(0.025)^{a}$ & $4-12$ & $5-20$ \\
Olanzapine & $0.51(0.16)^{i}$ & $10-20$ & $32-130$ \\
Quetiapine & $14(4)^{c}$ & $300-750 ?$ & $800-3200$ \\
Ziprasidone & $0.38(0.16)^{c}$ & $40-80 ?$ & $32-130$ \\
Remoxipride & $12(5.0)^{a}$ & $150-600$ & $1000-4000$ \\
Haloperidol & $0.067(0.025)^{a}$ & $5-20$ & $5-20$ \\
\hline
\end{tabular}

"Casey (1993). Dystonia-inducing threshold $(\mathrm{mg} / \mathrm{kg})$ is multiplied by a factor of 200-800 to give the dose range for induction of EPS by haloperidol.

${ }^{h}$ Casey $(1996 b)$.

Gerlach and Peacock (1995).

'Slight dystonia is observed at $1.1 \mathrm{mmol} / \mathrm{kg}, 24 \mathrm{~h}$ after administration, whereas moderate dystonia is induced within the first $6 \mathrm{~h}$ only at a dose of $2.3 \mathrm{mmol} / \mathrm{kg}$.

"Arnt and Halborg, unpublished observations.

$\mathrm{fmg} / \mathrm{kg}$ doses are indicated in parentheses.

For details of methods, please refer to the cited studies. 
obtain a dose range) gave valid predictions of EPS dose ranges for a number of marketed APDs. When this was done for novel APDs, it appeared that the antipsychotic dose-response curve could be dissociated from the EPS dose-response curve for some of the novel APDs.

Clozapine is the only known APD that does not induce dystonia and that accordingly should be free of EPS potential, whereas other novel APDs all have a potential to induce EPS at a certain dose level. However, large differences between potencies of novel APDs are apparent: sertindole has a large separation between predicted EPS dose and clinically effective dose (Casey 1996b). Olanzapine, quetiapine, and remoxipride are less selective but still have reasonable margins with respect to clinically studied doses (Gerlach and Peacock 1995) (Table 8), whereas it is predicted that risperidone (equipotent with haloperidol; Casey 1996b) and ziprasidone have little or no separation. It should be mentioned that the dystonia thresholds with olanzapine, quetiapine, and ziprasidone have been determined using a Cebus monkey colony at the laboratories of J. Gerlach in Denmark. These monkeys show a marginally higher sensitivity than those at D. Casey's site (Gerlach, personal communication; Gerlach and Peacock 1995) and may thus lead to a slight underestimation of EPS safety indexes for these compounds.

There are only few comparative reports on novel APDs in the literature. One study (Migler et al. 1993) showed very weak effects of quetiapine. Unfortunately it is difficult to compare the studies, because oral administration was used in the latter study versus subcutaneous or intramuscular injection in the studies shown in Table 8. The potencies after oral administration are to a large extent influenced by bioavailability, rate of absorption, and extent of metabolism-information that is not available for this species in the literature. Risperidone was the only other novel APD that was included in the latter study, but only one dose level was studied. In a more recent summary article from the same group, a complete series of novel APDs was investigated, but only qualitative results were shown, precluding any critical evaluation (Goldstein 1995). Quetiapine has also been administered weekly to drug-naive monkeys and induced negligible dystonia compared with that seen in a haloperidol-treated group (Migler et al. 1993).

The mechanism underlying the differences in dystonia-inducing potencies between novel APDs is not known, but it appears that all APDs with potent DA $D_{2}$ antagonistic actions induce dystonia. Dystonias are effectively reversed by additional treatment with a muscarinic antagonist, which is used as an antidote in the experiments if unacceptable dystonias develop. The muscarinic antagonism may thus contribute to the activity profile of clozapine and olanzapine. In contrast $5-\mathrm{HT}_{2}$ antagonism probably only weakly influences the response, as demonstrated by combination experiments with haloperidol and ritanserin (Casey 1995). Agonism at $5-\mathrm{HT}_{1 \mathrm{~A}}$ receptors can also diminish haloperidolinduced dystonia (loc. cit.). Although this effect has been proposed to be responsible for the lack of cataleptogenic effect of ziprasidone in rats (see previous section), this appears not to be of importance for the dystonia response in monkeys. No published evidence has evaluated the role of $\alpha_{1}$-adrenoceptor antagonism in the dystonia response, but our own unpublished studies of the combination of haloperidol and the $\alpha_{1}$-adrenoceptor antagonist aceperone do not suggest any reversal of haloperidol.

Vacuous Chewing Movements. Numerous studies have shown that long-term continuous or intermittent administration of classic APDs induce oral dyskinesias in rats, the so-called vacuous chewing movements (VCMs). It has been suggested that this behavior represents an animal model of tardive dyskinesia (Iversen et al. 1980; Glenthøj and Hemmingsen 1989). Very few studies have been conducted using novel APDs. Clozapine induces less vacuous chewing than haloperidol (See and Ellison 1990; Kakigi et al. 1995). Furthermore, preliminary studies have shown that continuous treatment with olanzapine and sertindole for 6 months in clinically relevant doses induces minimal vacuous chewing (Sakai et al. 1996). Although the extent to which VCMs are a model of tardive dyskinesia is uncertain, these results are encouraging. Long-term clinical experience will be required to determine if novel APDs actually induce less tardive dyskinesia than presently used APDs.

Conditioned Avoidance Responses. Only a few studies of novel APDs in rats are available for this model, which has been used for more than 25 years but apparently has declined somewhat in popularity. Conditioned avoidance responses are inhibited by all classes of APDs, including clozapine, and are from a mechanistic viewpoint sensitive to DA and $\alpha_{1}$-adrenoceptor antagonists as well as benzodiazepines (Arnt 1982; also, see review by Ellenbroek 1993). More recent studies confirm that remoxipride (Ögren and Archer 1994), olanzapine, quetiapine, risperidone, and ziprasidone also inhibit the response (Moore at al. 1992, 1993; Seeger et al. 1995). Inhibition of conditioned avoidance response by novel APDs is seen at doses below those inducing catalepsy, but close to those inhibiting hypermotility induced by DA stimulants and to doses depressing spontaneous locomotor activity. One study has confirmed the effect of risperidone on conditioned avoidance in the dog (Janssen et al. 1988). Another has shown effects of quetiapine in the Sidman avoidance paradigm in the monkey (Migler et al. 1993). For sertindole, unpublished observations show inhibitory effects in rats at high doses $(11-23 \mu \mathrm{mol} / \mathrm{kg})$. In conclusion, its low sensitivity to novel APDs questions the utility of 
this model. Because $\alpha_{1}$-adrenoceptor antagonists are effective inhibitors of the conditioned response, this mechanism is likely to contribute to the effects of novel APDs.

Operant Responding Patterns. It is well known that APDs can attenuate or suppress operant responding. A recent study compared the effects of classic and novel APDs on standard operant responding in rats (lever pressing for food reward) using two test variables, the overall response rate and the within-session response decrement (Sanger and Perrault 1995). The results indicate that all APDs decreased response rate dose-dependently, whereas only haloperidol and remoxipride, but not clozapine, sertindole, and risperidone, induced the within-session decrement. The meaning of this difference is unknown, but involvement of $5-\mathrm{HT}_{2}$ receptor blockade was excluded.

Another series of studies investigated the effect of APDs on lapping behavior (force, duration, and number of licks and lapping rhythm were measured). Furthermore, within-session decrements were studied. Haloperidol and clozapine were differentiated by effects on lick rhythm and within-session decrements (first parameter inhibited by clozapine, second by haloperidol). A follow-up study showed that olanzapine was similar to clozapine (Fowler and Das 1994; Das and Fowler 1996). Other novel APDs were not studied and accordingly the broader implications of the results are presently not known.

Social Interaction Studies. Deficits in social interaction between two animals induced by PCP or dizocilpine in rats have been suggested as models for the negative symptomatology of schizophrenia (Corbett et al. 1995; Sams-Dodd 1996). In the study by Corbett et al. (1995), acute administration of dizocilpine and APDs was used. Haloperidol was ineffective in reversing the effects of dizocilpine, whereas clozapine, olanzapine, and risperidone restored social behavior. The effect of risperidone was confounded by inhibition of motor activity. In a study by Sams-Dodd (1996), an automated model was used for measuring changes in active and passive social behavior as well as locomotor hyperactivity induced by PCP. Stereotypies were scored manually. Furthermore, repeated dosing of APDs and PCP were used to induce partial tolerance to the ataxic effects of PCP (while maintaining effects on social isolation) and to study the effects of APDs after treatment for 3 days or 3 weeks. Haloperidol did not reverse the deficits in social interaction induced by $\mathrm{PCP}$, whereas clozapine showed partial reversal in the absence of motor deficits. Studies of novel APDs have recently been completed in our laboratory. The results indicate that sertindole, risperidone, quetiapine, and remoxipride, but not olanzapine, to some extent reverse PCP-induced social isolation after daily treatment for 3 weeks, although none of the compounds normalize the rats to resemble control animals (Sams-Dodd 1997). Differences between the effects of the compounds were noted: quetiapine generally had weak effects, whereas risperidone affected the passive social interaction only. Furthermore, it should be noted that whereas olanzapine may be effective at higher doses, local toxicity precluded repeated administration of those. The relevance of the model for evaluation of negative symptomatology remains to be established.

AMPH failed to induce consistent social isolation in the rat models discussed previously (Corbett et al. 1995; Sams-Dodd 1996), but in Java monkeys AMPH-induced social isolation has been described (Ellenbroek 1991). Although only a few APDs have been studied for AMPH reversal, acute treatment with quetiapine and clozapine has recently been shown to reverse deficits induced by AMPH. It would be of considerable interest to perform comparative studies of the novel APDs (EIlenbroek et al. 1996a).

Drug Discrimination. The discriminative stimulus properties of AMPH in rats have previously been suggested to be a relevant animal model for evaluation of antipsychotic effects, because it detects the effects of classic APDs as well as clozapine (Nielsen and Jepsen 1985). Furthermore, the AMPH response is mediated by the limbic DA system: it can be elicited by local injection of AMPH into NAc (Nielsen and Scheel-Krüger 1986), and the response to systemic administration of AMPH is abolished by previous 6-OHDA lesion of NAc (Dworkin and Bimle 1989). The predictability of AMPH discrimination as a model of antipsychotic activity has, however, been questioned by the finding that sertindole is unable to inhibit the AMPH response even at high doses, whereas clozapine has the expected inhibitory effect (Arnt 1992). Subsequently, a series of novel APDs was studied (Table 9). It was found that these drugs differ in their ability to inhibit the AMPH stimulus effect: sertindole, quetiapine, and amperozide have no significant effects; remoxipride and risperidone have weak efficacies; whereas olanzapine and clozapine are more effective. Finally, the classic APDs completely block the AMPH response (Arnt 1996). It should, however, be mentioned that risperidone in another study of AMPH discrimination showed higher inhibitory activity, but no other novel APDs were included for comparison (Meert et al. 1990).

In parallel studies of DOI (a 5- $\mathrm{HT}_{2}$ agonist) and St 587 (an $\alpha_{1}$-adrenoceptor agonist) discrimination, sertindole showed marked and moderate antagonistic activity, respectively, corresponding to its inhibitory effects on these receptors (see in vitro and ex vivo sections). Other APDs also inhibited DOI and St 587 discrimination according to their effects on $5-\mathrm{HT}_{2}$ and $\alpha_{1}$-adrenoceptors, respectively (Arnt 1992, 1996).

Because several controlled clinical studies have con- 
firmed antipsychotic activity of both sertindole (e.g., Zimbroff et al. 1997) and quetiapine (e.g., Hirsch et al. 1996), it is obvious that AMPH discrimination is not an animal model of schizophrenia. Instead it has been suggested that the AMPH inhibition is a measure of inhibitory effects on the DA reward system and accordingly that the model may be relevant for evaluation of the so-called neuroleptic-induced deficit syndrome (for further discussion and references, see Arnt 1996; Brauer et al. 1997).

It would be interesting to study PCP or dizocilpine discrimination as an alternative model for detection of antipsychotic activity, but only a few data are available. Although it has been suggested that clozapine, but not haloperidol, can reverse dizocilpine discrimination, the relevant study lacked information on response rates necessary for evaluation of specificity (Corbett 1995).

Another application of drug discrimination is a mechanistic comparison of similarities between APDs. Clozapine is able to function as a discriminative stimulus, and it has been shown that olanzapine can generalize to clozapine within a narrow dose range, whereas haloperidol is ineffective (Moore et al. 1993). In another study (Hoenicke et al. 1992), risperidone failed to generalize to clozapine. The clozapine discrimination is complex, involving muscarinic antagonism as well as $5-\mathrm{HT}_{2}$ antagonism (Hoenicke et al. 1992; Nielsen 1988). Thus, it is not surprising that only close analogues to clozapine can mimic the response. A similar study has recently been performed in squirrel monkeys. It demonstrated that quetiapine can substitute for clozapine, olanzapine partially substituted, whereas risperidone, sertindole, and remoxipride failed to show generalization (Carey and Bergman 1997). These results confirm the differences in subjective effects of novel APDs. Furthermore, though clozapine and olanzapine appear to be very similar in rats, this is only partially so in monkeys, thus raising the possibility of species differences.

Table 9. Inhibitory Effects of APDs on the Discriminative Stimulus Properties of D-Amphetamine (AMPH; $1.0 \mathrm{mg} / \mathrm{kg}$, $\mathrm{IP})$ and the $5-\mathrm{HT}_{2}$ Agonist DOI $(0.63 \mathrm{mg} / \mathrm{kg}, \mathrm{IP})$

\begin{tabular}{lcc}
\hline & \multicolumn{2}{c}{ ED $_{50}\left(\mu\right.$ molkg,s.c. $^{\text {Compound (Treatment Time }}$} \\
\cline { 2 - 3 } before Test, h) & AMPH & DOI \\
\hline Sertindole (2) & $>23 \mathrm{~ns}$ & 0.076 \\
Clozapine (1) & 7.2 & 0.39 \\
Risperidone (2) & $>6.1$ & 0.23 \\
Olanzapine (2) & 5.9 & 0.088 \\
Quetiapine (0.5) & $>20 \mathrm{~ns}$ & $\mathrm{nt}$ \\
Amperozide (0.5) & $>2.9 \mathrm{~ns}$ & $\sim 0.5$ \\
Remoxipride (2) & $>47$ & $>23 . \mathrm{ns}$ \\
Haloperidol (2) & 0.30 & $\sim 0.4$
\end{tabular}

$\mathrm{ns}=$ Indicates no significant inhibition; $\mathrm{nt}=$ not tested.

Results are previously published (Arnt 1996). For details on methods, including data on latency times and response disruption, please refer to the original article.
It has recently been shown that olanzapine can function as a discriminative stimulus in rats, which generalizes to clozapine (Porter and Strong 1996). No information about receptor mechanisms are available.

Prepulse Inhibition (PPI) of Startle Response. Deficits in sensorimotor gating functions have been described in schizophrenic patients using the PPI of acoustic startle as model (for review, see Swerdlow et al. 1994a). Thus the model has construct validity for some aspects of the disease. The PPI of startle response can be modeled in experimental animals, most often by using acoustic stimuli. PPI is recorded by measuring the startle response to a short acoustic stimulus (=pulse) in the absence and presence of a smaller stimulus (=prepulse) presented 50 to $100 \mathrm{~s}$ before the startle stimulus. Animals showing normal PPI will show a significant decrease in startle amplitude upon prepulse pairing. Recent studies have explored the involvement of various neurotransmitter receptors on PPI as well as the effects of APDs on deficits in PPI induced by different agents, including DA agonists (apomorphine), noncompetitive NMDA antagonists (PCP or dizocilpine), and 5-HT agonists (DOI or 8-OH-DPAT). Few detailed studies have been performed, thus making it difficult to make firm statements on the comparative effects of novel APDs.

PPI-deficits induced by apomorphine can be reversed by both classic and novel APDs (clozapine, risperidone, olanzapine, and quetiapine); (Rigdon and Viik 1991; Swerdlow and Geyer 1993; Swerdlow et al. 1994b; Varty and Higgins 1995b; Rasmussen et al. 1997), though in some studies the effects of clozapine are confounded by marked inhibition of response amplitudes, thus questioning specificity (Rigdon and Viik 1991). A negative study has also been published (Varty and Higgins 1995b). The overall conclusion, however, is that compounds with marked antagonistic effects on DA receptors will reverse the effects of apomorphine.

Studies of classic APDs (usually haloperidol) have consistently failed to show reversal of PCP- or dizocilpine-induced deficits in PPI (Varty and Higgins 1995b; Hoffman et al. 1993; Wedzony et al. 1994; Swerdlow et al. 1996a), whereas the studies of clozapine have generated conflicting results. Some were unable to demonstrate reversal (Johansson et al. 1994; Hoffman et al. 1993; Varty and Higgins 1995b), whereas others found partial reversal at a single dose level (Bakshi et al. 1994; Wiley 1994; Swerdlow et al. 1996a). A partial response was also seen in a single study of olanzapine at a relatively high dose level (Bakshi and Geyer 1995), whereas risperidone was ineffective against PCP (Swerdlow et al. 1996a). Full reversal against dizocilpine has been obtained with risperidone and the $5-\mathrm{HT}_{2}$ antagonist ketanserin, though only one acute dose of each drug was studied (Varty and Higgins 1995a,b). Full reversal is also observed with remoxipride (Johansson et al. 1994) 
and quetiapine against PCP (Swerdlow et al. 1996a). The reversal induced by ketanserin was not confirmed in another interaction study of $\mathrm{PCP}$ and the $5-\mathrm{HT}_{2}$ antagonists ketanserin or ritanserin (Bakshi et al. 1994). No data for sertindole and ziprasidone are yet available, but ongoing studies in our laboratory suggest that sertindole, remoxipride, and quetiapine do not reverse PCP-induced deficits using a standard protocol of 3 days of daily treatment with the test compound and PCP (3 mg/kg/day; Arnt, unpublished observations).

These results suggest that the APD-induced reversals of PPI deficits induced by noncompetitive NMDA antagonists are not robust findings, and the partial responses and complex dose-response curves question the specificity of the effects. In several cases, these are confounded with nonspecific motor effects recorded as changes in the startle amplitude in the absence of the prepulse stimulus.

Deficits in PPI induced by the $5-\mathrm{HT}_{2}$ agonist $\mathrm{DOI}$ and the 5-HT releaser fenfluramine are readily reversed by risperidone and the selective $5-\mathrm{HT}_{2 \mathrm{~A}}$ antagonist $\mathrm{MDL}$ 100.907, whereas haloperidol and a $5-\mathrm{HT}_{2 \mathrm{C}}$ antagonist are ineffective (Varty and Higgins 1995b; Padich et al. 1996; Sipes and Geyer 1995b). This suggests a straightforward agonist/antagonist interaction at $5-\mathrm{HT}_{2 \mathrm{~A}}$ receptors, without contribution of DA systems. Similarly, 5- $\mathrm{HT}_{1 \mathrm{~A}}$ agonists (e.g., 8-OH-DPAT and buspirone) as well as $5-\mathrm{HT}_{1 \mathrm{~B}}$ agonists (RU 24969) reduce PPI, effects that can be reversed by antagonists at their respective sites (Sipes and Geyer 1995a; Rigdon and Weatherspoon 1992; Sipes and Geyer 1994).

Finally, it is relevant to mention that an interesting, nonpharmacological approach has been introduced in which deficits in PPI responses are demonstrated in untreated rats reared in social isolation, thus mimicking deficits in schizophrenic patients (Geyer et al. 1993; Varty and Higgins 1995b; Bristow et al. 1995). In the study of Varty and Higgins (1995b), haloperidol, clozapine, raclopride, and risperidone all reversed the isolation-induced deficits. However, only a single dose level was studied for each compound, making strict comparisons between relative efficacies of the compounds impossible (Varty and Higgins 1995b). In the other study, isolation-induced deficits were paradoxically reversed by the glycine/NMDA antagonist L-701.324 (Bristow et al. 1995). In addition to the incomplete nature of doseresponse curves, it should be mentioned that the magnitude of PPI deficits in rats reared in isolation is smaller than that induced by apomorphine, $\mathrm{PCP}$, or dizocilpine.

The effects on PPI deficits induced by PCP or dizocilpine are of potential interest, because this class of NMDA antagonists in humans induces a psychotic state consisting of positive as well as negative symptoms of schizophrenia (for references, see Sams-Dodd 1996). Thus, it will be interesting to see whether this approach can also be used to model part of the negative symptomatology. However, the differences between results obtained in different laboratories, particularly with clozapine, suggest that the model is highly sensitive to methodological differences, and thus comparative studies using identical experimental conditions are necessary to make fair comparisons between test compounds.

In conclusion, the concept of the PPI startle model is of potential interest, but important information is still lacking: no detailed studies of the effects of APDs in schizophrenic patients are available, and furthermore, no studies using subchronic APD treatment in animals have been published.

Latent Inhibition. Latent inhibition is defined as a retarded acquisition of a conditioned response that occurs if the subject being tested is preexposed to the same stimulus "to-be-conditioned" before the conditioning trials actually start. Thus, deficits in latent inhibition can be interpreted as reflecting an inability to ignore irrelevant stimuli and therefore shows some similarities to the above-mentioned prepulse startle response paradigm. Latent inhibition can be modeled in animals as well as in humans and has been shown to be deficient in schizophrenia (Feldon and Weiner 1991b), though some recent evidence has questioned this notion (Swerdlow et al. 1996b). Despite conceptual similarities, latent inhibition and prepulse startle inhibition are mediated by separate neuronal substrates (Ellenbroek et al. 1996b).

Latent inhibition is usually studied in rats by measuring the acquisition of a conditioned emotional response or conditioned taste aversion in the absence and presence of a series of unconditioned acoustic or visual preexposures. Using a low number of preexposures that do not induce latent inhibition in vehicle-treated rats, haloperidol and other classic APDs have consistently been shown to facilitate the response (Feldon and Weiner 1991a; Dunn et al. 1993), although there is controversy about the profile of clozapine. Some studies have failed to show positive effects of clozapine (Dunn et al. 1993), whereas three studies confirmed its efficacy (Feldon and Weiner 1991a; Moran et al. 1996; Weiner and Feldon 1994; Weiner et al. 1996). The discrepancy may be related to the disruptive effects of clozapine on the conditioned emotional response per se, leaving only a narrow dose range open for showing the positive effects. No systematic studies have been made with novel APDs, though a positive effect has been demonstrated with sertindole and MDL 100.907 at relatively high doses (Weiner et al. 1994; Moser et al. 1995).

The effects of antipsychotics can also be evaluated as a reversal of the deficits in latent inhibition induced by $\mathrm{AMPH}$, using a higher number of preexposures leading to maximum latent inhibition in the vehicle group. Such studies confirm that haloperidol, clozapine, sertindole, and MDL 100.907 prevent the AMPH-induced disruption (Moran et al. 1996; Warburton et al. 1994; Weiner et 
al. 1994; Moser et al. 1995). In conclusion, although the model detects classic and novel APDs, further work is needed to compare efficacies of the novel APDs with the classic compounds.

\section{OTHER BEHAVIORAL EFFECTS}

\section{Effects on Cognitive Responding}

Although the main focus in the search for novel APDs has been to diminish the EPS liability (as discussed earlier), the influence on cognitive function has been relatively neglected. In addition to the severe psychotic symptoms, schizophrenic patients often show impairment of cognitive function, i.e., compromised attention, associative abilities, judgment, concentration, planning ability, and memory. Although reports have suggested that memory deficits in schizophrenic patients could be drug-induced (Frith 1984) and that classic neuroleptics induce deficits in animals (Beatty and Rush 1983; Levin 1988), consensus has not been achieved. Recent reviews discussing results obtained within the last 5 years indicate that APDs have no marked effect on the deficits in working memory or secondary memory impairments in schizophrenic patients (Goldberg and Weinberger 1996). In contrast, some data do indicate an improvement in vigilance. In a review of 30 patient studies, Green and King (1996) concluded that there is poor consistency between the results of the studies, but a trend does suggest that there is an antipsychotic-induced improvement of cognitive function.

APDs have been reported to improve basic information processing in patients, but the medication effects are sensitive to different testing conditions (Cutmore and Beninger 1990). In memory tests including digit repetition, picture recall, and story repetition, chlorpromazine and thioridazine impaired short-term verbal memory, whereas trifluoperazine and haloperidol improved short-term verbal memory in schizophrenic patients. Immediate and long-term memory and visual short-term memory were unaffected by the medication (Eitan et al. 1992; Verdoux et al. 1995).

A recent review by Goldberg and Gold (1995) concluded that the cognitive measures are stable, independent of the medication status, and presumably a reflection of the clinical state. Additionally, cognitive impairment is not merely a function of psychotic symptomatology, as the BPRS scores (positive and negative) can be improved without a change in the cognitive rating, i.e., cognitive function constitutes a separate symptom dimension.

To gather comparative information on the effect of APDs on cognition in rats, we have tested the effect of haloperidol and novel APDs on spatial learning and memory in the Morris water maze (Morris 1984) and in a delayed nonmatch to position model, models for eval- uation of working and reference memory (Dunnett et al. 1988; Etherington et al. 1987; Didriksen 1995b).

Water Maze. In the water maze model, rats are encouraged to find a hidden platform beneath the water surface. Rats in the control group show a gradual decrease in escape latencies, whereas daily APD treatment $30 \mathrm{~min}$ before the swimming trials differentially influenced the performance. In general, three compounds were more or less inactive (sertindole, clozapine, and quetiapine) whereas risperidone, ziprasidone, and haloperidol significantly inhibited the spatial performance. Olanzapine significantly inhibited spatial performance after administration of high doses. The results are summarized in Table 10 (Skarsfeldt 1996).

Delayed Nonmatch to Position. In a test model for working memory, rats were tested in a visual-spatial version of the delayed nonmatching to position paradigm. Animals were first trained to perform the test until showing performance accuracy decreasing from $90-100 \%$ to approximately $60-70 \%$ correct responses with increasing delay time (delay from $0-9 \mathrm{~s}$ ). In general, APDs had marked inhibitory effects: risperidone and haloperidol potently decreased performance, whereas olanzapine, ziprasidone, and clozapine were somewhat weaker. Two compounds, sertindole and quetiapine, were inactive at the tested doses (Table 10) (Didriksen 1995b and unpublished results). Haloperidol, clozapine, and sertindole have also been studied after daily treatment for 3 weeks: haloperidol retained its marked inhibitory effect, whereas tolerance developed to the effect of clozapine. Sertindole induced no deficits, similar to the results obtained after acute administration (Didriksen and Sams-Dodd 1997). These results indicate that the depolarization blockade of DA neurons in the VTA seen after repeated treatment with APDs is unrelated to effects on cognitive performance.

Table 10. Effects of Antipsychotics in Two Rat Models of Cognition

\begin{tabular}{lcc}
\hline & \multicolumn{2}{c}{ MED $(\mu \mathrm{mol} / \mathrm{kg}$, s.c.) } \\
\cline { 2 - 3 } Compound & $\begin{array}{c}\text { Delayed Nonmatch } \\
\text { to Position }\end{array}$ & $\begin{array}{c}\text { Morris Water }^{\mathbf{M}} \\
\text { Maze }^{b}\end{array}$ \\
\hline Sertindole & $>5.7$ & $>5.7$ \\
Clozapine & 7.6 & $>31$ \\
Risperidone & 0.97 & 0.76 \\
Olanzapine & 4.0 & 8.0 \\
Quetiapine & $>40$ & $>11$ \\
Ziprasidone & 6.1 & 3.0 \\
Haloperidol & 0.11 & 0.11 \\
\hline
\end{tabular}

"Didriksen $1995 \mathrm{~b}$ and unpublished.

'Skarsfeldt 1996.

Some results are previously published, as indicated (Didriksen 1995b; Skarsteldt 1996). For details on methods, please refer to original articles. 
In conclusion, the present data suggest that several of the tested compounds (risperidone, ziprasidone, and haloperidol) more or less impair spatial learning in the water maze and working memory in the delayed nonmatching to position paradigm, whereas two of the novel APDs (sertindole and quetiapine) do not induce cognitive deficits. The reason for the pronounced effect of some of the compounds is unclear, but it is suggested that a marked DA $D_{2}$ receptor antagonism is mainly responsible for the impairment of responding. The differences might be of clinical significance as several of the novel APDs are weak or relatively weak $D A D_{2}$ receptor antagonists and hence might not aggravate the cognitive deficits often encountered in schizophrenic patients.

At present it is not known which human cognitive parameters correspond to these learning and memory functions in rats. The water maze is presumably a very stressful test model for the rats, and the stress level might influence the outcome of the test, suggesting that compounds possessing anxiolytic activity may indirectly improve spatial learning. However, diazepam does not improve performance in the maze. Instead, diazepam impairs acquisition (McNamara and Skelton 1991; Arolfo and Brioni 1991). In contrast, although the delayed nonmatch to position model is presumably less stressful, risperidone, ziprasidone, and haloperidol impair working memory at least as potently as observed in the water maze. The cognitive disturbances in schizophrenic patients are an important target for development of better APDs. However, the above-mentioned animal models have little chance to predict such effects, because cognitive performance is near optimal in normal rodents. Availability of animals with cognitive deficits relevant for schizophrenia will be of crucial importance for advances in this field of research. One such possibility is the model of neonatal hippocampal lesions (Weinberger and Lipska 1995) in which cognitive deficits have been described in the adult rats (Chambers et al. 1996).

\section{Anxiolytic Potential}

Anxiety and aggression are frequently accompanying symptoms in schizophrenic patients, and benzodiazepines are one of the most commonly used add-on treatments, both as anxiolytics and as sedative/hypnotics. Thus, an add-on anxiolytic effect of an APD might be desirable. Whereas classic APDs are generally ineffective in animal models of anxiety, some positive findings have been obtained with novel APDs, though only few studies are available.

In classic operant conflict procedures, clozapine and olanzapine have shown anxiolytic-like activity with a mechanism of action different from benzodiazepines (Moore et al. 1994; Wiley et al. 1993; Nanry et al. 1995), whereas risperidone and remoxipride are ineffective.
Selective antagonists at $5-\mathrm{HT}_{2}$ and muscarinic receptors are ineffective as well (Moore et al. 1994). Using Vogel's test (shock-induced suppression of drinking behavior), amperozide has anticonflict activity of similar magnitude to diazepam (Gustafsson and Christensson 1990a). Furthermore, clozapine and olanzapine have pronounced effects on conditioned freezing behavior induced by prior inescapable electric shock, whereas haloperidol is ineffective (Inoue et al. 1996).

Sertindole has no anticonflict activity. However, using alternative anxiolytic test models in mice and rats sertindole has potent effects: it markedly facilitates exploratory behavior in the light/dark exploration model (i.e., measuring the aversiveness of a highly illuminated test compartment in a free choice situation with a dark compartment of the text box), facilitates social interactions between unfamiliar rats in high-light conditions, and shows marked anxiolytic effects in the marmoset human threat test. At relatively high doses, sertindole inhibits aggressive behavior of mice kept in isolation (Sánchez et al. 1995). Facilitation of social behavior has been demonstrated by others for clozapine and risperidone, whereas haloperidol is ineffective (Corbett et al. 1993). In a follow-up to the sertindole study (Sánchez et al. 1995), a series of novel APDs and haloperidol was investigated in the light/dark exploration test in rats, for antiaggressive activity in isolated mice and for inhibition of shock-induced ultrasonic vocalization in rats (Sánchez and Arnt 1995). Haloperidol, clozapine, risperidone, olanzapine, quetiapine, and ziprasidone did not mimic the potent effect of sertindole in the light/ dark exploration test, whereas all compounds, except haloperidol, had antiaggressive effects. In the shockinduced ultrasonic vocalization test, sertindole was ineffective, haloperidol and ziprasidone had weak effects, whereas the remaining APDs showed reasonable inhibitory potencies.

It is not possible to deduce the mechanism behind these complex differences in anxiolytic profiles, but the studies suggest that the novel APDs may affect one or several symptoms of anxiety. They also suggest that the novel APDs comprise a heterogeneous group with respect to anxiolytic effects. Clinical experience is needed to confirm whether the effects seen in animals are relevant for treating anxiety in schizophrenic patients.

An important point for evaluation of a drug with anxiolytic potential is to demonstrate lack of abuse potential. This has been accomplished in the conditioned place preference paradigm for haloperidol, clozapine, risperidone, and sertindole, which all fail to induce preference or aversion. Rather they inhibit place preference induced by AMPH or metamphetamine (Hoffman and Donovan 1995a; Suzuki and Misawa 1995). Furthermore, remoxipride fails to sustain self-administration and rather attenuates AMPH self-administration (Amit and Smith 1991). 


\section{Antidepressant-like Activity}

In addition to anxiolytic co-medication, antidepressants are frequently combined with APDs as well. Very little evidence exists for positive or negative effects of classic and novel APDs in animal models of depression. This is probably related to the limited number of accepted models and to the theories favoring stimulation rather than inhibition of the limbic DA system to achieve antidepressant activity, using different treatment strategies (Willner et al. 1992). This is particularly shown in the chronic mild stress-induced anhedonia model in rats where DA agonists reverse anhedonia (Muscat et al. 1992), whereas DA antagonists can reverse the effects of an antidepressant (Willner et al. 1991, 1992) without having effect by themselves (Papp et al. 1996).

In the learned helplessness model of depression, a single study indicates that haloperidol and raclopride further enhance the deficits in shuttle-box responding following unavoidable shocks, whereas sertindole has a weak reversing ("antidepressant-like") activity in a narrow dose range and clozapine is ineffective (Christensen 1994). To our knowledge, other novel APDs have not been studied in this paradigm.

In the popular swim despair model devised by Porsolt, haloperidol increased (i.e., an effect opposite to antidepressants), whereas clozapine did not influence immobility time (Borsini et al. 1984; Kawashima et al. 1985). No published data are available for novel APDs.

Finally, a few comments on the model of differentialreinforcement-of-low-rate (DRL) responding in rats. This model is assumed to be a test of impulsivity and is able to detect effects of putative antidepressant treatments (drugs and electroconvulsive shock) (Seiden et al. 1985). Haloperidol and clozapine are ineffective (loc. cit.), though contrary evidence has been reported (Pollard and Howard 1986). Unpublished results show positive effects of sertindole (Richards and Seiden, personal communication), but the effect is probably related to its potent $5-\mathrm{HT}_{2}$ antagonistic activity, because selective $5-\mathrm{HT}_{2}$ antagonists are effective in the model as well (Marek et al. 1989).

Schedule-induced polydipsia is an acquired behavior that bears some resemblance to obsessive-compulsive disorders. Food-deprived rats receive food pellets at regular intervals during a 20 -min daily test session and develop excessive drinking behavior leading to consumption of more than the total daily need of water during this period. The acquisition of this behavior is inhibited by APDs, and it has been demonstrated that classic APDs have profound inhibitory effects on drinking, drinking efficiency as well as food reward, whereas clozapine and sertindole decrease only some patterns of the behavior. Risperidone has an intermediate activity profile (Didriksen and Christensen 1994; Didriksen 1995a). The clinical implications of this differentiation are not known, but it is hypothesized that the effects of classic APDs are related to their EPS potential. It is unclear whether the effects of novel APDs are a reflection of antipsychotic activity or suggest an additional effect on affective states.

\section{CLINICAL EXPERIENCE}

The ultimate question is whether the differences in pharmacological properties of classic and novel APDs are reflected in their clinical effects. It is premature to answer this question in depth presently, but some inferences can be made. Clinical findings from phase II and III clinical trials have recently been reviewed across novel APDs (Kerwin and Taylor 1996; Owens 1996).

\section{EPS Potential versus Clinical Efficacy on Positive Psychotic Symptoms}

The present consensus is that the efficacy against positive symptoms is similar for classic and novel APDs. Further, it appears that predictions of lower EPS risks from preclinical studies are correct for the novel APDs discussed in this article.

Clozapine is the only APD predicted to be free of EPS. It is accepted that clozapine has low EPS liability, although not necessarily nonoccurring (see review, Casey 1996c). In animal models of EPS, risperidone has shown an intermediate activity profile between haloperidol and clozapine. EPS occurs dose-dependently in clinical studies at the higher dose levels (above $10 \mathrm{mg}$ / day), although there may be a narrow dose range (less than $10 \mathrm{mg} /$ day) in which risperidone induces less EPS than haloperidol (Chouinard et al. 1993; Marder and Meibach 1994; Peuskens 1995; Song 1997). However, the dose-response studies with risperidone were made using a single, relatively high dose of haloperidol (10 or $20 \mathrm{mg}$ / day) as the comparator. Thus, strict comparisons between drugs are difficult, particularly with respect to EPS.

Sertindole phase III trials have recently been completed showing a clinically effective dose range between 12 and $24 \mathrm{mg} /$ day. In no instance did EPS frequency and severity differ from that of placebo-treated patients (van Kammen et al. 1996; Dunn and Fitton 1996; Tamminga and Lahti 1996; Wehnert et al. 1997). The most rigorous evaluation of sertindole is provided in a 7-arm placebo controlled study, consisting of three doses of sertindole $(12,20$, and $24 \mathrm{mg}$ /day), three doses of haloperidol $(4,6$, and $16 \mathrm{mg} /$ day) and placebo. All active treatment groups had significantly greater improvement from baseline to final evaluation on the total PANSS score compared to placebo. The incidence of EPS seen for sertindole is indistinguishable from placebo across the range of doses (12-24 mg/day), whereas 
all dose groups of haloperidol showed significantly more EPS compared to placebo and sertindole (Zimbroff et al. 1997; Tamminga and Lahti 1996). The efficacy of sertindole was maintained in a 1-year study (Swann et al. 1997).

In our preclinical evaluation, olanzapine is predicted to induce less EPS than risperidone, although it still shows significantly more acute DA-blocking activity than clozapine, sertindole, ziprasidone, and quetiapine. However, the first published controlled trial of olanzapine ( 1 and $10 \mathrm{mg} /$ daily) versus placebo did not reveal EPS different from placebo (Beasley et al. 1996a). In a subsequent large phase III study of olanzapine in daily doses of 2.5-7.5 mg, 7.5-12.5 mg, and 12.5-17.5 mg versus haloperidol 10-20 mg or placebo, the same conclusion was reached (Beasley et al. 1996b). Clinical efficacy of olanzapine was achieved at the two higher doses. However, it appeared that the consumption of anticholinergic EPS medication tended to increase dose-dependently with olanzapine, though it was still less frequently used than in haloperidol-treated patients. Very recently, the results of an even larger phase III trial have been published, reaching the same conclusions (Tollefson et al. 1997a). The published results, together with preliminary findings, have recently been reviewed (Fulton and Goa 1997). In addition, a few additional results deserve mention. The predicted difference in EPS rates between olanzapine and risperidone has now been confirmed in a controlled trial (Tollefson et al. 1997b). Finally, in a 1-year study compared with haloperidol, relapse rate is lower with olanzapine treatment (Weiden et al. 1996).

Quetiapine has shown antipsychotic efficacy at daily doses of $150-750 \mathrm{mg} /$ day. So far EPS have been reported to be at placebo level. No full articles are available to evaluate the findings that until now have only been presented at meetings (for reviews, see Hirsch et al. 1996; Casey 1996a, and a recent abstract, Rak and Arvanitis 1997).

Clinical studies of ziprasidone are limited to poster presentations (for review, see Kerwin and Taylor 1996). Ziprasidone has demonstrated antipsychotic activity at dose levels between 80 and $160 \mathrm{mg} /$ day, with low EPS frequency.

Although remoxipride is no longer on the market it should be mentioned that it-as predicted from preclinical studies-induced less EPS than classical APDs in equieffective doses in controlled clinical trials (review by Lewander et al. 1990; Owens 1996). Whether remoxipride is comparable to some of the other novel APDs in showing EPS at placebo level is likely, but cannot be answered due to lack of appropriate placebo-controlled clinical trials.

So far there is no evidence for differences in the timecourse of antipsychotic activity between classic and novel APDs. Thus, a decrease of the time to maximal antipsychotic effect still remains an attractive goal for continued drug development.

In conclusion, there is consistency between animal and human data for positive symptom efficacy and EPS, except that to date clinical trials have not demonstrated any differences among sertindole, olanzapine, and quetiapine. However, it should be mentioned that animal studies usually cover a larger dose range than the clinical studies and thereby increase the chance of finding differences between drugs with roughly similar profiles.

\section{Negative and Affective Symptoms and Effects in Patients Refractory to Classic APDs}

Drugs with effects on negative symptoms of schizophrenia are highly needed in the therapeutic armamentarium. Controlled studies of novel APDs indicate that risperidone, olanzapine, sertindole, and quetiapine all decrease PANSS (negative symptom subscale) or SANS ratings significantly in comparison with placebo, whereas haloperidol is ineffective (see references in previous section). The closest preclinical relation is to the reversal of PCP-induced social isolation in rats (Sams-Dodd 1996). The only failure in the prediction of clinical response from animal studies is olanzapine, and this may have been due to insufficient dosing.

It is difficult to distinguish effects on primary negative symptoms from indirect effects due to reduction of positive symptomatology and lack of induction of EPS. It is still debated whether the effects of clozapine on negative symptoms are direct or indirect (Owens 1996), and the same holds for patients treated with risperidone. From a path analysis of the results of the North American risperidone study, there is evidence that both direct and indirect effects of risperidone are involved in the decrease in negative symptoms (Möller et al. 1995). Other studies show only marginal effects of risperidone (metaanalysis by Carman et al. 1995). For sertindole and olanzapine, path analyses on phase III data also indicate an effect on primary negative symptoms (Lahti et al. 1997; Tollefson and Sanger 1997). However, large studies of patients with primary negative symptomatology are yet to be completed with novel APDs. Therefore, final conclusions on the comparative efficacies of novel APDs cannot yet be made.

The same lack of information on effects of novel APDs in patients refractory to the effects of classic APDs precludes any inferences on the promise of the novel APDs compared with the efficacy of clozapine (Kane et al. 1988; Jalenques 1996). Recent results suggest that risperidone has some efficacy in treatment-resistant patients: equal efficacy to clozapine was suggested in a pilot study (Bondolfi et al. 1996), whereas recent abstracts suggest that risperidone has intermediate efficacy compared with clozapine and classic APDs (Flynn et al. 1997; Ames et al. 1997). In contrast, the first dou- 
Table 11. Summary of Gross Activity Profiles of Haloperidol and Novel APDs in Animal Models

\begin{tabular}{|c|c|c|c|c|c|}
\hline Compound & $\begin{array}{l}\text { VTA/SNC } \\
\text { Selective }\end{array}$ & $\begin{array}{c}\text { AMPH Motility: } \\
\text { Selectivity vs. Stereotypy } \\
\text { and Catalepsy }\end{array}$ & $\begin{array}{c}\text { Dystonia } \\
\text { Primates, Inactive }\end{array}$ & $\begin{array}{l}\text { AMPH Discrim. } \\
\text { Lack of Inhib. }\end{array}$ & $\begin{array}{c}\text { Cognition } \\
\text { Lack of Inhib. }\end{array}$ \\
\hline Sertindole & v & $\sqrt{ }$ & $(\sqrt{ })$ & $\sqrt{ }$ & $\checkmark$ \\
\hline Clozapine & $\sqrt{ }$ & $\sqrt{ }$ & $\sqrt{ }$ & No & $(\sqrt{ })$ \\
\hline Risperidone & No & $(\sqrt{ })$ & No & $(\sqrt{ })$ & No \\
\hline Olanzapine & $\sqrt{ }$ & $(\sqrt{ })$ & $(\sqrt{ })$ & No & No \\
\hline Quetiapine & No or $\sqrt{ }$ & $?$ & $(\sqrt{ })$ & $\sqrt{ }$ & $(\sqrt{ })$ \\
\hline Ziprasidone & No & $\sqrt{ }$ & No & $?$ & No \\
\hline Amperozide & $(\sqrt{ })$ & $\sqrt{ }$ & $?$ & $\sqrt{ }$ & $?$ \\
\hline Remoxipride & $\sqrt{ }$ & $(\sqrt{ })$ & No & $(\sqrt{ })$ & $?$ \\
\hline Haloperidol & No & No & No & No & No \\
\hline
\end{tabular}

\footnotetext{
$V^{\prime}=$ favorable profile; $(\sqrt{ })=$ partially favorable profile; No = unfavorable profile with respect to each target effect (antipsychotic activity, EPS, and cognitive disturbances); ? = data are not available.

The evaluation is based on previous tables in this article and includes mainly results from our own laboratories. The statements indicate that haloperidol in all models has an unfavorable profile, whereas novel APDs show large variations in activity patterns.
}

ble-blind study of olanzapine versus chlorpromazine in refractory patients does not suggest a clozapine-like efficacy (Conley et al. 1997).

Few controlled studies are available with the novel APDs in affective disorders, but recent data show superiority to haloperidol for risperidone on anxiety items (Blin et al. 1996) and for olanzapine against haloperidol in depression ratings in schizoaffective patients (Tollefson et al. 1997c). These results confirm preclinical findings summarized in the anxiety and depression sections, but it is too early to judge about similarities and differences between the novel APDs.

\section{CONCLUSIONS}

This review indicates that it is inappropriate to divide APDs into two homogenous groups, the classic and novel APDs. Rather, each novel APD has its own specific pharmacological profile, ultimately determined by its effects on a variety of targets in the brain. The novel APDs discussed in this review have both similarities as well as differences in the spectrum of receptors they influence and in the balance between the relative affinities and potencies. Most of the novel APDs affect multiple receptors, with the exception of remoxipride. The promising preclinical profile of this, unfortunately withdrawn, drug remains impossible to explain.

An important point is to accept that very different results for the same APD can be obtained in a range of animal models of psychosis and EPS, even though these models are widely accepted as being of reasonable predictive validity. Thus, it is problematic to select a drug for clinical development based only on a few models. To illustrate this, we have summarized the APD profiles roughly in Table 11 for some of the important models in which comparative studies of the APDs have been made in our laboratories. This table illustrates that each
APD has its own pharmacological "fingerprint." It also illustrates that clozapine and sertindole across most models have similar pharmacological profiles, whereas the remaining compounds show variable outcomes. In some models the compounds are suggested to show limbic and/or cortical selectivity, whereas other models suggest nonselective profiles.

It is very satisfying that the accumulated clinical evidence (see previous section) largely confirms the predictions made from animal studies that the novel APDs are effective antipsychotics with less or no EPS compared with classic APDs. Nevertheless, much remains to be learned about subtle clinical differences between the novel APDs, particularly on specific patient groups, i.e., those with predominant negative symptoms, patients refractory to classic APDs, patients with cognitive disturbances, as well as anxiety and depression, etc. Furthermore, differences in the spectrum of side effects may show up when larger patient populations have been studied.

\section{ACKNOWLEDGMENTS}

We thank Drs. John Hyttel, Frank Sams-Dodd, Michael Didriksen, and Hanne Bak for helpful comments and Ms. Hanne Albertsen for excellent secretarial assistance.

\section{REFERENCES}

Aghajanian GK (1978): Feedback regulation of central monoaminergic neurons: evidence from single cell recording studies. In Youdin MBH, Lovenberg W, Sharman DF, Lagnado JR (eds), Essays in Neurochemistry and Neuropharmacology. New York, John Wiley \& Sons, pp 1-228

Ames D, Wirshing WC, Marshall BD, Green MF, McGurk SR, Mintz J, Marder SR (1997): Risperidone vs. haloperi- 
dol in treatment resistant schizophrenia. Schizophr Res 24:193

Amit Z, Smith BR (1991): Remoxipride, a specific D2 dopamine antagonist: An examination of its self-administration liability and its effects on d-amphetamine selfadministration. Pharmacol Biochem Behav 41:259-261

Arnt J, Christensen AV, Hyttel J (1981): Differential reversal by scopolamine of effects of neuroleptics in rats. Relevance for evaluation of therapeutic and extrapyramidal side-effect potential. Neuropharmacology 20:1331-1334

Arnt J (1982): Pharmacological specificity of conditioned avoidance response inhibition in rats: Inhibition by neuroleptics and correlation to dopamine receptor blockade. Acta Pharmacol Toxicol 51:321-329

Arnt J, Hyttel J, Bach-Lauritzen T (1986): Further studies of the mechanism behind scopolamine-induced reversal of antistereotypic and cataleptogenic effects of neuroleptics in rats. Acta Pharmacol Toxicol 59:319-324

Arnt J (1987): Behavioral studies of dopamine receptors: Evidence for regional selectivity and receptor multiplicity. In Creese I, Fraser CM (eds), Structure and Function of Dopamine Receptors. New York, Alan R. Liss, pp 199-231

Arnt J, Bøgesø KP, Boeck V, Christensen AV, Dragsted N, Hyttel J, Skarsfeldt T (1989): In vivo pharmacology of irindalone, a 5-HT2 receptor antagonist with predominant peripheral effects. Drug Dev Res 16:59-70

Arnt J (1992): Sertindole and several antipsychotic drugs differentially inhibit the discriminative stimulus effects of amphetamine, LSD and St 587 in rats. Behav Pharmacol 3:11-18

Arnt J (1995): Differential effects of classical and newer antipsychotics on the hypermotility induced by two dose levels of d-amphetamine. Eur J Pharmacol 283:55-62

Arnt J (1996): Inhibitory effects on the discriminative stimulus properties of D-amphetamine by classical and newer antipsychotics do not correlate with antipsychotic activity. Relation to effects on the reward system? Psychopharmacology 124:117-125

Arnt J, Christensen AV (1981): Differential reversal by scopolamine and THIP of the antistereotypic and cataleptic effects of neuroleptics. Eur J Pharmacol 69:107-111

Arnt J, Hyttel J (1986): Inhibition of SK \& F 38393- and pergolide-induced circling in rats with unilateral 6-OHDA lesion is correlated to dopamine D-1 and D-2 receptor affinities in vitro. J Neural Transm 67:225-240

Arolfo MP, Brioni JD (1991): Diazepam impairs place learning in the Morris water maze. Behav Neural Biol 55:131136

Ashby CR, Wang RY (1996): Pharmacological actions of the atypical antipsychotic drug clozapine-a review. Synapse 24:349-394

Bakshi VP, Swerdlow NR, Geyer MA (1994): Clozapine antagonizes, phencyclidine-induced deficits in sensorimotor gating of the startle response. J Pharmacol Exp Ther 271:787-794

Bakshi VP, Geyer MA (1995): Antagonism of phencyclidineinduced deficits in prepulse inhibition by the putative atypical antipsychotic olanzapine. Psychopharmacology 122:198-201
Baldessarini RJ, Huston-Lyons D, Campbell A, Marsh E, Cohen BM (1992): Do central antiadrenergic actions contribute to the atypical properties of clozapine? Br J Psychiatry 160:12-16

Baldessarini RJ, Frankenburg FR (1991): Drug therapyClozapine-A novel antipsychotic agent. N Engl J Med 324:746-754

Bean AJ, Roth RH (1991): Effects of haloperidol administration on in vivo extracellular dopamine in striatum and prefrontal cortex after partial dopamine lesions. Brain Res 549:155-158

Beasley CM, Sanger T, Satterlee W, Tollefson G, Tran P, Hamilton S, and The Olanzapine HGAD Study Group (1996a): Olanzapine versus placebo-Results of a doubleblind, fixed-dose olanzapine trial. Psychopharmacology 124:159-167

Beasley CM, Tollefson G, Tran P, Satterlee W, Sanger T, Hamilton $S$, and The Olanzapine HGAD Study Group (1996b): Olanzapine versus placebo and haloperidolAcute phase results of the north american double-blind olanzapine trial. Neuropsychopharmacology 14: 111-123

Beatty WW, Rush JR (1983): Spatial working memory in rats: Effects of monoaminergic antagonists. Pharmacol Biochem Behav 18:7-12

Bench CJ, Lammertsma AA, Grasby PM, Dolan RJ, Warrington SJ, Boyce M, Gunn KP, Brannick LY, Frackowiak RSJ (1996): The time course of binding to striatal dopamine D-2 receptors by the neuroleptic ziprasidone (CP-88,059-01) determined by positron emission tomography. Psychopharmacology 124:141-147

Bischoff S, Christen P, Vassout A (1988): Blockade of hippocampal dopamine (DA) receptors: A tool for antipsychotics with low extrapyramidal side effects. Prog Neuropsychopharmacol Biol Psychiatry 12:455-467

Blanc G, Trovero F, Vezina P, Hervé D, Godeheu A-M, Glowinski J, Tassin J-P (1994): Blockade of prefrontocortical alpha1-adrenergic receptors prevents locomotor hyperactivity induced by subcortical D-amphetamine injection. Eur J Neurosci 6:293-298

Blin O, Azorin JM, Bouhours P (1996): Antipsychotic and anxiolytic properties of risperidone, haloperidol, and methotrimeprazine in schizophrenic patients. J Clin Psychopharmacol 16:38-44

Blum PS, Robisch DM (1989): Effect of haloperidol (HAL) and risperidone (RIS) on dopaminergic (DA) neurons: Change in spontaneous activity and reversal of apomorphine (APO)-induced inhibition. Soc Neurosci Abstracts 15:1000

Bondolfi G, Baumann P, Dufour H (1996): Treatment-resistant schizophrenia-Clinical experience with new antipsychotics. Eur Neuropsychopharmacol 6(suppl. 2):S21-S25

Borsini F, Nowakowska E, Samanin R (1984): Effect of repeated treatment with desipramine in the behavioral "despair" test in rats: Antagonism by "atypical" but not "classical" neuroleptics or antiadrenergic drugs. Life Sci $34: 1171-1176$

Brauer LH, Goudie AJ, de Wit H (1997): Dopamine ligands and the stimulus effects of amphetamine: Animal models vs. human laboratory data. Psychopharmacology 130:2-13

Bristow LJ, Landon L, Saywell KL, Tricklebank MD (1995): 
The glycine/NMDA receptor antagonist, L-701,324 reverses isolation-induced deficits in prepulse inhibition in the rat. Psychopharmacology 118:230-232

Buchanan RW (1995): Clozapine-Efficacy and safety [review]. Schizophr Bull 21:579-591

Bunney BS, Walters JR, Roth RH, Aghajanian GK (1973): Dopaminergic neurons: Effect of antipsychotic drugs and amphetamine on single cell activity. Pharmacol Exp Ther 185: 560-571

Bunney BS, Aghajanian GK (1975): Antipsychotic drugs and central dopaminergic neurons: A model for predicting therapeutic efficacy and incidence of extrapyramidal side effects. In Sudilovsky A, Gershon S, Beer B (eds), Predictability in Psychopharmacology: Preclinical and Clinical Correlations. New York, Raven Press, pp 225-245

Bunney BS, Grace AA (1978): Acute and chronic haloperidol treatment: Comparison of effects on nigral dopaminergic cell activity. Life Sci 23:1715-1728

Busatto GF, Pilowsky LS, Costa DC, Ell PJ, Verhoeff NPLG, Kerwin RW (1995): Dopamine D-2 receptor blockade in vivo with the novel antipsychotics risperidone and remoxipride-an I-123-IBZM single photon emission tomography (spet) study. Psychopharmacology 117:55-61

Busatto GF, Kerwin RW (1997): Perspectives on the role of serotonergic mechanisms in the pharmacology of schizophrenia. J Psychopharmacol 11:3-12

Bymaster FP, Calligaro DO, Falcone JF, Marsh RD, Moore NA, Tye NC, Seeman P, Wong DT (1996a): Radioreceptor binding profile of the atypical antipsychotic olanzapine. Neuropsychopharmacology 14:87-96

Bymaster FP, Hemrickluecke SK, Perry KW, Fuller RW (1996b): Neurochemical evidence for antagonism by olanzapine of dopamine, serotonin, alpha $a_{1}$-adrenergic and muscarinic receptors in vivo in rats. Psychopharmacology 124:87-94

Carey GJ, Bergman J (1997): Discriminative-stimulus effects of clozapine in squirrel monkeys: Comparison with conventional and novel antipsychotic drugs. Psychopharmacology 132:261-269

Carlsson A, Lindquist M, Fuxe K, Hamberger G (1966): The effect of $(+)$-amphetamine on various central and peripheral catecholamine-containing neurones. J Pharm. Pharmacol 18:128-130

Carlsson ML (1995): The selective $5-\mathrm{HT}_{2 \mathrm{~A}}$ receptor antagonist MDL 100,907 counteracts the psychomotor stimulation ensuing manipulations with monoaminergic, glutamatergic or muscarinic neurotransmission in the mouse-Implications for psychosis. J Neural Transm 100:225-237

Carman J, Peuskens J, Vangeneugden A (1995): Risperidone in the treatment of negative symptoms of schizophrenia-A meta-analysis. Int Clin Psychopharmacol 10: 207-213

Casey DE (1993): Serotonergic and dopaminergic aspects of neuroleptic-induced extrapyramidal syndromes in nonhuman primates. Psychopharmacology 112:55-59

Casey DE (1995): The nonhuman primate model: Focus on dopamine D2 and serotonin mechanisms. In Fog R, Gerlach J, Hemmingsen R (eds), Schizophrenia, Alfred Benzon Symposium 38. Copenhagen, Munksgaard, pp 287-297
Casey DE (1996a): Seroquel (quetiapine): Preclinical and clinical findings of a new atypical antipsychotic. Expert Opinion Investigational Drugs 5:939-957

Casey DE (1996b): Behavioral effects of sertindole, risperidone, clozapine and haloperidol in cebus monkeys. Psychopharmacology 124:134-140

Casey DE (1996c): Side effect profiles of new antipsychotic agents. J Clin Psychiatry 57:40-45

Chambers RA, Moore J, Mcevoy JP, Levin ED (1996): Cognitive effects of neonatal hippocampal lesions in a rat model of schizophrenia. Neuropsychopharmacology 15:587-594

Chiodo LA, Bunney BS (1983): Typical and atypical neuroleptics: Differential effects of chronic administration on the activity of A9 and A10 midbrain dopaminergic neurons. J Neurosci 3:1607-1619

Chiodo LA, Bunney BS (1985): Possible mechanisms by which repeated clozapine administration differentially affects the activity of two subpopulations of midbrain dopamine neurons. J Neurosci 5:2539-2544

Chouinard G, Jones B, Remington G, Bloom D, Addington D, MacEwan GW, Labelle A, Beauclair L, Arnott W (1993): A Canadian multicenter placebo-controlled study of fixed doses of risperidone and haloperidol in the treatment of chronic schizophrenic patients. J Clin Psychopharmacol 13:25-40

Christensen AV (1994): Learned helplessness: An animal model of depression? In Palomo T, Archer T, Beninger R (eds), Strategies for Studying Brain Disorders. Madrid, Editorial Complutense, pp 33-53

Clarke PBS, Jakubovic A, Fibiger HC (1988): Anatomical analysis of the involvement of mesolimbocortical dopamine in the locomotor stimulant actions of $d$-amphetamine and apomorphine. Psychopharmacology 96:511-520

Conley RR, Tamminga CA, Beasley C (1997): Olanzapine vs. chlorpromazine in therapy-refractory schizophrenia. Schizophr Res 24:190

Cools AR, Prinssen EPM, Ellenbroek BA, Heeren DJ (1994): Role of olfactory tubercle and nucleus accumbens in the effects of classical and atypical neuroleptics: Search for regional specificity. In Palomo T, Archer T, Beninger R (eds), Strategies for Studying Brain Disorders. Madrid, Editorial Complutense, pp 33-53

Cools AR, Prinssen EPM, Ellenbroek BA (1995): The olfactory tubercle as a site of action of neuroleptics with an atypical profile in the paw test-Effect of risperidone, prothipendyl, org 5222, sertindole and olanzapine. Psychopharmacology 119:428-439

Corbett R, Hartman H, Kerman LL, Woods AT, Strupczewski JT, Helsley GC, Conway PC, Dunn RW (1993): Effects of atypical antipsychotic agents on social behavior in rodents. Pharmacol Biochem Behav 45:9-17

Corbett R, Camacho F, Woods AT, Kerman LL, Fishkin RJ, Brooks K, Dunn RW (1995): Antipsychotic agents antagonize non-competitive n-methyl-d-aspartate antagonist induced behaviors. Psychopharmacology 120:67-74

Corbett R (1995): Clozapine but not haloperidol antagonizes an MK-801 discriminative stimulus cue. Pharmacol Biochem Behav 51:561-564

Costall B, Domeney AM, Naylor RJ, Tyers MB (1987): Effects of the $5-\mathrm{HT}_{3}$ receptor antagonist, GR38032F, on raised 
dopaminergic activity in the mesolimbic system of the rat and marmoset brain. Br J Pharmacol 92:881-894

Coward DM (1991): Pharmacological approaches to the development of atypical antipsychotics. Schizophr Res 1:297305

Coward DM (1992): General pharmacology of clozapine. Br J Psychiatry 160:5-11

Cutmore THR, Beninger RJ (1990): Do neuroleptics impair learning in schizophrenic patients? Schizophr Res 3: 173-186

Das S, Fowler SC (1996): Similarity of clozapines and olanzapines acute effects on rats lapping behavior. Psychopharmacology 123:374-378

Deutch AY, Moghaddam B, Innis RB, Krystal JH, Aghajanian GK, Bunney BS, Charney DS (1991): Mechanisms of action of atypical antipsychotic drugs-Implications for novel therapeutic strategies for schizophrenia. Schizophr Res 4:121-156

Deutch AY, Lee MC, Iadarola MJ (1992): Regionally specific effects of atypical antipsychotic drugs on striatal fos expression: The nucleus accumbens shell as a locus of antipsychotic action. Mol Cell Neurosci 3:332-341

Deutch A (1992): The regulation of subcortical dopamine systems by the prefrontal cortex: Interactions of central dopamine systems and the pathogenesis of schizophrenia. J Neural Transm Suppl. 36:61-89

Deutch AY, Duman RS (1996): The effects of antipsychotic drugs on fos protein expression in the prefrontal cortex-Cellular localization and pharmacological characterization. Neuroscience 70:377-389

Di Chiara G, Imperato A (1985): Rapid tolerance to neuroleptic-induced stimulation of dopamine release in freely moving rats. J Pharmacol Exp Ther 235:487-494

Didriksen M (1995a): The effect of risperidone on scheduleinduced polydipsia. Behav Pharmacol 6:290-292

Didriksen M (1995b): Effects of antipsychotics on cognitive behaviour in rats using the delayed non-match to position paradigm. Eur J Pharmacol 281:241-250

Didriksen M, Christensen AV (1994): The effects of amphetamine, phencyclidine, dopaminergic antagonists and atypical neuroleptics on schedule-induced polydipsia (SIP) are distinguishable. Behav Pharmacol 5:32-41

Didriksen M, Sams-Dodd F (1997): Effects of haloperidol, clozapine, and sertindole on cognitive function in rats after chronic treatment. Soc Neurosci Abstracts 23, 1932

DiPaola ED, Richelson E (1990): Cardiovascular effects of neurotensin and some analogs on rats. Eur J Pharmacol $175: 279-283$

Domeney AM, Arnt J, Costall B, Naylor RJ, Sánchez C, Smith AG (1994): Effect of sertindole on raised mesolimbic dopaminergic activity in the rat. Drug Dev Res 31:175-185

Doucet J-P, Nakabeppu Y, Bedard PJ, Hope BT, Nestler EJ, Jasmin BJ, Chen J-S, Iadarola MJ, St-Jean M, Wigle N, Blanchet P, Grondin R, Robertson GS (1996): Chronic alterations in dopaminergic neurotransmission produce a persistent elevation of FosB-like protein(s) in both the rodent and primate stratum. Eur J Neurosci 8:365-381

Dragunow M, Robertson GS, Faull RLM, Robertson HA, Jansen $K$ (1990): $D_{2}$ dopamine receptor antagonists induce fos and related proteins in rat striatal neurons. Neuroscience 37:287-294.

Dunn CJ, Fitton A (1996): Sertindole. CNS Drugs 5:224-230

Dunn LA, Atwater GE, Kilts CD (1993): Effects of antipsychotic drugs on latent inhibition: Sensitivity and specificity of an animal behavioral model of clinical drug action. Psychopharmacology 112:315-323

Dunnett SB, Evenden JL, Iversen SD (1988): Delay-dependent short-term memory deficits in aged rats. Psychopharmacology 96:174-180

Dworkin S, Bimle C (1989): 6-Hydroxydopamine lesions of the nucleus accumbens attenuate the discriminative stimulus effects of amphetamine. Drug Dev Res 16:435-441

Eitan N, Levin Y, Ben-Artzi E, Levy A, Neumann M (1992): Effects on antipsychotic drugs on memory functions in schizophrenic patients. Acta Psychiatr Scand 85:74-76

Ellenbroek BA, Cools AR (1990): Animal models with construct validity for schizophrenia. Behav Pharmacol 1:469-490

Ellenbroek BA (1991): The ethological analysis of monkeys in a social setting as an animal model for schizophrenia. In Olivier B, Mos J, Slangen J (eds), Animal Models in Psychopharmacology, Birkhäuser, Verlag, pp 265-284

Ellenbroek BA (1993): Treatment of schizophrenia: A clinical and preclinical evaluation of neuroleptic drugs. Pharmacol Ther 57:1-78

Ellenbroek BA, Lubbers LJ, Cools AR (1996a): Activity of seroquel (ICI204,636) in animal models for atypical properties of antipsychotics-A comparison with clozapine. Neuropsychopharmacology 15:406 -416

Ellenbroek BA, Budde S, Cools AR (1996b): Prepulse inhibition and latent inhibition-The role of dopamine in the medial prefrontal cortex. Neuroscience 75:535-542

Etherington R, Mittleman G, Robbins TW (1987): Comparative effect of nucleus basalis and fimbria-fornix lesions on delayed matching and alternation tests of memory. Neurosci Res Commun 1:135-143

Farber NB, Foster J, Duhan NL, Olney JW (1996): Olanzapine and fluperlapine mimic clozapine in preventing mk-801 neurotoxicity. Schizophr Res 21:33-37

Farde L, Nordström AL, Wiesel FA, Pauli S, Halldin C, Sedvall G (1992): Positron emission tomographic analysis of central D1-dopamine and D2-dopamine receptor occupancy in patients treated with classical neuroleptics and clozapine-Relation to extrapyramidal side effects. Arch General Psychiatry 49:538-544

Farde L, Nyberg S, Oxenstierna G, Nakashima Y, Halldin C, Ericsson B (1995): Positron emission tomography studies on D-2 and 5-HT2 receptor binding in risperidonetreated schizophrenic patients. J Clin Psychopharmacol 15:S19-S23

Feldon J, Weiner I (1991a): The latent inhibition model of schizophrenic attention disorder-Haloperidol and sulpiride enhance rats' ability to ignore irrelevant stimuli. Biol Psychiatry 29:635-646

Feldon J, Weiner I (1991b): An animal model of attention deficit. In Boulton A, Baker G, Martin-Iverson M (eds), Neuromethods Vol 18. Animal Models in Psychiatry I. Totowa, NJ, The Humana Press Inc., pp 313-361

Fink-Jensen A, Ludvigsen TS, Korsgaard N (1995): The effect of clozapine on fos protein immunoreactivity in the rat 
forebrain is not mimicked by the addition of alpha(1)adrenergic or $5 \mathrm{HT}(2)$ receptor blockade to haloperidol. Neurosci Lett 194:77-80

Fink-Jensen A, Hansen L, Hansen JB, Nielsen EB (1996): Regional differences in the effect of haloperidol and atypical neuroleptics on interstitial levels of DOPAC in the rat forebrain. J Psychopharmacology 10:119-125

Fink-Jensen A, Kristensen P (1994): Effects of typical and atypical neuroleptics on fos protein expression in the rat forebrain. Neurosci Lett 182:115-118

Fischman AJ, Bonab AA, Babich JW, Alpert NM, Rauch SL, Elmaleh DR, Shoup TM, Williams SA, Rubin RH (1996): Positron emission tomographic analysis of central 5 -hydroxytryptamine(2) receptor occupancy in healthy volunteers treated with the novel antipsychotic agent, ziprasidone. J Pharmacol Exp Ther 279:939-947

Flynn SW, MacEwan GW, Altman S, Kopala LC, Smith GN, Honer WG (1997): A comparison of two atypical antipsychotics in treatment resistant schizophrenia. Schizophr Res 24:185

Fowler SC, Das S (1994): Haloperidol-induced decrements in force and duration of rats' tongue movements during licking are attenuated by concomitant anticholinergic. Pharmacol Biochem Behav 49:813-817

Frith CD (1984): Schizophrenia, memory and anticholinergic drugs. J Abnorm Psychol 93:339-341

Fulton B, Goa KL (1997): Olanzapine-A review of its pharmacological properties and therapeutic efficacy in the management of schizophrenia and related psychoses. Drugs 53:281-298

Gardner EL, Walker LS, Paredes W (1993): Clozapine's functional mesolimbic selectivity is not duplicated by the addition of anticholinergic action to haloperidol: A brain stimulation study in the rat. Psychopharmacology 110:119-124

Gefvert O, Lindström LH, Langstrom J, Bergstrom M, Lundberg T, Yates RA, Larsson SD, Tuersley MD (1995): Timecourse for dopamine and serotonin receptor occupancy in the brain of schizophrenic patients following dosing with $150 \mathrm{mg}$ seroquel (ici 204,636) tid. [abstract] Proc 34th ACNP Meeting

Gerlach J, Peacock L (1995): New antipsychotics-The present status. Int Clin Psychopharmacol 10:39-48

Geyer MA, Wilkinson LS, Humby T, Robbins TW (1993): Isolation rearing of rats produces a deficit in prepulse inhibition of acoustic startle similar to that in schizophrenia. Biol Psychiatry 34:361-372

Gleason SD, Shannon HE (1997): Blockade of phencyclidineinduced hyperlocomotion by olanzapine, clozapine and serotonin receptor subtype selective antagonists in mice. Psychopharmacology 129:79-84

Glenthøj B, Hemmingsen R (1989): Intermittent neuroleptic treatment induces long-lasting abnormal mouthing in the rat. Eur J Pharmacol 164:393-396

Goldberg TE, Gold JM (1995): Neurocognitive deficits in schizophrenia. In Hirsch SR, Weinberger DR (eds), Schizophrenia. Blackwell Science, pp 146-162

Goldberg TE, Weinberger DR (1996): Effects of neuroleptic medications on the cognition of patients with schizophrenia: A review of recent studies. J Clin Psychiatry 57:62-65
Goldstein JM, Litwin LC, Sutton EB, Malich JB (1993): Seroquel: Electrophysiological profile of a potential atypical antipsychotic. Psychopharmacology 112:293-298

Goldstein JM (1995): Pre-clinical pharmacology of new atypical antipsychotics in late stage development. Expert Opinion Investigational Drugs 4:291-298

Goyer PF, Berridge MS, Morris ED, Semple WE, Comptontoth BA, Schulz C, Wong DF, Miraldi F, Meltzer HY (1996): Pet measurements of neuroreceptor occupancy by typical and atypical neuroleptics. J Nucl Med 37:1122-1127

Grace AA, Bunney BS (1986): Induction of depolarization block of haloperidol: Analysis using in vivo intracellular recording. J Pharmacol Exp Ther 238:1092-1100

Grace AA, Bunney BS, Moore H, Todd CL (1997): Dopamine-cell depolarization block as a model for the therapeutic actions of antipsychotic drugs. Trends Neurosci 20:31-37

Gray JA, Feldon J, Rawlins JNP, Hemsley DR, Smith AD (1991): The neuropsychology of schizophrenia. Behav Brain Sci 14:1-84

Green JF, King D (1996): Cognitive functioning in schizophrenia. Effects of drug treatment. CNS Drugs 6:382-398

Grenhoff J, Tung C-S, Svensson TH (1988a): The excitatory amino acid antagonist kynurenate induces pacemakerlike firing of dopamine neurons in rat ventral tegmental area in vivo. Acta Physiol Scand 134:567-568

Grenhoff J, Ugedo L, Svensson TH (1988b): Firing patterns of midbrain dopamine neurons: Differences between A9 and A10 cells. Acta Physiol Scand 134:127-132

Grenhoff J, Tung C-S, Ugedo L, Svensson TH (1990): The effects of amperizide, a putative antipsychotic drug, on rat midbrain dopamine neurons recorded in vivo. Pharmacol Toxicol 66:29-33

Griffon N, Pilon C, Sautel F, Schwartz JC, Sokoloff P (1996): Antipsychotics with inverse agonist activity at the dopamine d-3 receptor. J Neural Transm 103:1163-1175

Gully D, Jeanjean F, Poncelet M, Steinberg R (1995): Neuropharmacological profile of non-peptide neurotensin antagonists. Fundam Clinical Pharmacol 9:513-521

Guo N, Klitenick MA, Tham C-S, Fibiger HC (1995): Receptor mechanisms mediating clozapine-induced $c$-fos expression in the forebrain. Neuroscience 65:747-756

Gustafsson B, Christensson E (1990a): Amperozide and emotional behaviour. Pharmacol Toxicol Suppl. 1:34-39

Gustafsson B, Christensson E (1990b): Amperozide-A new putatively antipsychotic drug with a limbic mode of action on dopamine mediated behaviour. Pharmacol Toxicol Suppl. 1:12-17

Halldin C, Farde L, Hogberg T, Mohell N, Hall H, Suhara T, Karlsson P, Nakashima Y, Swahn CG (1995): Carbon-11FLB 457-A radioligand for extrastriatal d2 dopamine receptors. J Nucl Med 36:1275-1281

Hertel P, Nomikos GG, Iurlo M, Svensson TH (1996): Risperidone: Regional effects in vivo on release and metabolism of dopamine and serotonin in the rat brain. Psychopharmacology 124:74-86

Hirsch SR, Link CGG, Goldstein JM, Arvanitis LA (1996): ICI 204,636-A new atypical antipsychotic drug. Br J Psychiatry 168:45-56 
Hoenicke EM, Vanecek SA, Woods JH (1992): The discriminative stimulus effects of clozapine in pigeons: Involvement of 5-hydroxytryptamine $1 \mathrm{C}$ and 5-hydroxytryptamine ${ }_{2}$ receptors. J Pharmacol Exp Ther 263:176-284

Hoffman DC, Donovan H, Cassella JV (1993): The effects of haloperidol and clozapine on the disruption of sensorimotor gating induced by the noncompetitive glutamate antagonist, MK-801. Psychopharmacology 111: 339-344

Hoffman DC, Donovan H (1995a): Effects of typical, atypical, and novel antipsychotic drugs on amphetamine-induced place conditioning in rats. Drug Dev Res 36: 193-198

Hoffman DC, Donovan H (1995b): Catalepsy as a rodent model for detecting antipsychotic drugs with extrapyramidal side effect liability. Psychopharmacology 120 : 128-133

Hökfelt T, Everitt BJ, Theodorsson-Nordtheim E, Goldstein M (1984): Occurrence of neurotensin-like immunoreactivity in subpopulations of hypothalamic, mesencephalic and medullary catecholamine neurons. J Comp Neurol 222:543-559

Hollerman JR, Grace AA (1989): Acute haloperidol administration induces depolarization block of nigral dopamine neurons in rats after partial dopamine lesions. Neurosci Lett 96:82-88

Hyttel J, Nielsen JB, Nowak G (1992): The acute effect of sertindole on brain neurotransmitter receptors (ex vivo radio-receptor studies). J Neural Transm 89:61-69

Ichikawa J, Meltzer HY (1992): Amperozide, a novel antipsychotic drug, inhibits the ability of d-amphetamine to increase dopamine release in vivo in rat striatum and nucleus accumbens. J Neurochem 58:2285-2291

Imperato A, Di Chiara G (1987): Dopamine release and metabolism in awake rats after systemic neuroleptics as studied by trans-striatal dialysis. J Neurosci 5:297-306

Imperato A, Angelucci L (1989): The effects of clozapine and fluperlapine on the in vivo release and metabolism of dopamine in the striatum and in the prefrontal cortex of freely moving rats. Psychopharmacol Bull 25:383-389

Inoue T, Tsuchiya K, Koyama T (1996): Effects of typical and atypical antipsychotic drugs on freezing behavior induced by conditioned fear. Pharmacol Biochem Behav 55:195-201

Invernizzi R, Morali F, Pozzi L, Samanin R (1990): Effects of acute and chronic clozapine on dopamine release and metabolism in the striatum and nucleus accumbens of conscious rats. Br J Pharmacol 100:774-778

Iversen SD, Howells RB, Hughes RF (1980): Behavioral consequences of long-term treatment with neuroleptic drugs. Adv Biochem Psychopharmacol 24:305-313

Jackson DM, Johansson C, Lindgren L-M, Bengtsson A (1994): Dopamine receptor antagonists block amphetamine and phencyclidine-induced motor stimulation in rats. Pharmacol Biochem Behav 48:465-471

Jackson DM, Westlind-Danielsson A (1994): Dopamine receptors: Molecular biology, biochemistry and behavioural aspects. Pharmacol Ther 64:291-369

Jalenques I (1996): Drug-resistant schizophrenia-Treatment options. CNS Drugs 5:8-23

Janssen PAJ, Niemegeers CJE, Awouters F, Schellekens
KHL, Megens AAHP, Meert TF (1988): Pharmacology of risperidone ( $\mathrm{R} 64766$ ), a new antipsychotic with serotonin-S2 and dopamine-D2 antagonistic properties. J Pharmacol Exp Ther 244:685-693

Johansson C, Jackson DM, Svensson L (1994): The atypical antipsychotic, remoxipride, blocks phencyclidine-induced disruption of prepulse inhibition in the rat. Psychopharmacology 116:437-442

Kakigi T, Gao XM, Tamminga CA (1995): Drug-induced oral dyskinesias in rats after traditional and new neuroleptics. J Neural Transm 101:41-49

Kane J, Honigfeld G, Singer J, Meltzer H (1988): Clozapine for the treatment-resistant schizophrenic: A doubleblind comparison with chlorpromazine. Arch Gen Psychiatry 45:789-796

Kapur S, Remington G, Zipursky RB, Wilson AA, Houle S (1995): The $D_{2}$ dopamine receptor occupancy of risperidone and its relationship to extrapyramidal symptoms-A PET study. Life Sci 57:PL103-PL107

Kapur S (1996): 5- $\mathrm{HT}_{2}$ antagonism and EPS benefits-Is there a causal connection. Psychopharmacology 124:35-39

Karlsson P, Smith L, Farde L, Harnryd C, Sedvall G, Wiesel FA (1995): Lack of apparent antipsychotic effect of the $\mathrm{D}_{1}$-dopamine receptor antagonist SCH39166 in acutely ill schizophrenic patients. Psychopharmacology 121: 309-316

Kasper S, Tauscher J, Küfferle B, Heiden A, Neumeister A, Barnas C, Asenbaum S, Podreka I, Brücke T (1995): Spect D2-Receptor imaging of typical and atypical antipsychotics. [abstract] Proc of 34th ACNP Meeting 228

Kawashima K, Araki H, Aihara H (1985): Effect of chronic administration of antidepressants on duration of immobility in rats forced to swim. Jpn J Pharmacol 40:199-204

Kehne JH, Baron BM, Carr AA, Chaney SF, Elands J, Feldman DJ, Frank RA, Vangiersbergen PLM, Mccloskey TC, Johnson MP, Mccarty DR, Poirot M, Senyah Y, Siegel BW, Widmaier C (1996): Preclinical characterization of the potential of the putative atypical antipsychotic MDL 100,907 as a potent $5 \mathrm{HT}_{2 \mathrm{a}}$ antagonist with a favorable cns safety profile. J Pharmacol Exp Ther 277:968-981

Kelly PH, Moore KE (1978): Mesolimbic dopamine neurons: effects of 6-hydroxydopamine-induced destruction and receptor blockade on drug-induced rotation in rats. Psychopharmacology 55:35-41

Kerwin R, Taylor D (1996): New antipsychotics. A review of their current status and clinical potential. CNS Drugs 6:71-82

Kilts CD, Anderson CM, Bissette G, Ely TD, Nemeroff CB (1988): Differential effects of antipsychotic drugs on the neurotensin concentration of discrete rat brain nuclei. Biochem Pharmacol 37:1547-1554

Kimura K, Nomikos G, Svensson TH (1993): Effects of amperozide on psychostimulant-induced hyperlocomotion and dopamine release in the nucleus accumbens. Pharmacol Biochem Behav 44:27-36

Kinon BJ, Lieberman JA (1996): Mechanisms of action of atypical antipsychotic drugs-A critical analysis [review]. Psychopharmacology 124:2-34

Kleven M, Prinssen EPM, Koek W (1996): Role of 5-HT1a receptors in the ability of mixed $5-\mathrm{HT}_{1 \mathrm{a}}$ receptor agonist/dopamine D-2 receptor antagonists to inhibit 
methylphenidate-induced behaviors in rats. Eur J Pharmacol 313:25-34

Klitenick MA, Taber MT, Fibiger HC (1996): Effects of chronic haloperidol on stress- and stimulation-induced increases in dopamine release: Tests of the depolarization block hypothesis. Neuropsychopharmacology 15 : $424-428$

Kohen R, Metcalf MA, Khan N, Druck T, Huebner K, Lachowicz JE, Meltzer HY, Sibley DR, Roth BL, Hamblin MW (1996): Cloning, characterization, and chromosomal localization of a human 5-HT6 serotonin receptor. J Neurochem 66:47-56

Köhler C, Radesater AC, Karlsson-Boethius G, Bryske B, Widman M (1992): Regional distribution and in vivo binding of the atypical antipsychotic drug remoxipride-A biochemical and autoradiographic analysis in the rat brain. J Neural Transm 87:49-62

Kufferle B, Brucke T, Topitzschratzberger A, Tauscher J, Gossler R, Vesely C, Asenbaum S, Podreka I, Kasper S (1996): Striatal dopamine-2 receptor occupancy in psychotic patients treated with risperidone. Psychiatry Res Neuroimaging 68:23-30

Lahti RA, Evans DL, Stratman NC, Figur LM (1993): Dopamine D4 versus D2 receptor selectivity of dopamine receptor antagonists: possible therapeutic implications. Eur J Pharmacol 236:483-486

Lahti RA, Lahti AC, Tamminga CA (1995a): D-2-family receptors in schizophrenia-Distribution and implications for treatment. Clin Neuropharmacol 18:S110-S120

Lahti RA, Roberts RC, Tamminga CA (1995b): D-2-family receptor distribution in human postmortem tissue-An autoradiographic study. Neuroreport 6:2505-2512

Lahti A, Silber C, Marck R, Bark N (1997): The action of sertindole on negative symptoms in schizophrenia. Schizophr Res 24:202

Levant B, Bissette G, Widerlov E, Nemeroff CB (1991): Alterations in regional brain neurotensin concentrations produced by atypical antipsychotic drugs. Regulatory Peptides 32:193-201

Levin ED (1988): Psychopharmacological effects in the radial-arm maze. Neurosci Biobehav Rev 12:169-175

Lewander T, Westerbergh S-E, Morrison D (1990): Clinical profile of remoxipride-A combined analysis of a comparative double-blind multicentre trial programme. Acta Psychiatr Scand 82:92-98

Liégeois J-F, Bonaventure P, Delarge J, Damas J (1995): Antipsychotics and neuropeptides: The atypical profile of CI-943 and its relationship to neurotensin. Neurosci Biobehav Rev 19:519-531

Lundkvist C, Halldin C, Ginovart N, Nyberg S, Swahn CG, Carr AA, Brunner F, Farde L (1996): [C-11]MDL 100907, a radioligand for selective imaging of $5-\mathrm{HT} 2 \mathrm{a}$ receptors with positron emission tomography. Life Sci 58:PL187PL192

Malmberg $\AA$, Jackson DM, Eriksson A, Mohell N (1993): Unique binding characteristics of antipsychotic agents interacting with human dopamine D2A, D2B, and D3 receptors. Mol Pharmacol 43:749-754

Marder SR, Meibach RC (1994): Risperidone in the treatment of schizophrenia. Am J Psychiatry 151:825-835
Marek GJ, Li AA, Seiden LS (1989): Evidence for involvement of 5-hydroxytryptamine-1 receptors in antidepressant-like drug effects on differential reinforcement-oflow-rate 72-second behavior. J Pharmacol Exp Ther 250:60-70

Marsha E, Stockton BS, Rasmussen K (1996): Electrophysiological effects of olanzapine, a novel atypical antipsychotic, on A9 and A10 dopamine neurons. Neuropsychopharmacology 14:97-104

Matsubara S, Matsubara R, Kusumi I, Koyama T, Yamashita I (1993): Dopamine D1, D2 and serotonin2 receptor occupation by typical and atypical antipsychotic drugs in vivo. J Pharmacol Exp Ther 265:498-508

Maurel-Remy S, Bervoets K, Millan MJ (1995): Blockade of phencyclidine-induced hyperlocomotion by clozapine and MDL 100,907 in rats reflects antagonism of $5-\mathrm{HT} 2 \mathrm{a}$ receptors. Eur J Pharmacol 280:R9-R11

McNamara RK, Skelton RW (1991): Diazepam impairs acquisition but not performance in the Morris water maze. Pharmacol Biochem Behav 30:651-658

Meert TF, De Haes PLAJ, Vermote PCM, Janssen PAJ (1990): Pharmacological validation of ritanserin and risperidone in the drug discrimination test procedure in the rat. Drug Dev Res 19:353-373

Megens AAHP, Niemegeers CJE, Awouters FHL (1992): Antipsychotic profile and side-effect liability of haloperidol, risperidone, and ocaperidone as predicted from their differential interaction with amphetamine in rats. Drug Dev Res 26:129-145

Megens AAHP, Awouters FHL, Schotte A, Meert TF, Dugovic C, Niemegeers CJE, Leysen JE (1994): Survey of the pharmacodynamics of the new antipsychotic risperidone. Psychopharmacology 114:9-23

Meltzer HY, Nash JF (1991): Effects of antipsychotic drugs on serotonin receptors. Pharmacol Rev 43:587-604

Meltzer HY, Chai BL, Thompson PA, Yamamoto BK (1994): Effect of scopolamine on the efflux of dopamine and its metabolites after clozapine, haloperidol or thioridazine. J Pharmacol Exp Ther 268:1452-1461

Merchant KM, Dobie DJ, Dorsa DM (1992): Expression of the proneurotensin gene in the rat brain and its regulation by antipsychotic drugs. Ann NY Acad Sci 668:54-69

Merchant KM, Dorsa DM (1993): Differential induction of neurotensin and $c$-fos gene expression by typical versus atypical antipsychotics. Proc Natl Acad Sci USA 90: $3447-3451$

Merchant KM, Dobie DI, Filloux FM, Totzke M, Aravagiri M, Dorsa DM (1994): Effects of chronic haloperidol and clozapine treatment on neurotensin and $c$-fos mRNA in rat neostriatum. J Pharmacol Exp Ther 271:460-471

Merchant KM, Gill GS, Harris DW, Huff RM, Eaton MJ, Lookingland K, Lutzke BS, Mccall RB, Piercey MF, Schreur PJKD, Sethy VH, Smith MW, Svensson KA, Tang AH, Vonvoigtlander PF, Tenbrink RE (1996a): Pharmacological characterization of $\mathrm{u}-101387$, a dopamine d4 receptor selective antagonist. J Pharmacol Exp Ther 279:1392-1403

Merchant KM, Figur LM, Evans DL (1996b): Induction of c-fos mRNA in rat medial prefrontal cortex by antipsychotic drugs: Role of dopamine $\mathrm{D}_{2}$ and $\mathrm{D}_{3}$ receptors. Cereb Cortex 6:561-570 
Migler BM, Warawa EJ, Malick JB (1993): Seroquel: Behavioral effects in conventional and novel tests for atypical antipsychotic drug. Psychopharmacology 112:299-307

Mijnster MJ, Docter GJ, Voorn P (1995): Risperidone does not elevate neurotensin MRNA in rat nucleus accumbens and caudate-putamen. Neuroreport 6:2209-2212

Millan MJ, Peglion JL, Vian J, Rivet JM, Brocco M, Gobert A, Newmantancredi A, Dacquet C, Bervoets K, Girardon S, Jacques V, Chaput C, Audinot V (1995): Functional correlates of dopamine D-3 receptor activation in the rat in vivo and their modulation by the selective antagonist, (+)-S 14297.1. Activation of postsynaptic D-3, receptors mediates hypothermia, whereas blockade of D-2 receptors elicits prolactin secretion and catalepsy. J Pharmacol Exp Ther 275:885-898

Miller J (1990): Induction of c-fos mRNA expression in rat striatum by neuroleptic drugs. J Neurochem 54:14531455

Moghaddam B, Bunney BS (1990): Acute effects of typical and atypical antipsychotic drugs on the release of dopamine from prefrontal cortex, nucleus accumbens and striatum of the rat: An in vivo microdialysis study. Neurochemistry 54:1755-1760

Moghaddam R, Bunney BS (1993): Depolarization inactivation of dopamine neurons: Terminal release characteristics. Synapse 14:195-200

Möller HJ, Müller H, Borison RL, Schooler NR, Chouinard G (1995): A path-analytical approach to differentiate between direct and indirect drug effects on negative symptoms in schizophrenic patients-A re-evaluation of the North American risperidone study. Eur Arch Psychiatry Clin Neurosci 245:45-49

Moore NA, Tye NC, Axton MS, Risius FC (1992): The behavioral pharmacology of olanzapine, a novel "atypical" antispychotic agent. J Pharmacol Exp Ther 262:545-551

Moore NA, Calligaro DO, Wong DT, Bymaster F, Tye NC (1993): The pharmacology of olanzapine and other new antipsychotic agents. Curr Opin Invest Drugs 2:281-293

Moore NA, Rees G, Sanger G, Tye NC (1994): Effects of olanzapine and other antipsychotic agents on responding maintained by a conflict schedule. Behav Pharmacol 5:196-202

Moran PM, Fischer TR, Hitchcock JM, Moser PC (1996): Effects of clozapine on latent inhibition in the rat. Behav Pharmacol 7:42-48

Morris RGM (1984): Development of a water maze procedure for studying spatial learning in the rat. J Neurosci Methods 11:47-60.

Moser PC, Moran PM, Frank RA, Kehne JH (1995): Reversal of amphetamine-induced behaviours by MDL 100,907, a selective 5-HT2a antagonist. Behav Brain Res 73:163-167

Murase S, Grenhoff J, Chouvet G, Gonon FG, Svensson TH (1993): Prefrontal cortex regulates burst firing and transmitter release in rat mesolimbic dopamine neurons studied in vivo. Neurosci Lett 157:53-56

Muscat R, Papp M, Willner P (1992): Antidepressant-like effects of dopamine agonists in an animal model of depression. Biol Psychiatry 31:937-946

Nanry KP, Pollard GT, Howard JL (1995): Olanzapine moderately increases conflict responding but does not pro- duce a benzodiazepine-like cue in rat. Drug Dev Res 34:317-319

Nemeroff CB (1980): Neurotensin: Perchance an endogenous neuroleptic? Biol Psychiatry 15:283-302

Newman-Tancredi A, Chaput C, Verriele L, Millan MJ (1996): Clozapine is a partial agonist at cloned, human serotonin 5-HT1a receptors. Neuropharmacology 35: 119-121

Nielsen EB (1988): Cholinergic mediation of the discriminative stimulus properties of clozapine. Psychopharmacology 94:115-118

Nielsen EB, Jepsen SA (1985): Antagonism of the amphetamine cue by both classical and atypical antipsychotic drugs. Eur J Pharmacol 111:167-176

Nielsen EB, Scheel-Krüger J (1986): Cueing effects of amphetamine and LSD: Elicitation by direct microinjections of the drugs into the nucleus accumbens. Eur J Pharmacol 125:85-92

Nilsson CL, Ekman A, Hellstrand M, Eriksson E (1996): Inverse agonism of dopamine $\mathrm{D}_{2}$ receptors. Haloperidol-induced prolactin release from $\mathrm{GH}_{4} \mathrm{C}_{1}$ Cells transfected with the human $\mathrm{D}_{2}$ receptor is antagonized by $\mathrm{R}(-)$-n-propylnorapomorphine, raclopride, and phenoxybenzamine. Neuropsychopharmacology 15:53-61

Nomikos GG, Iurlo M, Andersson JL, Kimura K, Svensson TH (1994): Systemic administration of amperozide, a new atypical antipsychotic drug, preferentially increases dopamine release in the rat medial prefrontal cortex. Psychopharmacology 115:147-156

Nordström AL, Farde L, Nyberg S, Karlsson P, Halldin C, Sedvall G (1995): D-1, D-2, and 5-HT2 receptor occupancy in relation to clozapine serum concentration-A pet study of schizophrenic patients. Am J Psychiatry 152:1444-1449

Nyberg S, Farde L, Eriksson L, Halldin C, Eriksson B (1993): 5-HT2 and D2 dopamine receptor occupancy in the living human brain. Psychopharmacology 110:265-272

Nyberg S, Farde L, Halldin C, Dahl M-L, Bertilsson L (1995): $\mathrm{D}_{2}$ dopamine receptor occupancy during low-dose treatment with haloperidol decanoate. Am J Psychiatry 152:173-178

Nyberg S, Farde L, Halldin C (1997): A PET study of 5- $\mathrm{HT}_{2}$ and $D_{2}$ dopamine receptor occupancy induced by olanzapine in healthy subjects. Neuropsychopharmacology $16: 1-7$

O'Dell SJ, La Hoste GJ, Widmark CB, Shapiro RM, Potkin SG, Marshall JF (1990): Chronic treatment with clozapine or haloperidol differentially regulates dopamine and serotonin receptors in rat brain. Synapse 6:146-153

Ögren SO, Hall H, Köhler C, Magnusson O, Lindblom L-O, Ängeby K, Florvall L (1984): Remoxipride, a new potential antipsychotic compound with selective antidopaminergic actions in the rat brain. Eur J Pharmacol 102:459-474

Ögren SO, Rosén L, Fluxe K (1994): The dopamine $D_{2}$ antagonist remoxipride acts in vivo on a subpopulation of dopamine $\mathrm{D}_{2}$ receptors. Neuroscience 61:269-283

Ögren SO, Archer T (1994): Effects of typical and atypical antipsychotic drugs on two-way active avoidance. Relationship to DA receptor blocking profile. Psychopharmacology 114:383-391 
Olney JW, Farber NB (1995): Glutamate receptor dysfunction and schizophrenia [review]. Arch Gen Psychiatry 52: 998-1007

Osborne PG, O'Connor WT, Beck O, Ungerstedt U (1994): Acute versus chronic haloperidol: Relationship between tolerance to catalepsy and striatal and accumbens dopamine, GABA and acetylcholine release. Brain Res 634:20-30

Owens DGC (1996): Adverse effects of antipsychotic agentsDo newer agents offer advantages. Drugs 51:895-930

Padich RA, Mcloskey TC, Kehne JH (1996): 5-HT Modulation of auditory and visual sensorimotor gating .2. Effects of the 5-HT2a antagonist MDL 100,907 on disruption of sound and light prepulse inhibition produced by 5-HT agonists in wistar rats. Psychopharmacology 124:107-116

Papp M, Moryl E, Willner P (1996): Pharmacological validation of the chronic mild stress model of depression. Eur J Pharmacol 296:129-136

Pazos A, Cortes R, Palacios JM (1985): Quantitative autoradiographic mapping of serotonin receptors in the brain. II. Serotonin-2 receptors. Brain Res 346:231-249

Peuskens J (1995): Risperidone in the treatment of patients with chronic schizophrenia-A multi-national, multicentre, double-blind, parallel-group study versus haloperidol. Br J Psychiatry 166:712-726

Pilowsky LS, Busatto GF, Taylor M, Costa DC, Sharma T, Sigmundsson T, Ell PJ, Nohria V, Kerwin RW (1996): Dopamine $D_{2}$ receptor occupancy in vivo by the novel atypical antipsychotic olanzapine-A I-123 IBZM single photon emission tomography (spet) study. Psychopharmacology 124:148-153

Pilowsky LS, Mulligan RS, Acton PD, Gacinovic S, Busatto GF, Kessler RM, Ell PJ, Travis MJ, Bigliani V, Stephenson C, Costa DC, Kerwin RW (1997a): Preliminary report: Effects of clozapine and typical antipsychotics on striatal and limbic dopamine $D_{2} / D_{2}$-like receptors in vivo by 123 epidepride SPET. Schizophr Res 24:181

Pilowsky LS, Oconnell P, Davies N, Busatto GF, Costa DC, Murray RM, Ell PJ, Kerwin RW (1997b): In vivo effects on striatal dopamine $\mathrm{d}-2$ receptor binding by the novel atypical antipsychotic drug sertindole-A i-123 ibzm single photon emission tomography (spet) study. Psychopharmacology 130:152-158

Pollard GT, Howard JL (1986): Similar effects of antidepressant and non-antidepressant drugs on behavior under an interresponse-time $>72-\mathrm{s}$ schedule. Psychopharmacology 89:253-258

Porter JH, Strong SE (1996): Discriminative stimulus control with olanzapine-Generalization to the atypical antipsychotic clozapine. Psychopharmacology 128:216-219

Prinssen EPM, Ellenbroek BA, Cools AR (1994): Combined antagonism of adrenoceptors and dopamine and 5-HT receptors underlies the atypical profile of clozapine. Eur J Pharmacol 262:167-170

Pugsley TA, Davis MD, Akunne HC, Mackenzie RG, Shih YH, Damsma G, Wikstrom H, Whetzel SZ, Georgic LM, Cooke LW, Demattos SB, Corbin AE, Glase SA, Wise LD, Dijkstra D, Heffner TG (1995): Neurochemical and functional characterization of the preferentially selective dopamine D3 agonist PD 128907. J Pharmacol Exp Ther 275:1355-1366

Rak IW, Arvanitis LA (1997): Overview of the efficacy of "seroquel" (quetiapine). Schizophr Res 24:199

Rasmussen K, Gates MR, Burger JE, Czachura JF (1997): The novel atypical antipsychotic olanzapine, but not the cck-b antagonist ly288513, blocks apomorphine-induced disruption of pre-pulse inhibition. Neurosci Lett 222:61-64

Rayevsky KS, Gainetdinov RR, Grekhova TV, Sotnikova TD (1995): Regulation of dopamine release and metabolism in rat striatum in vivo: Effects of dopamine receptor antagonists. Prog Neuropsychopharmacol Biol Psychiatry 19:1285-1303

Rigdon GC, Viik K (1991): Prepulse inhibition as a screening test for potential antipsychotics. Drug Dev Res 3:91-99

Rigdon GC, Weatherspoon JK (1992): 5-Hydroxytryptamine ${ }_{1 a}$ receptor agonists block prepulse inhibition of acoustic startle reflex. J Pharmacol Exp Ther 263:486-493

Robertson GS, Fibiger HC (1992): Neuroleptics increase c-fos expression in the forebrain: Contrasting effects of haloperidol and clozapine. Neuroscience 46:315-328

Robertson GS, Matsumura H, Fibiger HC (1994): Induction patterns of fos-like immunoreactivity in the forebrain as predictors of atypical antipsychotic activity. J Pharmacol Exp Ther 271:1058-1066

Robertson GS, Fibiger HC (1996): Effects of olanzapine on regional c-Fos expression in rat brain. Neuropsychopharmacology 14:105-110

Ross CA, Pearlson GD (1996): Schizophrenia, the heteromodal association neocortex and development: potential for a neurogenetic approach. Trends Neurosci 19:171-176

Roth BL, Craigo SC, Choudhary MS, Uluer A, Monsma FJ, Jr., Shen Y, Meltzer HY, Sibley DR (1994): Binding of typical and atypical antipsychotic agents to 5-hydroxytryptamine-6 and 5-hydroxytryptamine-7 receptors. J Pharmacol Exp Ther 268:1403-1410

Roth BL, Tandra S, Burgess LH, Sibley DR, Meltzer HY (1995): D-4 dopamine receptor binding affinity does not distinguish between typical and atypical antipsychotic drugs. Psychopharmacology 120:365-368

Rowley M, Broughton HB, Collins I, Baker R, Emms F, Marwood R, Patel S, Patel S, Ragan CI, Freedman SB, Leeson PD (1996): 5-(4-chlorophenyl)-4-methyl-3-(1-(2-phenylethyl)piperidin-4-yl)isoxazole-A potent, selective antagonist at human cloned dopamine D4 receptors. J Med Chem 39:1943-1945

Sakai K, Gao X-M, Tamminga CA (1996): Neurolepticinduced oral dyskinesias in rats treated with olanzapine, sertindole and haloperidol. Soc Neurosci 22: Abstr. 431.15

Saller CF, Salama AI (1993): Seroquel: Biochemical profile of a potential atypical antipsychotic. Psychopharmacology 112:285-292

Sams-Dodd F (1996): Phencyclidine-induced stereotyped behaviour and social isolation in rats: A possible animal model of schizophrenia. Behav Pharmacol 7:3-23

Sams-Dodd F (1997): Effect of novel antipsychotic drugs on phencyclidine-induced stereotyped behaviour and social isolation in the rat social interaction test. Behav Pharmacol 8:196-215 
Sánchez C, Arnt J, Dragsted N, Hyttel J, Lembø̨l HL, Meier E, Skarsfeldt T (1991): Neurochemical and in vivo pharmacological profile of sertindole, a limbic-selective neuro leptic compound. Drug Dev Res 22:239-250

Sánchez C, Arnt J, Costall B, Domeney AM, Kelly E, Naylor RJ (1995): Sertindole: A limbic selective neuroleptic with potent anxiolytic effects. Drug Dev Res 34:19-29

Sánchez C, Arnt J (1995): Different anxiolytic-like profiles of novel antipsychotics in rodents. Soc Neurosci 21: Abstr. 827.10

Sanger DJ, Perrault G (1995): Effects of typical and atypical antipsychotic drugs on response decrement patterns in rats. J Pharmacol Exp Ther 272:708-713

Scheel-Krüger J, Christensen AV, Arnt J (1978): Muscimol differentially facilitates stereotypy but antagonizes motility induced by dopaminergic drug: A complex GABAdopamine interaction. Life Sci 22:75-84

Schotte A, Janssen PFM, Gommeren W, Luyten WHML, Vangompel P, Lesage AS, Deloore K, Leysen JE (1996a): Risperidone compared with new and reference antipsychotic drugs-In vitro and in vivo receptor binding. Psychopharmacology 124:57-73

Schotte A, Janssen PFM, Bonaventure P, Leysen JE (1996b): Endogenous dopamine limits the binding of antipsychotic drugs to $D_{3}$ receptors in the rat brain-A quantitative autoradiographic study. Histochem J 28:791-799

Sebens JB, Koch T, ter Horst GJ, Korf J (1995): Differential fos-protein induction in rat forebrain regions after acute and long-term haloperidol and clozapine treatment. Eur J Pharmacol 273:175-182

See RE, Ellison G (1990): Comparison of chronic administration of haloperidol and the atypical neuroleptics, clozapine and raclopride, in an animal model of tardive dyskinesia. Eur J Pharmacol 181:175-186

Seeger TF, Seymour PA, Schmidt AW, Zorn SH, Schulz DW, Lebel LA, Mclean S, Guanowsky V, Howard HR, Lowe JA, Heym J (1995): Ziprasidone (CP-88,059): A new antipsychotic with combined dopamine and serotonin receptor antagonist activity. J Pharmacol Exp Ther 275: $101-113$

Seeman P, Corbett R, Vantol HHM (1997): Atypical neuroleptics have low affinity for dopamine $D_{2}$ receptors or are selective for $D_{4}$ receptors. Neuropsychopharmacology 16:93-110

Seeman P, Van Tol HHM (1994): Dopamine receptor pharmacology. Tips 15:264-270

Seiden LS, Dahms JL, Shaughnessy RA (1985): Behavioral screen for antidepressants: The effects of drugs and electroconvulsive shock on performance under a differentialreinforcement-of-low-rate schedule. Psychopharmacology 86:55-60

Sipes TA, Geyer MA (1994): Multiple serotonin receptor subtypes modulate prepulse inhibition of the startle response in rats. Neuropharmacology 33:441-448

Sipes TA, Geyer MA (1995a): 8-OH-DPAT disruption of prepulse inhibition in rats: Reversal with $(+)$ WAY 100,135 and localization of site of action. Psychopharmacology 117:41-48

Sipes TA, Geyer MA (1995b): DOI disruption of prepulse inhibition of startle in the rat is mediated by $5-$ HT2 $\mathrm{a}$ and not by 5-HT2c receptors. Behav Pharmacol 6:839-842
Skarsfeldt T (1992): Electrophysiological profile of a new atypical neuroleptic, sertindole, on midbrain dopamine neurones in rats: Acute and repeated treatment. Synapse 10:25-33

Skarsfeldt T (1995): Differential effects of repeated administration of novel antipsychotic drugs on the activity of midbrain dopamine neurons in the rat. Eur J Pharmacol 281:289-294

Skarsfeldt T (1996): Differential effect of antipsychotics on place navigation of rats in the Morris water maze-A comparative study between novel and reference antipsychotics. Psychopharmacology 124:126-133

Song F (1997): Risperidone in the treatment of schizophrenia: A meta-analysis of randomized controlled trials. J Psychopharmacol 11:65-71

Sorensen SM, Kehne JH, Fadayel GM, Humphreys TM, Ketteler HJ, Sullivan CK, Taylor VL, Schmidt CJ (1993): Characterization of the 5-HT2 receptor antagonist MDL 100907 as a putative atypical antipsychotic: Behavioral, electrophysiological and neurochemical studies. J Pharmacol Exp Ther 266:684-691

Stockmeier CA, DiCarlo JJ, Zhang Y, Thompson P, Meltzer HY (1993): Characterization of typical and atypical antipsychotic drugs based on in vivo occupancy of serotonin 2 and dopamine2 receptors. J Pharmacol Exp Ther 266:1374-1384

Stockton ME, Rasmussen K (1993): The electrophysiological effects of olanzapine, a novel atypical antipsychotic, on midbrain dopamine cells. Schizophr Res 15:166

Stockton ME, Rasmussen K (1996a): Olanzapine, a novel atypical antipsychotic, reverses $\mathrm{D}$-amphetamine-induced inhibition of midbrain dopamine cells. Psychopharmacology 124:50-56

Stockton ME, Rasmussen K (1996b): Electrophysiological effects of olanzapine, a novel atypical antipsychotic, on A9 and A10 dopamine neurons. Neuropsychopharmacology 14:97-104

Stowe ZN, Nemeroff CB (1991): The electrophysiological actions of neurotensin in the central nervous system. Life Sci 49:987-1002

Sumiyoshi T, Kido H, Sakamoto H, Urasaki K, Suzuki K, Yamaguchi N, Mori H, Shiba K, Yokogawa K (1994): In vivo dopamine- $\mathrm{D}_{2}$ and serotonin-5- $\mathrm{HT}_{2}$ receptor binding study of risperidone and haloperidol. Pharmacol Biochem Behav 47:553-557

Sumiyoshi T, Suzuki K, Sakamoto H, Yamaguchi N, Mori H, Shiba K, Yokogawa K (1995): Atypicality of several antipsychotics on the basis of in vivo dopamine-D-2 and serotonin-5HT(2) receptor occupancy. Neuropsychopharmacology 12:57-64

Suzuki T, Misawa M (1995): Sertindole antagonizes morphine-, cocaine-, and methamphetamine-induced place preference in the rat. Life Sci 57:1277-1284

Svendsen O, Arnt J, Boeck V, Begese KP, Christensen AV, Hyttel J, Larsen J-J (1986): The neuropharmacological profile of tefludazine, a potential antipsychotic drug with dopamine and serotonin antagonistic effects. Drug Dev Res 7:35-47

Svensson TH, Tung C-S (1989): Local cooling of pre-frontal cortex induces pacemaker-like firing of dopamine neu- 
rons in rat ventral tegmental area in vivo. Acta Physiol Scand 136:135-136

Swann AC, Holgate KL, Staser JA, Silber CJ, Mack RJ (1997): Sertindole: A multi-center, 1 year, haloperidol controlled trial assessing the long-term safety, efficacy and quality of life in stable schizophrenic patients. Schizophr Res 24:203

Swerdlow NR, Geyer MA (1993): Clozapine and haloperidol in an animal model of sensorimotor gating deficits in schizophrenia. Pharmacol Biochem Behav 44:741-744

Swerdlow NR, Braff DL, Taaid N, Geyer MA (1994a): Assessing the validity of an animal model of deficient sensorimotor gating in schizophrenic patients. Arch Gen Psychiatry 51:139-154

Swerdlow NR, Zisook D, Taaid N (1994b): Seroquel (ICI 204,636) restores prepulse inhibition of acoustic startle in apomorphine-treated rats: Similarities to clozapine. Psychopharmacology 114:675-678

Swerdlow NR, Bakshi V, Geyer MA (1996a): Seroquel restores sensorimotor gating in phencyclidine-treated rats. J Pharmacol Exp Ther 279:1290-1299

Swerdlow NR, Braff DL, Hartston H, Perry W, Geyer MA (1996b): Latent inhibition in schizophrenia. Schizophr Res 20:91-103

Tamminga CA, Lahti AC (1996): The new generation of antipsychotic drugs. Int Clin Psychopharmacol 11:73-76

Todd CL, Moore H, Harden DG, Grace AA (1996): Microdialysis probe implantation into striatum disrupts haloperidol-induced DA cell depolarization block [abstract]. Soc Neurosci Abstracts 22 Abstr. 145.9

Tollefson GD, Beasley CM, Tran PV, Street JS, Krueger JA, Tamura RN, Graffeo KA, Thieme ME (1997a): Olanzapine versus haloperidol in the treatment of schizophrenia and schizoaffective and schizophreniform disordersResults of an international collaborative trial. Am J Psychiatry 154:457-465

Tollefson GD, Tran PV, Hamilton SH, Kuntz AJ (1997b): Olanzapine versus risperidone in the treatment of schizophrenia and other psychotic disorders: a preliminary report. Schizophr Res 24:191

Tollefson G, Lu Y, Sanger T, Beasley C, Tran P (1997c): Olanzapine in the treatment of schizoaffective disorder. Schizophr Res 24:192

Tollefson GD, Sanger TM (1997): Negative symptoms-A path analytic approach to a double-blind, placebo- and haloperidol-controlled clinical trial with olanzapine. Am J Psychiatry 154:466-474

Uhl GR, Kuhar M, Snyder SH (1977): Neurotensin: Immunohistochemical localization in rat central nervous system. Proc Natl Acad Sci USA 74:4059-4063

Vahid-Ansari F, Nakabeppu Y, Robertson GS (1996): Contrasting effects of chronic clozapine, seroquel (ICI 204,636) and haloperidol administration on FosB-like immunoreactivity in the rodent forebrain. Eur J Neurosci 8:927-936

van Kammen DP, Mcevoy JP, Targum SD, Kardatzke D, Sebree TB, Sertindole Study Group (1996): A randomized, controlled, dose-ranging trial of sertindole in patients with schizophrenia. Psychopharmacology 124:168-175
Van Tol HHM, Bunzow JR, Guan H-C, Sunahara RK, Seeman P, Niznik HB, Civelli O (1991): Cloning of the gene for a human dopamine D4 receptor with high affinity for the antipsychotic clozapine. Nature 350:610-614

Varty GB, Higgins GA (1995a): Reversal of a dizocilpineinduced disruption of prepulse inhibition of an acoustic startle response by the 5-HT2 receptor antagonist ketanserin. Eur J Pharmacol 287:201-205

Varty GB, Higgins GA (1995b): Examination of druginduced and isolation-induced disruptions of prepulse inhibition as models to screen antipsychotic drugs. Psychopharmacology 122:15-26

Verdoux H, Magnin E, Bourgeois M (1995): Neuroleptic effects on neuropsychological test. Schizophrenia 14: 133-139

Wadenberg M-L, Ahlenius S (1995): Antipsychotic-like profile of combined treatment with raclopride and $8-\mathrm{OH}-$ DPAT in the rat: Enhancement of antipsychotic-like effects without catalepsy. Eur J Pharmacol 294:247-251

Wagstaff AJ, Bryson HM (1995): Clozapine-A review of its pharmacological properties and therapeutic use in patients with schizophrenia who are unresponsive to or intolerant of classical antipsychotic agents. CNS Drugs $4: 370-400$

Warburton EC, Joseph MH, Feldon J, Weiner I, Gray JA (1994): Antagonism of amphetamine-induced disruption of latent inhibition in rats by haloperidol and ondansetron: Implications for a possible antipsychotic action of ondansetron. Psychopharmacology 114:657-664

Wedzony K, Golembiowska K, Zazula M (1994): Differential effects of CGP 37849 AND MK-801, competitive and noncompetitive NMDA antagonists, with respect to the modulation of sensorimotor gating and dopamine outflow in the prefrontal cortex of rats. Naunyn-Schmiedebergs Arch Pharmacol 350:555-562

Wehnert A, van der Burght M, Sloth-Nielsen M (1997): Comparing sertindole clinical data and patients across the oceans. Schizophr Res 24:203

Weiden P, Aquila R, Standard J (1996): Atypical antipsychotic drugs and long-term outcome in schizophrenia. J Clin Psychiatry 57:53-60

Weinberger DR (1988): Schizophrenia and the frontal lobe. Trends Neurosci 11:367-370

Weinberger DR, Lipska BK (1995): Cortical maldevelopment, anti-psychotic drugs, and schizophrenia-A search for common ground. Schizophr Res 16:87-110

Weiner I, Kidron R, Tarrasch R, Arnt J, Feldon J (1994): The effects of the new antipsychotic, sertindole, on latent inhibition in rats. Behav Pharmacol 5:119-124

Weiner I, Shadach E, Tarrasch R, Kidron R, Feldon J (1996): The latent inhibition model of schizophrenia-Further validation using the atypical neuroleptic, clozapine. Biol Psychiatry 40:834-843

Weiner I, Feldon J (1994): The latent inhibition model of schizophrenic attention disorder and of antipsychotic drug action: Comment on Dunn, Atwater and Kilts (Psychopharmacology 1993; 112:315-323). Psychopharmacology 116:379-380

Westerink BH, Kikkert RJ (1986): Effect of various centrally 
acting drugs on the efflux of dopamine metabolites from the rat brain. J Neurochem 46:1145-1152

Westphal R, Sanders-Bush E (1994): Reciprocal binding properties of 5 -hydroxytryptamine type $2 \mathrm{C}$ receptor agonists and inverse agonists. Mol Pharmacol 46:937-942

White FJ, Wang RY (1993): Differential effects of classical and atypical antipsychotic drugs on A9 and A10 dopamine neurons. Science 221:1054-1057

Wiley JL, Compton AD, Porter JH (1993): Effects of four antipsychotics on punished responding in rats. Pharmacol Biochem Behav 45:263-267

Wiley JL (1994): Clozapines effects on phencyclidine-induced disruption of prepulse inhibition of the acoustic startle response. Pharmacol Biochem Behav 49:1025-1028

Willner P, Golembiowska K, Klimek V, Muscat R (1991): Changes in mesolimbic dopamine may explain stressinduced anhedonia. Psychobiology 19:79-84

Willner P, Muscat R, Papp M (1992): Chronic mild stress- induced anhedonia: A realistic animal model of depression. Neurosci Biobehav Rev 16:525-534

Youngren KD, Moghaddam B, Bunney BS, Roth RH (1994): Preferential activation of dopamine overflow in prefrontal cortex produced by chronic clozapine treatment. Neurosci Lett 165:41-44

Zeng XP, Le F, Richelson E (1997): Muscarinic m4 receptor activation by some atypical antipsychotic drugs. Eur J Pharmacol 321:349-354

Zhang H, Kiyatkin EA, Stein EA (1994): Behavioral and pharmacological modulation of ventral tegmental dendritic dopamine release. Brain Res 656:59-70

Zimbroff DL, Kane JM, Tamminga CA, Daniel DG, Mack RJ, Wozniak PJ, Sebree TB, Wallin BA, Kashin KB (1997): A controlled, dose-response study of sertindole and haloperidol in schizophrenia. Am J Psychiatry 154:782-791

Zorn SH, Jones SB, Ward KM, Liston DR (1994): Clozapine is a potent and selective muscarinic $M(4)$ receptor agonist. Eur J Pharmacol-Mol Pharmacol Sect 269:R1-R2 